Aus der Abteilung für Neurogenetik

(Prof. K.-A. Nave, PhD)

des Max-Planck-Instituts für Experimentelle Medizin

in Göttingen

\title{
Die Effekte des WIds-Gens und der Gabe von Nikotinamid auf akute und chronisch-sekundäre Axon-Degeneration
}

\author{
INAUGURAL - DISSERTATION \\ zur Erlangung des Doktorgrades \\ der Medizinischen Fakultät der Georg-August-Universität \\ zu Göttingen
}

vorgelegt von

Timo Arjuna Miesbach

aus Hannover

Göttingen 2021 
Dekan:

Referent/in:

Ko-Referent/in:

Drittreferent/in:
Prof. Dr. med. W. Brück

Prof. Dr. med. M. W. Sereda

Prof. Dr. med. S. Hülsmann

Prof. Dr. med. J. Gärtner 
Hiermit erkläre ich, die Dissertation mit dem Titel "Die Effekte des WIds-Gens und der Gabe von Nikotinamid auf akute und chronisch-sekundäre AxonDegeneration" eigenständig angefertigt und keine anderen als die von mir angegebenen Quellen und Hilfsmittel verwendet zu haben.

Göttingen, den 10.07.2021 
Die Daten, auf denen die vorliegende Arbeit basiert, wurden teilweise publiziert in:

Meyer zu Horste G, Miesbach TA, Muller JI, Fledrich R, Stassart RM, Kieseier BC, Coleman MP, Sereda MW (2011): The Wlds transgene reduces axon loss in a Charcot-Marie-Tooth disease $1 \mathrm{~A}$ rat model and nicotinamide delays post-traumatic axonal degeneration Neurobiol Dis $\underline{42}, 1-8$ 


\section{Inhaltsverzeichnis}

Abkürzungsverzeichnis III

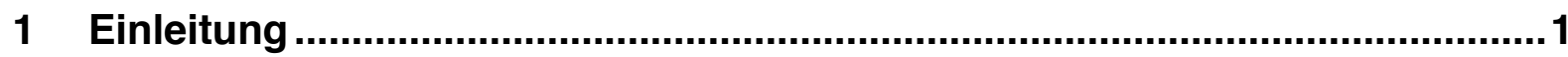

1.1 Strukturelle und funktionale Grundlagen der Informationsübertragung

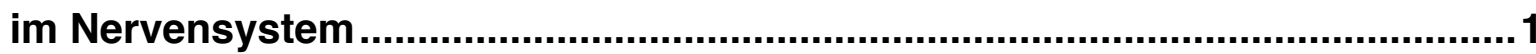

1.2 Der Prozess der axonalen Degeneration..............................................4

1.3 Die Wallerian-degeneration-slow (WIds) -Mutation und axonale

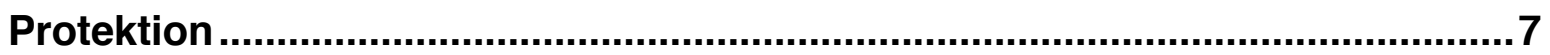

1.4 Die Charcot-Marie-Tooth (CMT) -Erkrankungen ..................................11

1.4.1 Typische Symptome und natürlicher Verlauf .......................................12

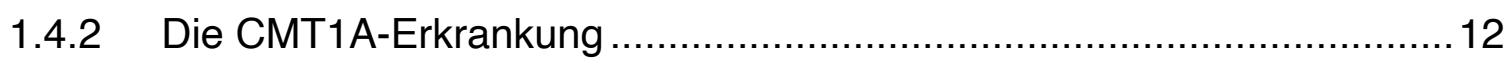

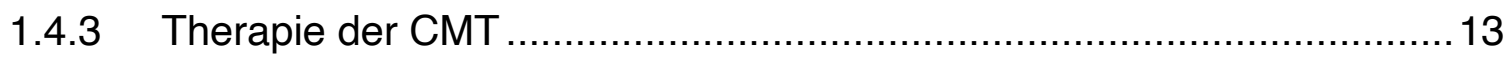

1.5 Fragestellung und Hypothese dieser Arbeit ..........................................14

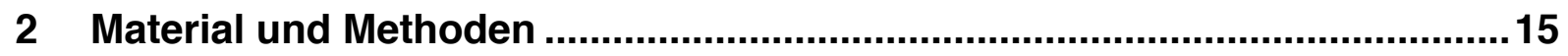

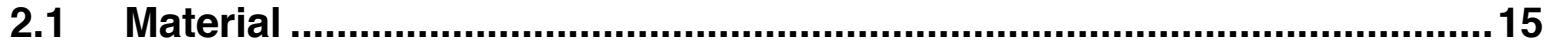

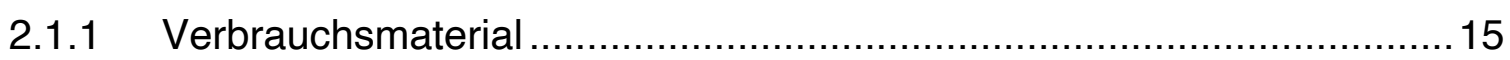

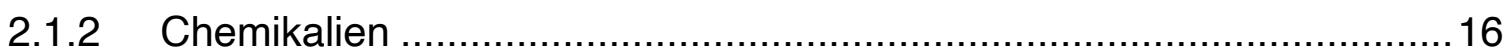

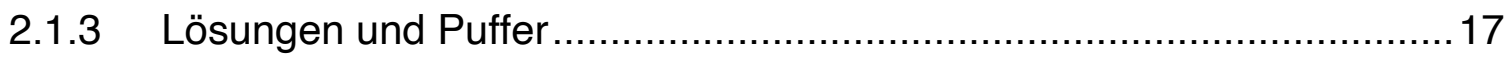

2.1.4 Enzyme und Reaktionskomplettsysteme ……................................... 18

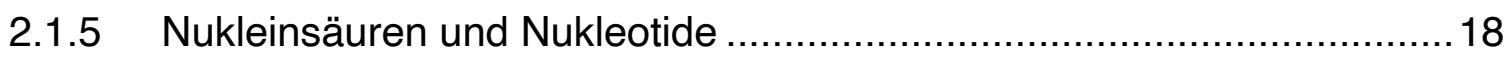

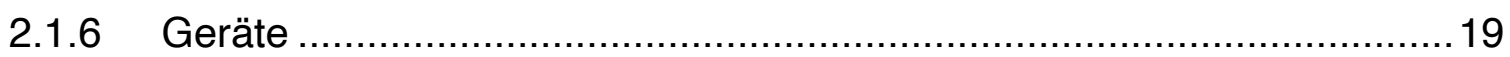

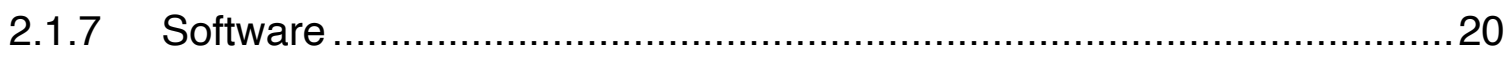

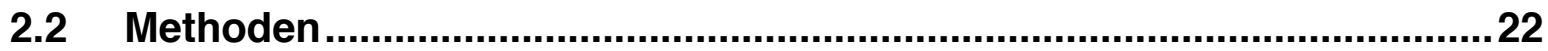

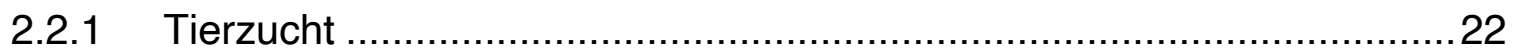

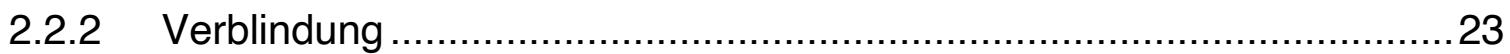

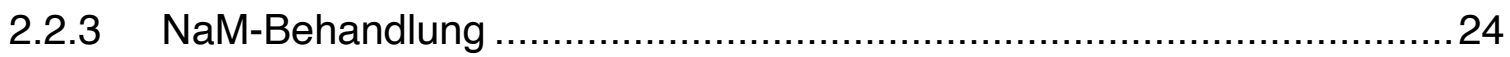

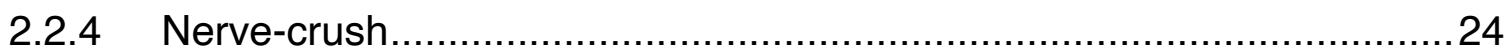

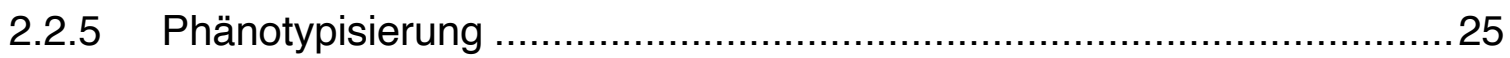

2.2.6 Perfusion und Herstellung histologischer Präparate .............................26

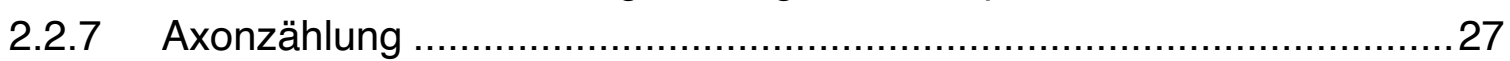

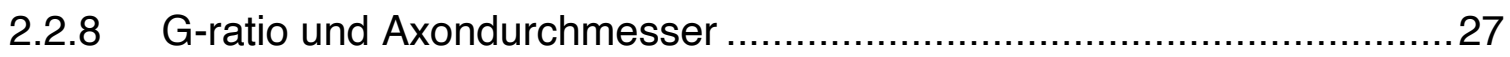

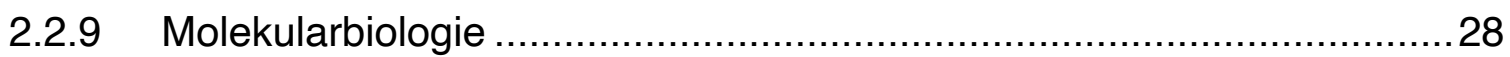

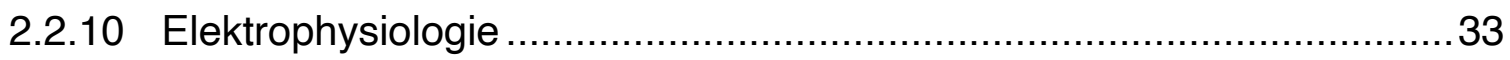

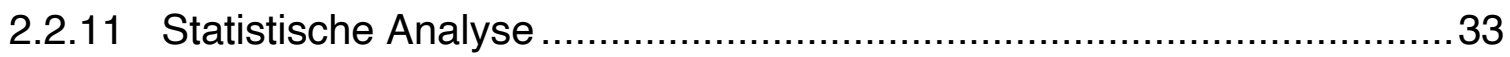

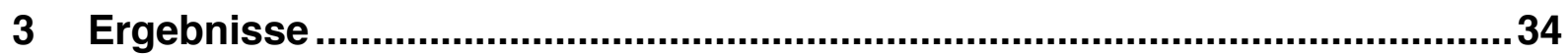

3.1 Verpaarungsstudie zur Erzeugung doppelt-transgener Versuchstiere

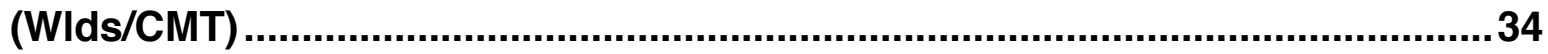

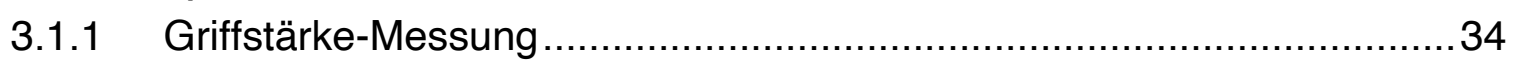

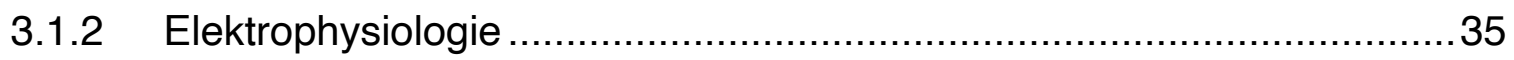

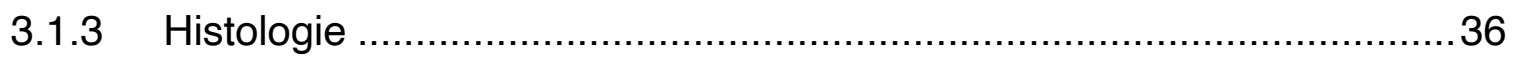




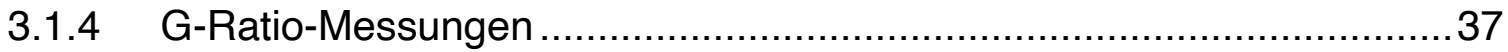

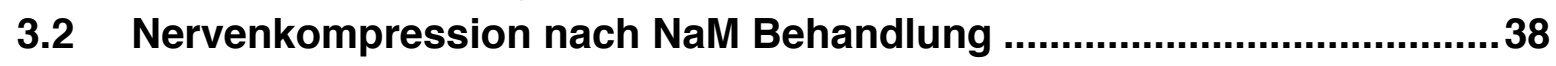

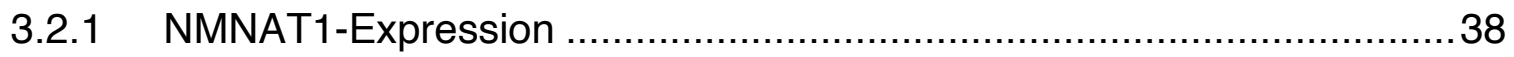

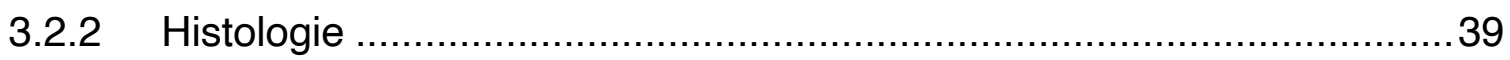

3.2.3 Nikotinamid-Konzentration in Serum und Nervengewebe ...................41

3.3 Nikotinamid-Behandlung von Wildtyp- und CMT-Ratten .......................41

3.3.1 NaM-Konzentration in Serum und Nervengewebe..............................42

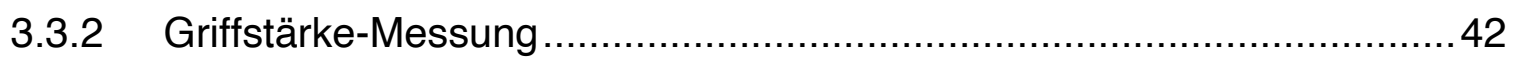

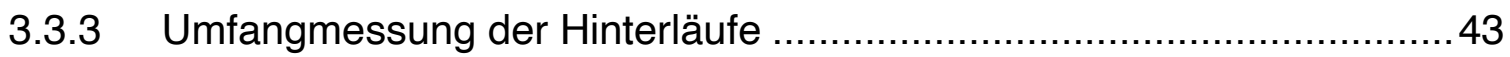

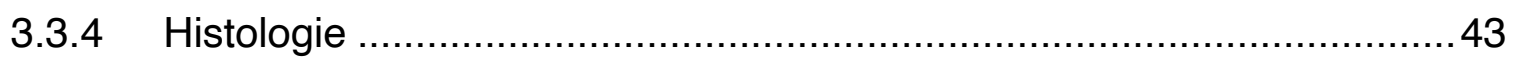

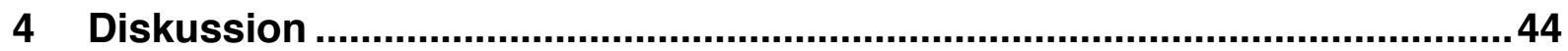

4.1 Erzeugung und Charakterisierung von doppelt-transgenen

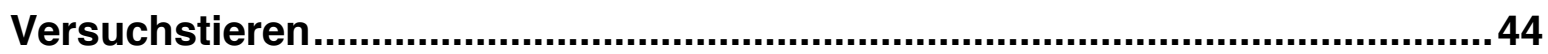

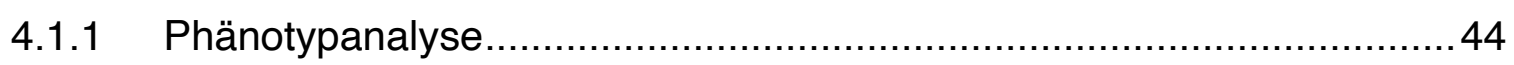

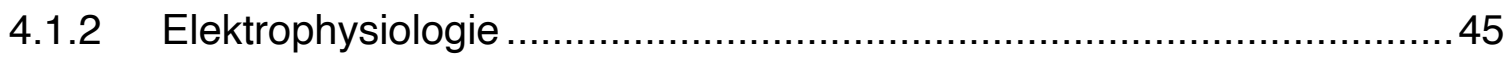

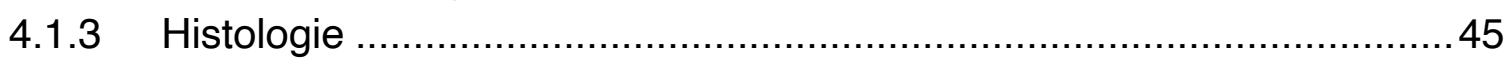

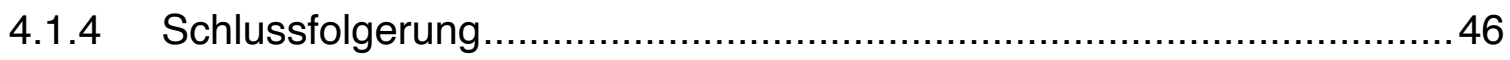

4.2 Behandlung mit Nikotinamid und Nervenkompression ........................47

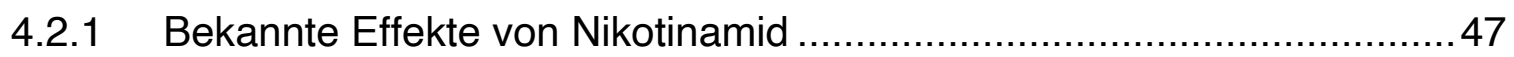

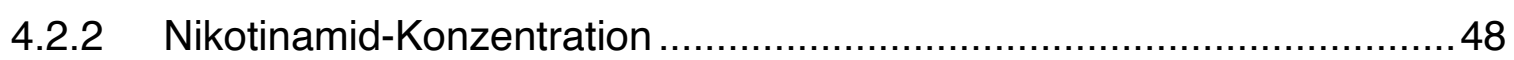

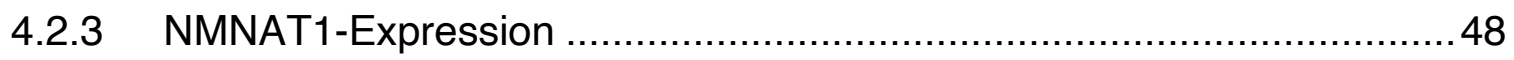

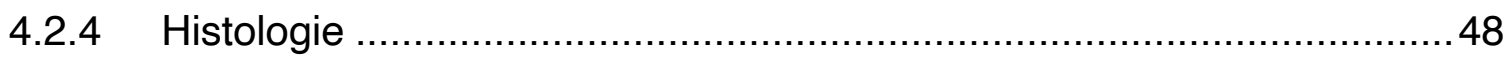

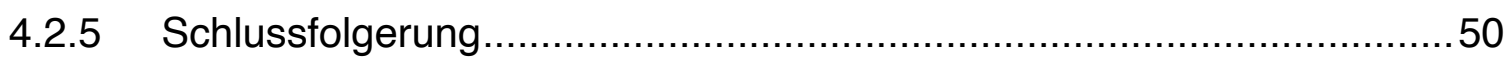

4.3 Langzeit-Behandlung von CMT1A-Tieren mit Nikotinamid ..................50

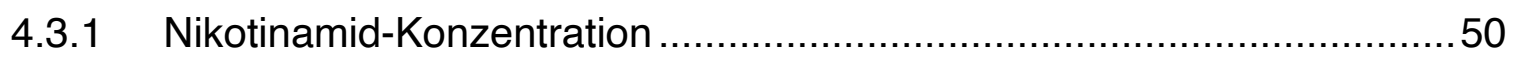

4.3.2 Phänotypanalyse und Histologie ........................................................51

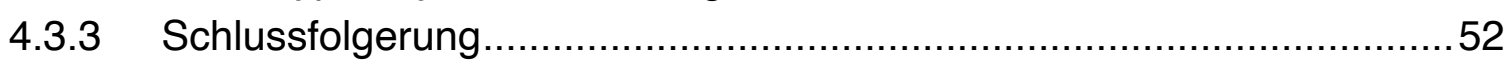

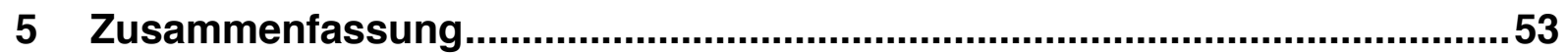

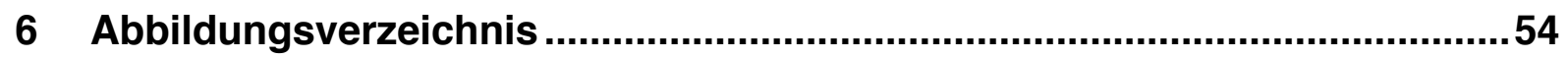

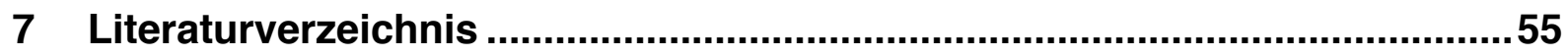




\section{Abkürzungsverzeichnis}

\begin{tabular}{|c|c|}
\hline AAD & acute axonal degeneration \\
\hline ADP & Adenosindiphosphat \\
\hline ADPR & Adenosindiphosphat-Ribose \\
\hline AMP & Adenosinmonophosphat \\
\hline ARM & armadillo repeat motif \\
\hline ATP & Adenosintriphosphat \\
\hline cADPR & zyclische Adenosindiphosphat-Ribose \\
\hline cDNA & complementary DNA \\
\hline CMAP & $\begin{array}{l}\text { compound muscle action potential } \\
\text { (Muskelsummenaktionspotential) }\end{array}$ \\
\hline CMDS & CPMP und Wlds doppelt-transgen \\
\hline CMT & Charcot-Marie-Tooth-Erkrankung \\
\hline $\mathrm{ddH}_{2} \mathrm{O}$ & double distilled water \\
\hline DDSA & 2-Duodecenyl-succinicacidanhydrid \\
\hline DLK & dual leucine zipper kinase \\
\hline DMP30 & 2,4,6-tris-dimethylaminomethyl-Phenol \\
\hline dNTP & Desoxyribonukleosid-Triphosphat \\
\hline dsDNA & doppelsträngige Desoxyribonukleinsäure \\
\hline EDTA & Ethylendiamintetraacetat \\
\hline ERK & extracellular signal-regulated kinase \\
\hline f.c. & final concentration \\
\hline Fwd & forward \\
\hline G & Gauge \\
\hline GIn & Glutamin \\
\hline Glu & Glutamat \\
\hline HBSS & Hanks Balanced Salts Solution \\
\hline $\mathrm{HCl}$ & Salzsäure \\
\hline HNPP & hereditary neuropathy with liability for pressure palsies \\
\hline HPLC & high-pressure liquid chromatography \\
\hline IPL & intraperiod line \\
\hline JNK & c-Jun N-terminal kinase \\
\hline kb & Kilobasen \\
\hline KG & Körpergewicht \\
\hline M & Mol \\
\hline MAPK & mitogen-activated protein kinase \\
\hline $\mathrm{Mb}$ & Megabasen \\
\hline MBP & myelin basic protein \\
\hline MDL & major dense line \\
\hline MEKK4 & MAP/ERK kinase kinase 4 \\
\hline MKK4\&7 & mitogen-activated protein kinase kinase $4 \& 7$ \\
\hline MLK2 & mixed-lineage kinase 2 \\
\hline
\end{tabular}




\begin{tabular}{|c|c|}
\hline MNA & MethyInadicanhydrid \\
\hline MPZ/PO & myelin protein zero \\
\hline mRNA & messenger ribonucleid acid \\
\hline $\mathrm{N}$ & Newton \\
\hline N. & Nervus \\
\hline NA & Nikotinsäure \\
\hline $\mathrm{NaM}$ & Nikotinamid \\
\hline NAAD & Nikotinsäureadenindinukleotid \\
\hline NAD & Nikotinamidadenindinukleotid \\
\hline NADS & Nikotinamidadenindinukleotid-Synthetase \\
\hline NAMPT & Nikotinamid-Phosphoribosyltransferase \\
\hline NaMN & Nikotinsäure Mononukleotid \\
\hline $\mathrm{NaOH}$ & Natriumhydroxid \\
\hline NAPRT & Nikotinsäure-Phosphoribosyltransferase \\
\hline NCV & nerve conduction velocity \\
\hline $\mathrm{nM}$ & Nanomol \\
\hline NMN & Nikotinamid-Mononukleotid \\
\hline NMNAT1,2,3 & Nikotinamid-Mononukleotid-Adenylyltransferase 1,2,3 \\
\hline Nn. & Nervi \\
\hline NNMNAT & N-Methyl-N-Acetyltransferase \\
\hline NR & Nikotinamid-Ribosid \\
\hline NRK & Nikotinamid-Ribosid-Kinase \\
\hline NS & Nervensystem \\
\hline NT-3 & Neurotrophin-3 \\
\hline PARP & Poly(ADP-Ribosyl)Polymerase \\
\hline PCR & polymerase chain reaction \\
\hline PMP22 & peripheral myelin protein of 22-kilodalton \\
\hline PN & peripherer Nerv \\
\hline PNS & peripheres Nervensystem \\
\hline PPi & Pyrophosphat \\
\hline PRPP & Phosphoribosylpyrophosphat \\
\hline QA & Quinolinsäure \\
\hline QAPRT & Quinolinsäure-Phosphoribosyltransferase \\
\hline QPCR & quantitative PCR \\
\hline Rev & reverse \\
\hline RM & Rückenmark \\
\hline RNA & Ribonukleinsäure \\
\hline rpm & revolutions per minute \\
\hline SAM & sterile alpha motif \\
\hline SARM & sterile alpha and TIR motif-containing \\
\hline SC & Schwann-Zelle \\
\hline siRNA & small-interfering-Ribonukleinsäure \\
\hline SLI & Schmidt-Lantermann-Inzisur \\
\hline
\end{tabular}


TAE

TIR

Tris

U

u/o

UV

VCP

W

WIds

WD

Wt

YFP

ZNS
Tris/Acetat-Puffer mit EDTA

Toll-interleukin-Rezeptor

Tris(hydroxymethyl)aminomethan-Base

Unit(s)

und/oder

ultraviolett

valosin-containing protein

Woche(n)

Wallerian-degeneration slow

Waller'sche Degeneration

Wildtyp

yellow fluorescent protein

zentrales Nervensystem 


\section{Einleitung}

\subsection{Strukturelle und funktionale Grundlagen der Informationsübertragung im Nervensystem}

Zur Übertragung von Informationen im menschlichen Nervensystem (NS) hat sich eine spezielle Art der Informationsübertragung in und zwischen den Neuronen entwickelt. Diese soll, zusammen mit den sie ermöglichenden Strukturelementen, im Folgenden in allgemeiner Form kurz dargestellt werden. Entsprechend den lokal unterschiedlichen Ansprüchen an die Funktion des NS werden die Spezifika der Vorgänge im peripheren und zentralen Nervensystem (PNS/ZNS) an die jeweiligen Gegebenheiten angepasst und können zum Teil erheblich von den hier beschriebenen allgemeinen Prinzipien abweichen. Der Informationsübertragung zwischen Gehirn und Rückenmark und der Körperperipherie dienen Axonbündel unterschiedlichen Kalibers, nämlich die peripheren Nerven. Sie übertragen verschiedene Signalqualitäten (motorisch, sensibel, propriozeptiv etc.) vom und zum ZNS (Efferenz/Afferenz). Informationsübertragung im Gehirn findet in den zu Fasertrakten gebündelten ZNSAxonen in der weißen Substanz statt (Kugler 2004). Der Transport der Information erfolgt als Aktionspotential. Dies ist eine zeitlich eng begrenzte Änderung des Membranpotentials eines Neurons, bei dem sich die über der Axonmembran anliegende Potentialdifferenz durch den schnellen Einstrom positiv geladener NatriumIonen in das Axon plötzlich ändert (Scheschonka et al. 2006; Silbernagl und Despopoulos 2007).

Unabdingbar für die erfolgreiche Informationsübermittlung ist die strukturelle Integrität des Neurons. Es besteht aus dem Zellsoma mit dem Zellkern als Ort der Transkription, dem Dendritenbaum, der die ankommenden Aktionspotentiale empfängt und integriert (Input) sowie dem Axon, das für die Weiterleitung der Information zuständig ist (Output). Variationen dieser Grundstruktur treten bei spezialisierten Neuronen auf. Generell kann jedoch festgestellt werden, dass Zellsoma sowie Input- und Output-Pol für die Funktion der Informationsübertragung unabdingbar sind. Eine Schädigung des Axons z. B. kann ein Absterben des ganzen Neurons zur Folge haben (s. u.). Das Axon entspringt aus dem Zellsoma am Axonhügel. Von hier zieht es zu seinem Ende, 
dem Axonterminus, unter Abgabe einer unterschiedlichen Anzahl von AxonKollateralen und meist dem Erwerb einer Myelinscheide auf dem Weg (s. u.). Das Zytoskelett des Axons besteht aus in Längsrichtung verlaufenden Neurofilamenten und -tubuli, entlang derer ante- und retrograder Transport von zumeist in Vesikel verpackten Proteinen und Neurotransmittern erfolgt. Das Axon endet schließlich mit der Ausbildung synaptischer Boutons, die den proximalen Teil der Synapse bilden. Das am Bouton ankommende elektrische Aktionspotential wird hier, unter dem Einfluss regulierender Faktoren, in ein chemisches Signal umgewandelt, indem es eine Fusion von Transmittervesikeln mit der präsynaptischen Membran auslöst und dadurch der jeweilige Botenstoff in den synaptischen Spalt freigesetzt wird. Dieser überträgt nun die Information über den synaptischen Spalt zur postsynaptischen Membran des nächsten Neurons (Kugler und Drenckhahn 2003).

Um die strukturelle und funktionelle Integrität der Neuronen im ZNS und PNS sicherzustellen, hat sich ein hochspezialisiertes Umgebungsgewebe aus Gliazellen entwickelt. Ein wesentlicher Bestandteil davon ist das Myelin. Die dicht gepackten Axone im zentralen Nervensystem erhalten ihre Myelinscheide von Oligodendrozyten, die ihre Fortsätze zu bis zu 50 verschiedenen Axonen aussenden und Segmente von diesen mit einer Myelinschicht umwickeln. Axone eines peripheren Nerven mit einem Durchmesser $>1 \mu \mathrm{m}$ werden in Reihe von mehreren Schwann-Zellen (SC) umschlossen, die je ein Myelin-Segment von ca. 1mm Länge bilden (Suzuki 2010). Dünnere Axone im PNS werden zu mehreren von einer nicht-myelinisierenden SC umgeben (sog. Remak-Bündel) (Kugler und Drenckhahn 2003).

Auf Grund der hohen Relevanz einer intakten Myelinscheide für die Funktion von Axon und Neuron als Ganzes soll deren Struktur im Folgenden kurz beschrieben werden. Die Bildung der Myelinscheide erfolgt durch mehrfaches Umwickeln des Axons mit einem Membranfortsatz der Gliazelle und Ausbildung einer spezifischen Membranstruktur (Sherman und Brophy 2005). Ultrastrukturell lässt sich Myelin in nicht-kompaktes und kompaktes und dieses wiederum in sich abwechselnde Schichten unterteilen, die sich regelmäßig wiederholen. Entsprechend ihrer Dichte in der Elektronenmikroskopie werden sie major dense lines (MDL) und intraperiod lines (IPL) genannt. Erstere entsprechen den zwei dicht gepackten zytoplasmatischen, 
letztere den zwei äußeren Membranschichten. Das nicht-kompakte Myelin wird weiter in mehrere spezifische Kompartimente unterteilt: Das ad- und abaxonale Segment, die Schmidt-Lantermann Inzisuren (SLI), die paranodalen Regionen zu beiden Seiten der Ranvier'schen Schnürringe und die Cajal-Bänder (Aggarwal et al. 2011; Nave und Werner 2014). Zu den peripheren Myelinproteinen gehören u. a. das Myelin Protein Zero (MPZ / P0), das über 50\% der Myelinproteine ausmacht, das Myelin-basische Protein (MBP, 30-40\% der Myelinproteine) und das periphere Myelin-Protein 22 (PMP22) (Scheschonka et al. 2006).
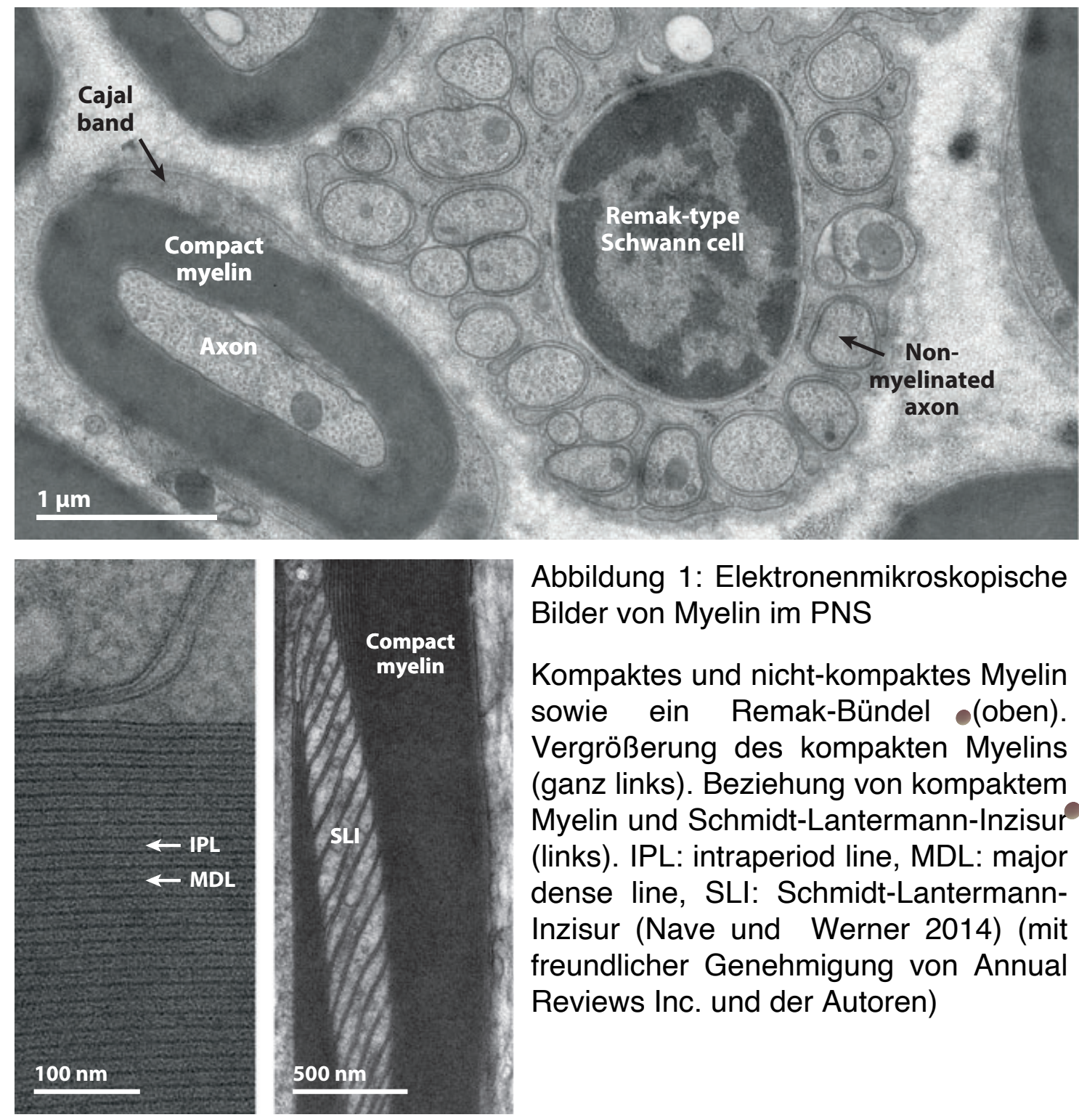

Abbildung 1: Elektronenmikroskopische Bilder von Myelin im PNS

Kompaktes und nicht-kompaktes Myelin sowie ein Remak-Bündel (oben). Vergrößerung des kompakten Myelins (ganz links). Beziehung von kompaktem Myelin und Schmidt-Lantermann-Inzisur (links). IPL: intraperiod line, MDL: major dense line, SLI: Schmidt-LantermannInzisur (Nave und Werner 2014) (mit freundlicher Genehmigung von Annual Reviews Inc. und der Autoren)

Insgesamt besteht das Myelin im PNS zu ca. 70\% aus Lipiden und zu ca. 30\% aus Proteinen (Scheschonka et al. 2006). In verschiedenen Wirbeltier-Spezies ist das 
Verhältnis von Axondurchmesser zu Myelinscheiden-Durchmesser (sog. g-ratio) mit 0,6 - 0,7 etwa gleich und wird zur Quantifizierung von Myelindefekten herangezogen. Myelin führt zu einer elektrischen Isolation der Axonmembran, womit die saltatorische Erregungsleitung im NS möglich wird. Hierbei "springt" ein Aktionspotential von einem Ranvier'schen Schnürring (Zwischenraum von zwei Schwann-Zellen) zum nächsten. Die Geschwindigkeit der Signaltransduktion wird so stark erhöht (von 0,5 m/s in unmyelinisierten Axonen auf bis zu 120 m/s in myelinisierten Axonen). Das erstmalige Auftreten von Myelin vor ca. 600 Millionen Jahren während der Evolution dürfte daher einen deutlichen Selektionsvorteil bedeutet haben (Nave und Trapp 2008).

Schwann-Zellen nehmen außerdem Einfluss auf die Organisation und Funktion von Axonen, indem sie das Clustering von lonenkanälen in der Axonmembran im Bereich der Ranvier-Schnürringe und die Struktur der paranodalen Membrankomponenten induzieren (Sherman und Brophy 2005). Es gibt außerdem Hinweise darauf, dass die Schwann-Zellen weitere Myelin-unabhängige Funktionen haben, wie etwa trophische Unterstützung des Axons (Nave 2010). Nehmen die Schwann-Zellen dauerhaft Schaden, verliert ein Axon seine Myelinscheide und wird zu Grunde gehen, was schließlich zum Absterben des gesamten Neurons führt (Suzuki 2010). Klinisch zeigt sich dies im peripheren Nervensystem an den Symptomen von peripheren Neuropathien wie Muskelschwund, Parästhesien, afferenter Ataxie, etc. (s. u.).

\subsection{Der Prozess der axonalen Degeneration}

In der Pathophysiologie vieler unterschiedlicher neurologischer Erkrankungen spielt die Akkumulation axonaler Schäden und der darauf folgende Verlust funktionsfähiger Axone und Synapsen eine große Rolle. Die Symptome so unterschiedlicher Erkrankungen wie Schlaganfall, periphere Neuropathien, Multiple Sklerose, posttraumatische Defizite etc. lassen sich zumindest teilweise darauf zurückführen (Coleman 2005). Man kann den Axonverlust als die gemeinsame pathophysiologische Endstrecke der Erkrankungen bezeichnen. Die Vorgänge auf molekularer Ebene bei chronischer und akuter Schädigung haben dabei viele Gemeinsamkeiten. So reagiert ein Axon auf Demyelinisierung, toxische (wie etwa Kontakt mit Taxol) und mechanische Schädigung sehr ähnlich. Als Modell zur Erforschung der Vorgänge während der axonalen Degeneration wird daher häufig die methodisch einfache 
axonale Transsektion verwandt. Die Ansammlung axonaler Schäden kann über die unten beschriebenen Mechanismen wie Calcium-Einstrom, Unterbrechung des axonalen Transports, Denervation etc. zum Untergang des ganzen Neurons führen und so einer Neurodegeneration und Atrophie in größerem Maße Vorschub leisten (Coleman und Freeman 2010; Neukomm und Freeman 2014; Wang et al. 2012).

Es lassen sich drei verschiedene Phasen dieser subzellulären, intrinsisch im Axon ablaufenden Reaktion unterscheiden: Eine frühe, akute axonale Degeneration (AAD, 5 - 60 min. nach Schädigung) führt zu einer Retraktion des proximalen und distalen Stumpfes des Axons um einige Mikrometer. Durch Unterbrechung des axonalen Transportes und Akkumulation der Fracht kommt es zur Bildung von Auftreibungen beidseits des Schnittes. Der Membrankanal-vermittelte Einstrom von Calcium-Ionen und die darauf folgende Aktivierung der Protease Calpain, die Proteine des Axonskeletts spaltet, ist für diesen Prozess Voraussetzung. Man vermutet, dass die AAD auch der Wegbereiter für die Regeneration geschädigter Nerven ist, da sie die Voraussetzung für den Untergang des distalen Axons und für die Sprossung des proximalen Axonstumpfes ist (Wang et al. 2012).

Auf die AAD folgt die klassische Waller'sche Degeneration (Waller 1850), die noch einmal in eine Latenzphase (ca. 24-48 Std.) und eine Phase der granulären Fragmentierung des distalen Axonsegments (ca. 72 Std. nach Schädigung) unterteilt werden kann. Zunächst zeigt sich am proximalen Teil des Axons bereits wenige Stunden nach der Schädigung ein Auswachsen von neuen Sprossen als Zeichen der Regeneration. Währenddessen zeigt der distale Teil des Axons eine strukturelle und funktionelle Latenzphase (Wang et al. 2012).

Danach kommt es zu weiteren Änderungen des intra-axonalen Stoffwechsels im distalen Axonstumpf, die sich nun entscheidend von den Vorgängen im proximalen, mit dem Soma verbundenen Anteil, unterscheiden. Zunächst ist auch hier ein Anstieg der intra-axonalen Calcium-Konzentration durch Kanal-vermittelten Einstrom oder Freisetzung aus endogenen Reservoirs zu verzeichnen, der Calpain aktiviert. Es zeigt sich jedoch, dass dieser Vorgang von zeitlich und hierarchisch übergeordneten Faktoren abhängt (Freeman 2014; Wang et al. 2012). 
Welche Faktoren spielen nun die zentrale Rolle im koordinierten Ablauf der Axondegeneration? Lange ging es hier um die Frage, ob es sich um die Aktivierung eines death signals handelt oder vielmehr um den Verlust eines survival factors. Es stellt sich nun mit der Zeit heraus, dass beide Vermutungen zutreffen.

Zum einen wurde ein Netzwerk von Molekülen aus der Familie der Mitogen-aktivierten Proteinkinasen (MAPK) identifiziert, darunter DLK (dual leucine zipper kinase), MEKK4 (MAP/ERK kinase kinase 4), MLK2 (mixed-lineage kinase 2), MKK4\&7 (mitogenactivated protein kinase kinase 4\&7) und JNK1-3 (c-Jun N-terminal kinase), deren Aktivität zu Axonverlust führt (Yang et al. 2015). Die Upstream-Aktivatoren und Downstream-Ziele der Aktivität dieser Kinasen sind bisher nicht vollständig bekannt. Es konnte jedoch ein Molekül identifiziert werden, das für die Regulation der axonalen Degeneration eine Schlüsselstellung in diesem Netzwerk einnimmt: SARM1 (Gerdts et al. 2013; Osterloh et al. 2012). Es handelt sich hierbei um ein intrazelluläres Protein, das v. a. in der äußeren Mitochondrienmembran vorkommt, aber auch an Synapsen und räumlich mit Mikrotubuli assoziiert. Es enthält mehrere Interaktionsdomänen für Protein-Protein-Wechselwirkungen: eine Toll-Interleukin Rezeptor (TIR)-, zwei sterile alpha motif (SAM)- und multiple armadillo repeat motif (ARM)-Domänen. Kürzlich konnte nachgewiesen werden, dass die TIR-Domäne von SARM eine intrinsische NADase-Aktivität besitzt und Nikotinamid-Adenin-Dinukleotid (NAD) in die Produkte Nikotinamid (NaM), Adenosin-Diphosphat-Ribose (ADPR) und cyklische ADPR (cADPR) spaltet (Essuman et al. 2017).

Entsprechend den bekannten Funktionen dieser Protein-Strukturelemente nimmt man an, dass Axonschäden zu einer Multimerisierung von SARM über die SAMs führen und dadurch die auto-inhibitorische multi-AMR-Region von der funktionellen TIRDomäne entfernt wird, wodurch es zu einer Destruktion von lokalem NAD, Aktivierung des MAPK-Signalwegs (s. o.) und Interaktion mit dem TIR-Signalweg kommt und dabei weitere Schritte im Axon-Degenerationsprogramm aktiviert werden (Gerdts et al. 2016). Mit der Identifikation von SARM scheint daher der zentrale Aktivator der axonalen Degeneration gefunden zu sein (death signal).

Zum anderen wurde in Untersuchungen zum protektiven Phänotyp der Wallerian degeneration slow (WIds)-Mutation die axonal lokalisierte Nikotinamid-MononukleotidAdenylyltransferase 2 (NMNAT2, s. u.) als Kandidat für einen survival factor identifiziert. Es handelt sich um eine Isoform des Synthase-Enzyms, das den letzten 
Schritt der Bildung von NAD katalysiert. NAD ist ein Co-Faktor in Redox-Reaktionen und ein Substrat für verschiedene Nicht-Redox-Reaktionen, u. a. für posttranslationale Protein-Modifikation und intrazelluläre Kommunikation (Di Stefano und Conforti 2013). Es konnte gezeigt werden, dass NMNAT2 eine Schlüsselstellung im axonalen NAD-Stoffwechsel einnimmt und als instabiles Molekül kontinuierlich vom Zellkörper aus in das Axon zugeführt werden muss. Dieser Nachschubweg wird nun durch die axonale Schädigung/Transsektion unterbrochen, weshalb das Axon degeneriert. So führt ein Knockdown von NMNAT2 mit small interferingRibonukleinsäure (siRNA) zu axonaler Degeneration ohne äußere Schäden am Axon (Gilley und Coleman 2010).

Schließlich, ausgehend von der Idee, dass der Proteinumsatz im Axonstumpf nun keinen neuen Zustrom vom Soma erfährt, lässt sich die axonale Degeneration durch Inhibition des Ubiquitin-Proteasom-Systems - und damit des Proteinabbaus verlangsamen. Dies ist ein weiteres Argument für das Vorliegen eines survival factors, der nach Transsektion nicht mehr ausreichend nachgeliefert wird (Wang et al. 2012).

\subsection{Die Wallerian-degeneration-slow (WIds) -Mutation und axonale Protektion}

Die Wlds-Mutation stellt ein interessantes Werkzeug zur Erforschung axonaler Degeneration dar. Es handelt sich um eine Spontanmutation bei Mäusen, die 1989 erstmals beschrieben wurde (Lunn et al. 1989). Weitere Analysen (Mack et al. 2001) des „Wlds-Gens“ zeigten, dass es sich um eine Gen-Chimäre handelt, bei der es zu einer in-frame-Fusion des NMNAT1-Gens (Nikotinamid Mononukleotid Adenylyltransferase 1) mit den 70 n-terminalen Aminosäuren (N70) des Ubiquitinierungsfaktors Ube4b kommt. NMNAT1 ist eine der drei bekannten Isoformen des Enzyms, das den letzten Schritt im NAD-Stoffwechsel katalysiert, nämlich den Transfer eines Adenylyl-Restes von ATP auf NMN oder NAMN (Abb. 3). Die drei Isoformen werden unterschiedlich exprimiert: So ist NMNAT1 ein nukleär lokalisiertes Protein und wird ubiquitär exprimiert. NMNAT2 ist im Zyto- und Axoplasma lokalisiert und findet sich vor allem im Hirn. NMNAT3 schließlich ist vermutlich mitochondrial lokalisiert und wird schwach im Hirn exprimiert (Di Stefano und Conforti 2013). Die N70-Region enthält zwar nicht die katalytische Sequenz des Ubiquitinierungsfaktors, aber eine kurze Region, die die Bindung mit valosin-containing protein (VCP) vermittelt 
(s. u.). Außerdem enthält das Wlds-Gen eine spezifische, 18 Aminosäuren lange Verbindungsregion, die keine bekannte Funktion hat (Abb. 2). Bei Vorhandensein des Gens in Mäusen oder als Transgen in Ratten (Adalbert et al. 2005) kommt es zu einer deutlichen Steigerung der Widerstandsfähigkeit der Axone gegenüber vielen Arten von Schädigungen wie u. a. Axotomie (Wang et al. 2005) und Behandlung mit Toxinen (Wang et al. 2002). Auch in vivo konnte eine Abmilderung des klinischen Phänotyps bei verschiedenen neurodegenerativen Erkrankungen in Modelltieren festgestellt werden (Fischer et al. 2005; Mi et al. 2005; Samsam et al. 2003).

\section{WLD $^{\mathrm{S}}$}

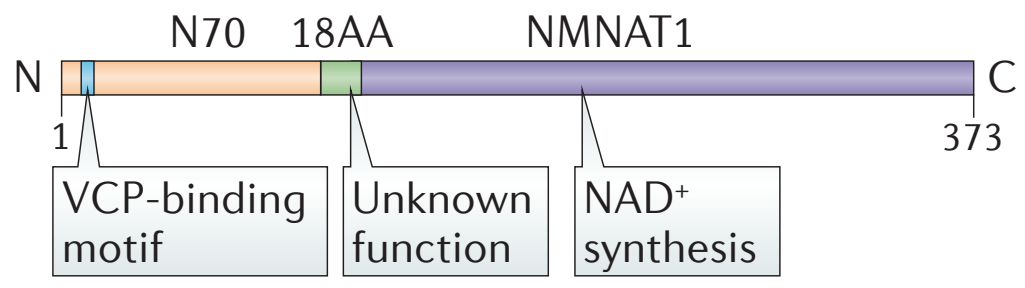

Abbildung 1: Die Proteindomänen-Struktur von Wlds. Das Gen codiert die volle Sequenz von NMNAT1, eine Verbindungsregion mit 18 Aminosäuren (18AA) und einen Aminosäuren-Rest des Ubiquitinierungsfaktors Ube4b (N70), s. Text. VCP: valosin-containing protein (Conforti et al. 2014) (mit freundlicher Genehmigung von Springer Nature).

Der Mechanismus der Neuroprotektion durch Wids ist bisher nicht vollständig geklärt. Verschiedene Mechanismen sind vorgeschlagen worden. Die meiste Evidenz wurde bisher zur Rolle der enzymatischen Funktion des NMNAT-Anteils des Wids-Proteins gesammelt. So scheint die subzelluläre Lokalisation sowie eine wahrscheinlich damit einhergehende Umstellung der bioenergetischen Abläufe in der Zelle eine Rolle zu spielen.

WIds ist wie NMNAT1 zwar vor allem nukleär lokalisiert (Di Stefano und Conforti 2013; Mack et al. 2001), es konnte jedoch gezeigt werden, dass die N70-Sequenz von WIds eine Relokalisation in das Axoplasma verursacht, die für die neuroprotektive Wirkung Voraussetzung ist, ebenso wie die funktionell intakte NMNAT1-Sequenz (Avery et al. 2009; Conforti et al. 2009). Überexpression von nukleär lokalisiertem NMNAT1 führt nicht zu einem protektiven Phänotyp (Conforti et al. 2007). Aber nach Relokalisation von NMNAT1 in das Axon zeigt sich ein neuroprotektiver Phänotyp (Sasaki und 
Milbrandt 2010) und axonale Aktivität von NMNAT/Wlds ist für die Protektion der Axone Voraussetzung (Wang et al. 2015). Dies zeigt die Notwendigkeit einer axonal lokalisierten enzymatischen Aktivität von NMNAT für den neuroprotektiven Effekt des Proteins.

Neben dieser Argumentationslinie wurden alternative/ergänzende Mechanismen für die neuroprotektive Wirkung von Wlds vorgeschlagen. Die Überexpression von NMNAT ohne enzymatische Aktivität in Drosophila zeigte ebenfalls eine neuroprotektive Wirkung (Zhai et al. 2006). Hierfür ist in diesem Falle eine ChaperoneFunktion des Proteins verantwortlich gemacht worden (Zhai et al. 2008). Vor kurzem konnte diese auch in Ex-vivo- und In-vitro-Experimenten nachgewiesen werden (Ali et al. 2016). Dies gibt somit Hinweise darauf, dass NMNAT auf mindestens zwei verschiedene Arten zur Neuroprotektion beitragen kann, zum einen über den NADStoffwechselweg und die Verringerung von Exzitotoxizität und zum anderen über die Chaperone-Funktion und die Verringerung von Proteotoxizität.

In-vitro-Experimente einer anderen Arbeitsgruppe haben des Weiteren eine Vermittlung des protektiven Phänotyps über die nukleär lokalisierten Deacetylasen der Sirtuin-Familie postuliert, da eine Blockierung dieser die Neurodegeneration nach Axon-Transsektion verringern konnte (Araki et al. 2004).

Als ein möglicher Überlebensfaktor (survival factor, s. o.) wurde die axonal lokalisierte NMNAT2-Isoform postuliert. Sie unterliegt einem raschen Protein-Umsatz und muss kontinuierlich vom Nukleus durch axonalen Transport nachgeliefert werden. Nach Axonschädigung wird sie daher schnell abgebaut und sowohl die damit verbundene Akkumulation von Nikotinamid-Mononukleotid (NMN, (Di Stefano et al. 2015) als auch der lokale Verlust von NAD (Gerdts et al. 2015) werden mit axonaler Degeneration in Zusammenhang gebracht. Ihre Funktion wird mutmaßlich durch Wids ersetzt, durch das ein enzymatisch funktionales NMNAT-Enzym von nukleär nach axonal relokalisiert wird (Gilley und Coleman 2010).

Eine Axonprotektion kann in vitro auch durch die Zugabe von verschiedenen Molekülen aus dem NAD-Stoffwechselweg erreicht werden. So führt $u$. a. die Zugabe von Nikotinamid (Wang et al. 2005), NMN (Sasaki et al. 2006) und NAD (Araki et al. 2004; Sasaki et al. 2006; Wang et al. 2005) zu einer Verzögerung der axonalen 
Degeneration nach Transsektion. Nikotinamid, die bioverfügbare Substratvorstufe für die NMNATs, hat noch weitere neuroprotektive Effekte gezeigt.

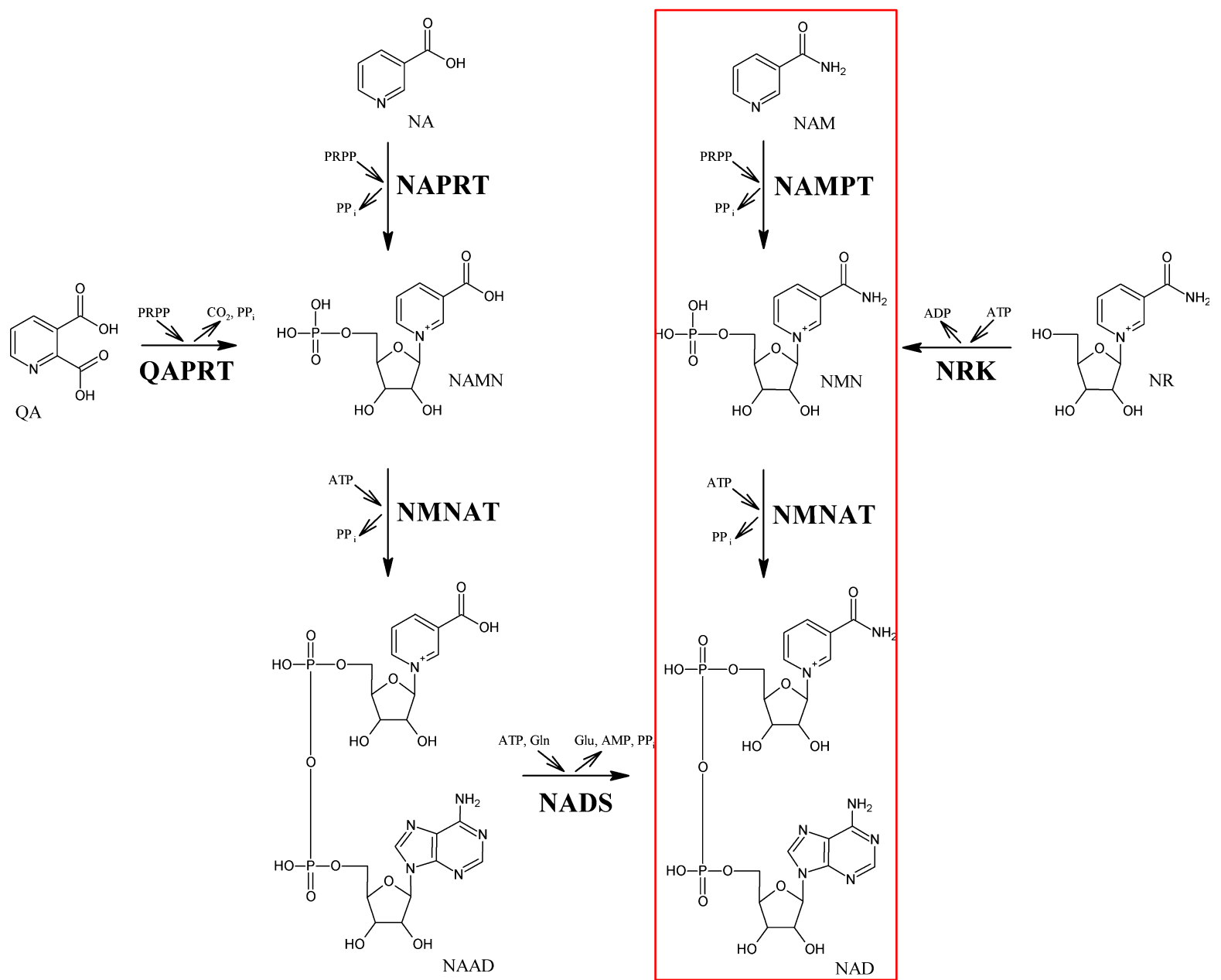

Abbildung 2: Die NAD-Synthese beim Menschen, rot umrandet der Pfad über die Zufuhr von NaM. Für die Erklärung der Abkürzungen s. Abkürzungsverzeichnis (Di Stefano und Conforti 2013) (mit freundlicher Genehmigung von John Wiley \& Sons).

Es reduziert neben der Nervenschädigung nach Axotomie in vitro (Wang et al. 2005) (s. o.) auch entzündlich vermittelte Neurodegeneration (Kaneko et al. 2006) und die Größe der Infarktzone in Tiermodellen des ischämischen Hirnschlags (Mokudai et al. 2000; Sadanaga-Akiyoshi et al. 2003) (s. u.). Dies ist ein weiteres Argument für die Vermittlung der Wids-Neuroprotektion über den bioenergetischen NADStoffwechselweg. 


\subsection{Die Charcot-Marie-Tooth (CMT) -Erkrankungen}

Die große Gruppe der CMT-Erkrankungen umfasst durch unterschiedliche genetische Mechanismen verursachte peripherere Neuropathien. Zusammen-genommen gehören diese mit einer Inzidenz von 1/2500 zu den häufigsten Erbkrankheiten des Menschen (Gutmann und Shy 2015). Eine Beschreibung der klinischen Symptome gelang bereits 1856 durch Eulenburg (Eulenburg 1856). Die Anerkennung als eigene Krankheit mit Namensgebung erfolgte schließlich nach den Beschreibungen von Charcot und Marie und zeitgleich von Tooth 1886 (Charcot und Marie 1886; Tooth 1886).

Die Diagnose und Klassifizierung der Erkrankungen erfolgt über die klinischen Symptome, eine Stammbaumanalyse, die elektrophysiologische Untersuchung und schließlich eine molekulargenetische Analyse. Eine grundsätzliche pathophysiologische Einteilung in demyelinisierende (CMT1) und axonale (CMT2) Formen hat nach wie vor Gültigkeit, musste jedoch durch die Entdeckung von neuen genetischen Mechanismen kontinuierlich erweitert werden. Im Falle einer demyelinisierenden Pathologie finden sich histologisch Zeichen für vermehrte De- und Remyelinisierung. Die Anzahl von myelinisierten Axonen ist insgesamt reduziert, und die Schwann-Zellen enthalten mehr Zellkerne und bilden sog. Zwiebelschalen-Formationen (onion bulbs) aus (Lupski und Chance 2005). Der damit einhergehende Funktionsdefekt der Myelinscheide ist die primäre Pathologie. Diese wird klinisch $u$. a. durch verlangsamte Nervenleitgeschwindigkeit (NCV) in der elektrophysiologischen Untersuchung ausgedrückt. Schließlich führt sie zu einer sekundären axonalen Degeneration. Nach mehrjährigem Krankheitsverlauf kann dann auch das Muskel-Summenaktionspotential (CMAP) verringert sein. Bei der axonalen Form kommt es bei erhaltener NCV primär zu einer Abnahme des CMAP und histologisch zu Regenerationsvorgängen u/o versuchen des Axons.

Inzwischen sind durch die Fortschritte in der Gen-Sequenzierungstechnologie über 1000 Mutationen in über 80 Genen bekannt, die eine CMT-Erkrankung auslösen können (Gutmann und Shy 2015). Diese Daten haben das alte Klassifizierungsschema verkompliziert, da eine ähnliche Klinik durch viele unterschiedliche Mutationen ausgelöst werden kann, aber auch Mutationen in demselben Gen unterschiedliche Erkrankungen und Symptome hervorbringen können 
(Suter und Scherer 2003). Der pathophysiologische Zusammenhang von Genotyp und klinischen Symptomen ist daher bei vielen CMT-Formen noch nicht verstanden.

\subsubsection{Typische Symptome und natürlicher Verlauf}

Die Erkrankung führt bei genetischer Heterogenität zu ähnlichen klinischen Symptomen. Die Patienten leiden an einer von distal nach proximal fortschreitenden Muskelatrophie v. a. der Beine, begleitet von Fußdeformitäten wie Hammerzehen, Hohlfuß und Kallusbildung. Später im Verlauf der Erkrankung sind auch die Arme betroffen mit Atrophie der intrinsischen Handmuskeln und Feinmotorikstörungen. Sensible Defizite können ebenfalls auftreten. Erste Symptome treten meist in der zweiten Lebensdekade auf und zeigen eine langsame Progredienz über Jahrzehnte. Die klinische Ausprägung der Erkrankung unterscheidet sich interindividuell stark, sogar zwischen Geschwistern und Zwillingen. Das Spektrum reicht von einer verringerten NCV ohne klinische Symptome bis zur Rollstuhlpflichtigkeit. Der Grund hierfür ist nicht bekannt (Pareyson und Marchesi 2009).

\subsubsection{Die CMT1A-Erkrankung}

Die größte und damit klinisch relevanteste Gruppe der CMT-Erkrankungen ist die CMT1A. Der Auslöser ist in den meisten Fällen eine intrachromosomale Duplikation eines 1,4 Mb großen DNA-Fragments auf Chromosom 17q zwischen den Banden 11.2 - 12. Dadurch kommt es zu Überexpression des peripheren Myelinproteins von 22 kDa (PMP 22), dessen Sequenz in diesem Fragment enthalten ist. Im Gegensatz dazu führt eine Deletion des Fragments zur Ausbildung der hereditary neuropathy with liability for pressure palsies (HNPP), einer anderen Form der genetischen Neuropathie mit anderer Symptomatik. In seltenen Fällen können auch Punktmutationen im PMP22-Gen beide Erkrankungen auslösen. Die Vererbung erfolgt in aller Regel autosomal dominant, wobei wenige rezessiv vererbte Mutationen beschrieben wurden (Lupski und Chance 2005).

PMP22 macht ca. 3-5\% der Myelinproteine aus. Ultrastrukturell ist es ein Zellmembran-Protein mit vier transmembranösen Domänen und in Regionen mit kompaktem Myelin zu finden (Abb. 4). Die Funktion von PMP22 in normalem Myelin ist nicht vollständig verstanden, eine Rolle als Strukturprotein wird vermutet. Die 
Gruppe der durch Änderungen in der Expression von PMP22 verursachten CMTFormen werden als Gendosis-Erkrankungen bezeichnet, da eine zu hohe oder zu niedrige Menge an PMP22-messenger RNA (mRNA) mit den klinischen Symptomen korreliert. Je mehr PMP22-Kopien im Tiermodell exprimiert werden, desto ausgeprägter der Phänotyp (Sereda et al. 1996).

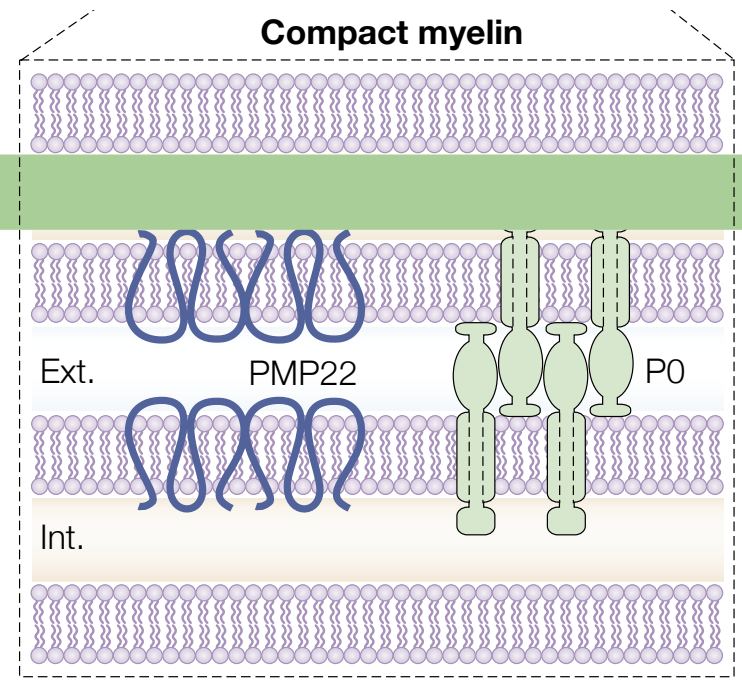

Abbildung 4: Die zwei peripheren Myelinproteine PMP22 und MPZ/P0 und ihre Lokalisation. Defekte dieser zwei Proteine sind zusammen für die meisten CMT-Fälle verantwortlich. Int.: intrazellulär, Ext.: extrazellulär (Suter und Scherer 2003) (mit freundlicher Genehmigung von Springer Nature).

Durch die Überexpression kommt es durch einen ebenfalls nicht vollständig verstandenen Mechanismus zu Demyelinisierung des Axons und in der Folge zu axonaler Degeneration und schließlich Axon- und Neuronenverlust (s. o.). Dieser Prozess betrifft dabei zuerst die längsten und kaliberstärksten Axone (Scherer und Wrabetz 2008). Dies erklärt die von distal nach proximal progrediente neurologische Symptomatik der Patienten (s. o.).

\subsubsection{Therapie der CMT}

Für eine spezifische pharmakologische Therapie gab es mehrere vielversprechende präklinische Ergebnisse. So wurde in tierexperimentellen Studien die positive Wirkung von Curcumin (Khajavi et al. 2005), Ascorbinsäure (Passage et al. 2004), Neurotrophin-3 (Sahenk et al. 2005) und Progesteron-Antagonisten (Meyer zu Horste et al. 2007; Sereda et al. 2003) auf den Verlauf der Erkrankung festgestellt. Der Effekt 
von Ascorbinsäure konnte in klinischen Studien am Menschen jedoch nicht repliziert werden (Micallef et al. 2009; Pareyson et al. 2011; Verhamme et al. 2009). Auch bei den anderen genannten Ansätzen entstanden größere Schwierigkeiten beim Versuch der Anwendung beim Menschen. So sind Progesteron-Antagonisten in ihrer Anwendung z.T. zu toxisch und NT-3 hat eine zu kurze Halbwertszeit für die nötige Langzeit-Therapie und ist nur schwer in größeren Mengen zu bekommen.

Daher gibt es leider weiterhin keine etablierten kausalen Therapien für diese Erkrankung. Die aktuell verfügbaren Therapien beschränken sich auf eine Linderung der Symptome wie Schmerzen, Deformitäten oder Mobilitätseinschränkungen.

\subsection{Fragestellung und Hypothese dieser Arbeit}

Mit dieser Arbeit soll die Frage beantwortet werden, ob das Wids-Gen den Phänotyp der CMT1A-Erkrankung im Modelltier beeinflussen kann und ob ein solcher Effekt über Gabe von Nikotinamid als bioverfügbare Substratvorstufe des NMNAT1-Enzyms - therapeutisch nutzbar gemacht werden kann. 


\section{Material und Methoden}

\subsection{Material}

\subsubsection{Verbrauchsmaterial}

$\mathrm{CO}_{2}$-Gas

Einmalhandschuhe Latex

Messer-Griesheim, Krefeld

Hartmann, Heidenheim

Einmalhandschuhe Nitril

Carl Roth, Karlsruhe

Eppendorfgefäße, Größen 0,5; 1,5; 2 ml

Eppendorf, Hamburg

Falconröhrchen, Größen 15; 50 ml

Becton Dickinson, Heidelberg

Falconröhrchen Rundboden 6 ml

Becton Dickinson, Heidelberg

Histologisches Einschlussmittel "Eukitt"

O. Kindler, Freiburg

Immersionsöl "Immersol 518 N"

Carl Zeiss, Göttingen

Injektionskanülen, Größen: 17G, 20G, 23G

Becton Dickinson, Heidelberg

Linsenpapier

Macherey-Nagel, Düren

Nahtfaden

Objektträger und Deckgläser

Fine Science Tools, Heidelberg

Menzel-Gläser, Braunschweig

PCR-Mikrotiterplatten

Thermo Fisher Scientific, Waltham

PCR-Plattenfolie "easy peel"

Thermo Fisher Scientific, Waltham

Pasteurpipetten

WU, Mainz

Photometerküvetten "Uvette 220-1600 nm"

Eppendorf, Hamburg

Pipettenspitzen, versch. Größen

Molecular Bioproducts, San Diego

Rasierklingen

American Safety Razor Company,

Verona, USA

Ratten-Standarddiät "R/M-H V1535"

Ssniff Spezialdiäten, Soest

Skalpellklingen

Spritzen, versch. Größen

Swann Morton Limited, Sheffield, UK

Spritzenaufsatzfilter "Millex GP 0,22 $\mu \mathrm{m}$ "

Becton Dickinson, Heidelberg

Transferpipetten

Millipore, Cork, Irland

Bio-Rad, Hercules, USA

Trockeneis

Messer-Griesheim, Krefeld

Venenpunktionsbesteck "Venofix"

Braun, Melsungen

Verschlussfolie "Parafilm" 


\subsubsection{Chemikalien}

Agarose

Azur-II-Farbstoff

Benzylbenzoat

Chloroform

DDSA (2-Duodecenyl-

succinicacidanhydrid)

Dinatriumhydrogenphosphat-2-hydrat

$\left(\mathrm{Na}_{2} \mathrm{HPO}_{4}{ }^{\star} 2 \mathrm{H}_{2} \mathrm{O}\right.$ )

DMP30 (2,4,6-tris-dimethylaminomethyl-

Phenol)

DTT (1,4-Dithiotreitol)

EDTA (Ethylendiamintetraacetat)

Essigsäure

Ethanol

Ethidiumbromid

Glutardialdehyd

Glycidether

HBSS (Hanks Balanced Salts Solution)

Isopropanol

Ketamin (Ketanest $\left.{ }^{\circledR}\right)$

Methylenblau

Methylnadicanhydrid (MNA)

Natriumchlorid $(\mathrm{NaCl})$

Natriumdihydrogenphosphat-hydrat

$\left(\mathrm{NaH}_{2} \mathrm{PO}_{4}{ }^{*} \mathrm{H}_{2} \mathrm{O}\right)$

Natriumhydroxid $(\mathrm{NaOH})$

Nikotinamid

Osmiumtetroxid

Paraformaldehyd

Propylenoxid

Salzsäure $(\mathrm{HCl})$

Stickstoff, flüssig (N2)
Bio-Rad, Hercules, USA

Merck, Darmstadt

Sigma, Hamburg

Merck, Darmstadt

Serva, Heidelberg

Merck, Darmstadt

Serva, Heidelberg

GibcoBRL, Karlsruhe

Merck, Darmstadt

Merck, Darmstadt

Merck, Darmstadt

Sigma-Aldrich, Schnelldorf

Merck, Darmstadt

Serva, Heidelberg

GibcoBRL, Karlsruhe

Merck, Darmstadt

Parke-Davis, Berlin/Detroit

Merck, Darmstadt

Serva, Heidelberg

Merck, Darmstadt

Merck, Darmstadt

Merck, Darmstadt

Sigma-Aldrich, Schnelldorf

Serva, Heidelberg

Serva, Heidelberg

Serva, Heidelberg

Serva, Heidelberg

Air Liquide, Düsseldorf 
Tris-HCl Base

Xylazin (Rompun®)

Xylol
Sigma-Aldrich, Schnelldorf

Bayer, Leverkusen

Merck, Darmstadt

\subsubsection{Lösungen und Puffer}

Fixativ für die Licht- und Elektronenmikroskopie (Karlsson und Schultz 1965):

Paraformaldehydlösung (10\%) $400 \mathrm{ml}$

Glutardialdehyd (25\%) $100 \mathrm{ml}$

$\mathrm{H}_{2} \mathrm{O} \quad 500 \mathrm{ml}$

Natriumchlorid $\quad 5,0 \mathrm{~g}$

Natriumdihydrogenphosphat-hydrat $\quad 1,8 \mathrm{~g}$

Dinatriumhydrogenphosphat-2-hydrat $\quad 15,5 \mathrm{~g}$

Das Paraformaldehyd $(50 \mathrm{~g})$ auf $500 \mathrm{ml}$ mit $\mathrm{H}_{2} \mathrm{O}$ vermischen und auf $60^{\circ} \mathrm{C}$ erhitzen.

Dann mit 1 M Natronlauge klar filtrieren. Restliche Bestandteile hinzufügen. Auf dem Magnetrührer ca. 30 min. rühren lassen. Anschließend abkühlen lassen und steril filtrieren. Den $\mathrm{pH}-\mathrm{Wert}$ mit $\mathrm{NaOH}$ auf 7,2 bis 7,4 einstellen.

Kunstharzmischung Epon (Luft 1961):

Glycidether 21,4 g

DDSA $14,4 \mathrm{~g}$

MNA $\quad 11,3 \mathrm{~g}$

10 min mit Magnetrührer rühren

DMP-30 0,84 ml

20 min mit Magnetrührer rühren

Methylen-Azur-II-Färbelösung (Richardson et al. 1960):

Methylenblau-Lösung: 1\% Methylenblau in 1\% wässriger Boraxlösung

Azur-II-Lösung: 1\% Azur II in H2O

Beide Lösungen in einem Verhältnis von 1:1 mischen.

Puffer AE, AL/E, ATL, AW1, AW2 (Bestandteile des DNeasy 96 Kit)

Zusammensetzung vom Hersteller nicht angegeben. 
QIAzol-Reagenz, Puffer RW1, RPE (Bestandteile des RNeasy Lipid Tissue Mini Kit)

Zusammensetzung von Hersteller nicht angegeben.

$\underline{\text { RedTaq PCR Reaction Buffer 10x }}$

Sigma, Hamburg

TAE (50x, 1000ml)

Tris-HCl Base $242 \mathrm{~g}$

Essigsäure $100 \%$

$\operatorname{EDTA}(0,5 \mathrm{M}, \mathrm{pH}) \quad 100 \mathrm{ml}$

Ansatz mit dd $\mathrm{H}_{2} \mathrm{O}$ auf $1000 \mathrm{ml}$ auffüllen.

\subsubsection{Enzyme und Reaktionskomplettsysteme}
Absolute QPCR ROX Mix
Abgene, Hamburg
DNase freie RNaseH
Invitrogen, Karlsruhe
DNeasy 96 Kit
Qiagen, Hilden

High Capacity cDNA Reverse Transcription KitApplied Biosystems, Foster City, USA

Proteinase K (Lyophilisat, f.c. $10 \mathrm{U} / \mu \mathrm{l}$ ) Boehringer Mannheim

RedTaq DNA Polymerase (5 U/ $\mu \mathrm{l}) \quad$ Sigma, Hamburg

RNasin RNase-Inhibitor

Promega, Mannheim

RNeasy Lipid Tissue Mini Kit

Quiagen, Hilden

Superscript III Reverse Transcriptase Kit

Invitrogen, Karlsruhe

SYBR Green PCR Master Mix

Applied Biosystems, Foster City, USA

\subsubsection{Nukleinsäuren und Nukleotide}

Desoxyribonukleosid-Triphosphate

DNA-Größenmarker $1 \mathrm{~kb}$

Boehringer Mannheim, Mannheim

Nonamerprimer Promega, Mannheim

Abteilung 501, MPI für Exp. Med.

Primer zur Genotypisierung PMP22-transgener Ratten

CPMP Fwd 5'-GACAAACCCCAGACAGTTG-3'

CPMP Rev 5'-CCAGAAAGCCAGGGAACTC-3' 
Primer zur Genotypisierung Wlds-transgener Ratten

Wids Fwd 5'-ACCATTAAGAGGAAAGCGATG-3'

Wids Rev 5'-TCACAGAGTGGAATGGTTGTG-3'

Primer zur Messung der Expression von NMNAT1

NMNAT1 Fwd 5'-TAGGTGAGCCAGTGGTCCAC-3'

NMNAT1 Rev 5'-TGGTTCTAGGCGGCTCG-3'

\subsubsection{Geräte}

ABI Prism 7900 Sequence Det. System

Agarose-Gelkämme

Agarose-Gelkammern

Agarosegel-Dokumentationsanlage „ImageMaster VDS“

Diamantmesser „Ultrathin Diamond Knife HI 4317, 45 \%

Drucker "Minolta-QMS magicolor 2“

Einschweißgerät "Polystar 401M"

Eismaschine "Typ ZBE 350/200"

Elektrophysiologiegerät "Neuroscreen"

Fräse für Epon-Präparate "EM Trim"

Gefrierschrank $-20^{\circ} \mathrm{C}$

Gefrierschrank $-80^{\circ} \mathrm{C}$

Gewebe-Einbettautomat "Lynx el"

Gewebehomogenisator „Ultraturrax T8“

Glaswaren

Härtofen für histologische Präparate

Heizplatte "HI 1220"

Inkubator/Schüttler "Innova 4000"

Kraftmessgerät "Typ 708"

Applied Biosystems, Foster City, USA MPI Exp. Med. wiss. Werkstatt MPI Exp. Med. wiss. Werkstatt

Amersham Biotech, Freiburg

Diatome, Fort Washington, USA

Minolta, München

Rische \& Herfurth, Hamburg

Ziegra, Isernhagen

Jaeger-Toennies, Würzburg

Leica Microsystems, Wetzlar

Liebherr, Ochsenhausen

New Brunswick Scentific, Nürtingen

Vision BioSystems Inc, Norwell, USA

IKA Labortechnik, Staufen

Schott, Mainz

Memmert, Schwabach

Leica Microsystems, Wetzlar

New Brunswick Scentific, Nürtingen

Erichsen, Wuppertal 
Kühlzentrifuge "4K15C"

Magnetrührer „RCT basic Ikamag“

Massenspektrometer "API400"

Mikroskop „Leica DM RXA2“

Mikrowellengerät "KOR-6DO7"

PCR-Thermocycler „T3“

PCR-Versiegler „Combi Thermosealer“

Peristaltikpumpe

Pipetten $10 \mu \mathrm{l}, 20 \mu \mathrm{l}, 200 \mu \mathrm{l}, 1000 \mu \mathrm{l}$

Präparationsbesteck

Präzisionswaage, elektrisch "Extend"

Probenmischgerät „Vortexer“

Professional Radio/Cassette Player "RR640"

Reinstwasseranlage „SeralPur Pro 90 CN“

Reinstwasseranlage "Arium 611 VF"

Rotationsmikrotom „Ultracut S“

Spannungsgeräte Elektrophorese

"ECPS 3000/150"

Spektralphotometer "Bio Photometer"

Thermomixer

Trocknungszentrifuge „Speed Vac“

UV-Illuminator

Videomikroskopie-Kameras "DX4C" und "DX 40"

Zentrifuge „Biofuge pico“
Sigma, Osterode am Harz

Omnilab, Bremen

Applied Biosystems, Foster City, USA

Leica Microsystems, Wetzlar

Deawoo Deutschland, Frankfurt

Biometra, Göttingen

Thermo Fisher Scientific, Waltham

Heraeus Instruments, Langenselbold

Gilson, Villiers-le-Bel, Frankreich

Fine Science Tools, Heidelberg

Sartorius, Göttingen

Bender \& Hobein, München

Grundig, Nürnberg

Seral, Ransbach

Sartorius, Göttingen

Leica Microsystems, Wetzlar

Amersham Biotech, Freiburg

Eppendorf, Hamburg

Eppendorf, Hamburg

Eppendorf, Hamburg

Amersham Biotech, Freiburg

Kappa Optronics, Gleichen

Heraeus Instruments, Langenselbold

\subsubsection{Software}

DNAstar SeqMan

Excel für WindowsXP Professional

GraphPad Prism 5.0

ImageJ

Illustrator CS3

Kappa Camera Control V 1.4.2.8121
DNAstar Inc., Madison, USA

Microsoft Europe, Berlin

GraphPad Software, San Diego, USA

www.rsb.info.nih.gov/ij/

Adobe Software, Saggart, Irland

Kappa Optronics GmbH, Gleichen 
Photoshop CS3

Adobe Software, Saggart, Irland

PrimerExpress v1.65

Applied Biosystems, Foster City, USA

Statistica 6.0

StatSoft Europe, Hamburg

Word für WindowsXP Professional

Microsoft Europe, Berlin 


\subsection{Methoden}

\subsubsection{Tierzucht}

Für diese Arbeit wurden ausschließlich weibliche Tiere aus zwei transgenen Rattenstämmen sowie die aus der Verpaarung dieser hervorgegangenen doppelt transgenen Tiere verwandt. Die eine Ursprungslinie exprimiert zusätzliche Kopien des PMP22-Gens (Sereda et al. 1996), die andere Linie exprimiert das Maus-Transgen Wlds (Adalbert et al. 2005). Beide Linien wurden aus einem Sprague-DawleyHintergrund erzeugt, sind aber seit ca. 20 Generationen separat gehalten worden. Zusätzlich kamen Wildtyp-Tiere aus dem CMT-Stamm sowie Wildtyp Wistar-Ratten (Nervenkompressionsexperiment) zum Einsatz. Eine Genehmigung der Tierversuche durch das Niedersächsische Landesamt für Verbraucherschutz und Lebensmittelsicherheit liegt vor (AZ: 33.11.42502-04-005/06).

Die Tiere wurden unter standardisierten Bedingungen im Tierhaus des MPI für experimentelle Medizin gehalten, Nahrung (Ssniff Spezialdiäten) und Trinkwasser stand jederzeit ad libitum zur Verfügung.

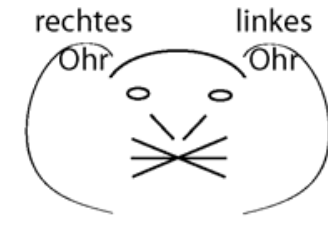

Tier Nr. 1

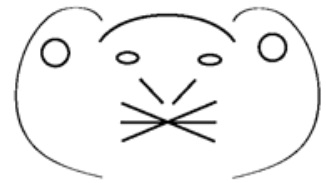

Tier Nr. 4

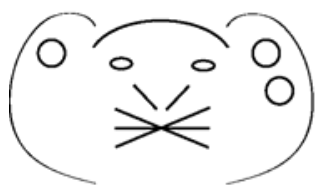

Tier Nr.7

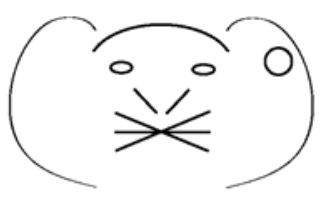

Tier Nr.2

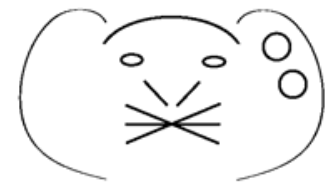

Tier Nr. 5

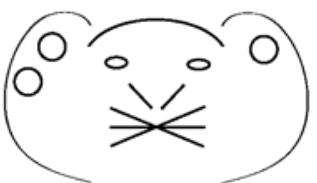

Tier Nr. 8

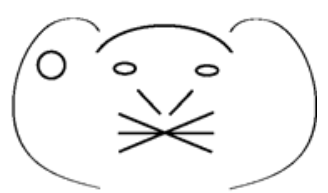

Tier Nr.3

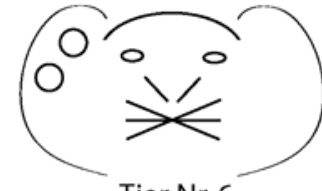

Tier Nr.6

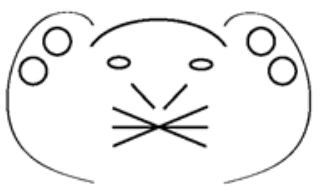

Tier Nr. 9

Abbildung 5: Ohrloch-Code zur eindeutigen Identifikation der Versuchstiere (Erklärung s. Text). 
Zur eindeutigen Identifikation der Tiere wurde diesen im Alter von ca. drei Wochen unter $\mathrm{CO}_{2}$-Narkose eine Schwanzbiopsie entnommen. Zur gleichen Zeit erfolgte das Absetzen von der Mutter und die fortlaufende Nummerierung der Tiere innerhalb eines Wurfes durch Anbringung eines standardisierten Ohrlochcodes (Abb. 5). Dieser wurde zusammen mit Wurfnummer und Linienkennung zur eindeutigen Identifikation genutzt und zusammen mit Geburtsdatum, Geschlecht und Nummern der Elterntiere auf einer am Käfig befindlichen Karte notiert. Jede Schwanzbiopsie wurde in einem mit der Tiernummer versehenen Gefäß bei $-20^{\circ} \mathrm{C}$ aufbewahrt und so erfolgte nach der Genotypisierung (s. u.) die Zuordnung des Genotyps zum entsprechenden Tier über dessen eindeutige Nummer.

\subsubsection{CMT-Zucht}

Bei der CMT-Zucht handelte es sich um eine heterozygote Zucht. Bei der Verpaarung von zwei heterozygoten Elterntieren erhielten wir Wildtyp, PMP22-heterozygote und PMP22-homozygote Nachkommen im Verhältnis 1:2:1.

\subsubsection{WIds-Zucht}

Bei der Wlds-Zucht handelte es sich um eine homozygote Zucht. Verpaarungen zweier homozygoter Elterntiere ergaben stets 100\% Wlds-homozygote Nachkommen.

\subsubsection{CMDS-Zucht}

Für die Erzeugung der neuen CMDS Linie wurden ein PMP22-heterozygotes und ein Wlds-homozygotes Tier verwandt. Die Nachkommen waren so zu $100 \%$ Wldsheterozygot, sowie für das PMP22-Gen entweder heterozygot (50\%) oder Wildtyp (50\%). Zur weiteren Analyse wurden nur die weiblichen Tiere mit dem Genotyp WIdsheterozygot und PMP22-heterozygot verwandt. Für die Gruppenbezeichnung wurde das aus den ersten und letzten zwei Buchstaben von CMT und WIds bestehende Akronym „CMDS“ arbiträr ausgewählt.

\subsubsection{Verblindung}

Zur Durchführung der Phänotypisierung und histologischen Auswertung wurde der Untersuchende zum Genotyp der Tiere verblindet. Hierzu erfolgte in der zu untersuchenden Kohorte eine neue, von der Nummer Eins fortlaufende Nummerierung und eine zufällige Zuordnung der Tiere. Die Liste mit der Zuordnung der eindeutigen 
Tiernummer zur neuen Nummerierung wurde in einem verschlossenen Umschlag aufbewahrt.

\subsubsection{NaM-Behandlung}

Für die Behandlungsstudie wurden weibliche transgene $(n=36)$ und Wildtyp $(n=7)$ CMT-Ratten zunächst anhand ihrer Griffstärke im Alter von 5 Wochen in Behandlungsund Placebogruppe aufgeteilt, um vergleichbare Ausgangswerte zu garantieren. Die Tiere der Behandlungsgruppe (CMT: $n=17$, wt: $n=3)$ erhielten täglich zur selben Zeit (09:00 Uhr) eine intraperitoneale Injektion einer Lösung von Nikotinamid in isotonischer Kochsalzlösung ( $\mathrm{NaCl}$ ) in einer Dosis von 500 mg/kg KG. Die PlaceboGruppe (CMT: $n=19$, wt: $n=4$ ) erhielt NaCl-Injektionen. Die Behandlung wurde über acht Wochen durchgeführt (Abb. 6).

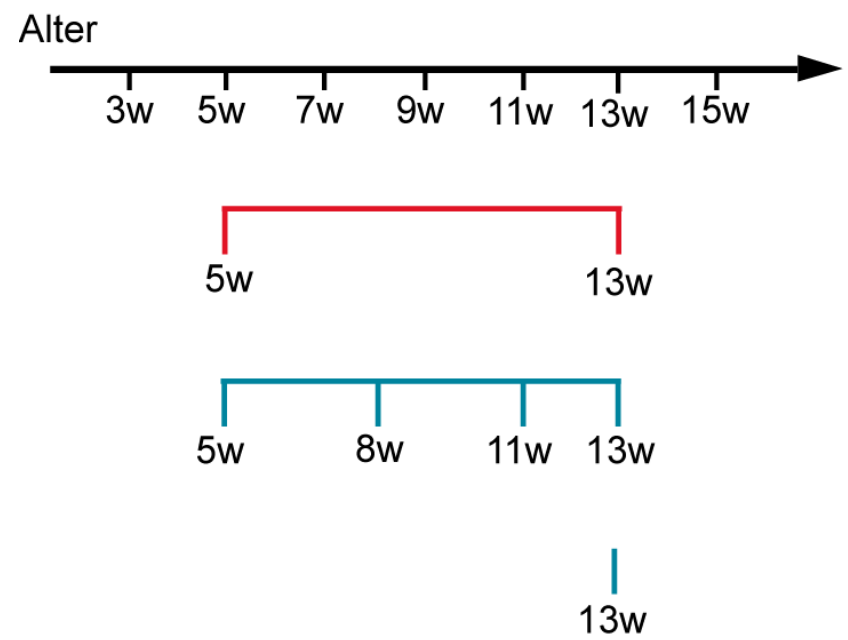

tägliche Nicotinamid-Injektionen

Abbildung 6: Studienverlauf der Behandlungsstudie, Alter der Tiere in Wochen (w).

\subsubsection{Nerve-crush}

Für die Nervenkompressionsanalyse behandelten wir adulte weibliche Wildtyp-Ratten vom Wistar-Stamm mit einer täglichen intraperitonealen Injektion von Nikotinamid (500 $\mathrm{mg} / \mathrm{kg} \mathrm{KG}$ ) oder Placebo (NaCl-Lösung). Unbehandelte Wlds Tiere dienten der Positivkontrolle. Nach drei Tagen erhielten die Tiere eine Injektionsnarkose mit Ketamin (100 mg/kg KG) und Xylazin (5 mg/kg KG) und der rechte N. ischiadicus wurde freipräpariert. Der Nerv wurde dann mit einem chirurgischen Nadelhalter für 60 Sek. komprimiert und die Kompressionsstelle mit Graphit markiert. Nach 24, 36 und 
72 Stunden wurden je $n=5$ Tiere pro Gruppe geopfert und für die histologische Analyse präpariert (s. u.).

\subsubsection{Phänotypisierung}

Zur Analyse der Ausprägung des klinischen Phänotyps einer peripheren Neuropathie wurde die Muskelkraft der Versuchstiere als Messgröße gewählt. Mit den Tieren aus der Verpaarungs- und der Behandlungsstudie wurde ein standardisierter Griffstärketest durchgeführt (Meyer et al. 1979; Meyer zu Horste et al. 2007). Hierzu wurden die Tiere alle drei Wochen so vor einem Griffstärkemessgerät positioniert, dass sie mit den Vorderläufen eine daran befestigte Stange greifen konnten (Abb. 7). Durch sanften Zug am Schwanz der Ratte wurde diese dann gezwungen die Stange loszulassen. Die maximale Kraft in Newton, die aufgewandt werden musste um die Ratte von der Stange zu trennen, wurde aufgezeichnet. Jeder Wert ist der Mittelwert aus mindestens fünf Einzelmessungen. Die Messungen erfolgten bei einem Alter der Tiere von 5, 8, 11 und 13 Wochen. Zu diesen Zeitpunkten wurden die Tiere auch gewogen.

Zum Ende der Behandlungsstudie wurde der Umfang der Muskeln am Oberschenkel der Hinterläufe auf halbem Weg zwischen Hüft- und Kniegelenk gemessen. Dies geschah durch Umwickeln der Hinterläufe mit einem Nylonfaden und Ermittlung der Länge des so bestimmten Fadenstücks.
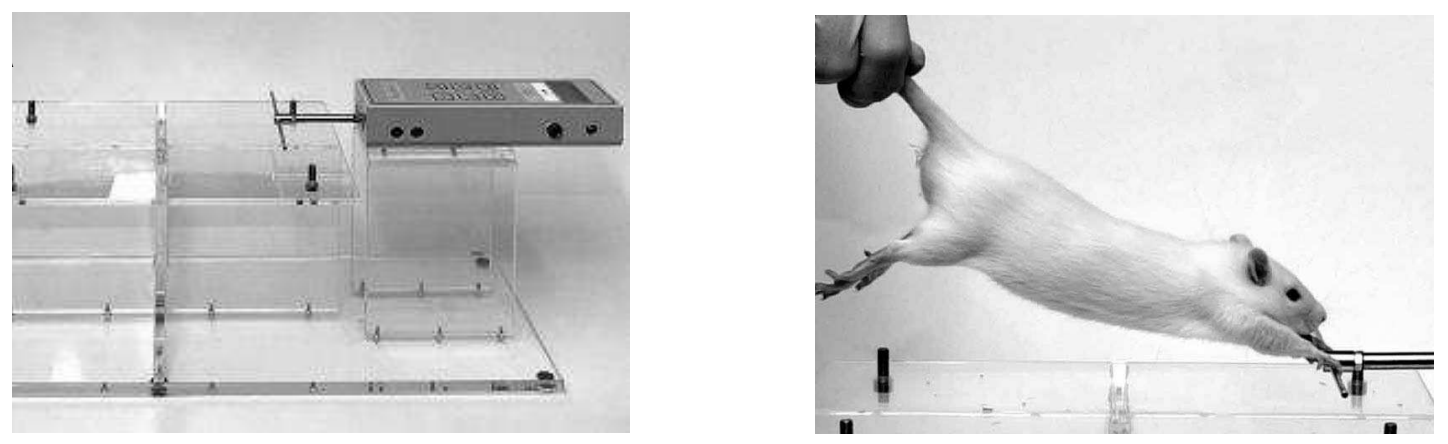

Abbildung 7: Kraftmessvorrichtung und deren Anwendung, Beschreibung s. Text (mit freundlicher Genehmigung von T. Prukop und G. Meyer zu Hörste, MPI für experimentelle Medizin). 


\subsubsection{Perfusion und Herstellung histologischer Präparate}

Für die histologische Analyse von Nervengewebe wurden die Tiere nach Abschluss der Analysen durch $\mathrm{CO}_{2}$-Inhalation getötet. Im Anschluss erfolgte die intrakardiale Perfusion mit HBSS und einer Fixierungslösung mit Paraformaldehyd und Glutardialdehyd nach Karlsson und Schultz (s. o.). Der N. tibialis wurde präpariert und nach folgendem Schema in Kunstharz (sog. Epon) eingebettet:

\begin{tabular}{|l|l|l|}
\hline Lösung & Dauer & Temperatur \\
\hline Phosphatpuffer 0,1M & 15 Minuten & $4{ }^{\circ} \mathrm{C}$ \\
\hline $1 \%-$ OsO4 / Osmiumtetroxid & 2 Stunden & $4{ }^{\circ} \mathrm{C}$ \\
\hline Phosphatpuffer $0,1 \mathrm{M}$ & 20 Minuten & $20^{\circ} \mathrm{C}$ \\
\hline Phosphatpuffer $0,1 \mathrm{M}$ & 20 Minuten & $20^{\circ} \mathrm{C}$ \\
\hline Phosphatpuffer $0,1 \mathrm{M}$ & 20 Minuten & $20^{\circ} \mathrm{C}$ \\
\hline $30 \%$ Ethanol & 30 Minuten & $20^{\circ} \mathrm{C}$ \\
\hline $50 \%$ Ethanol & 30 Minuten & $20^{\circ} \mathrm{C}$ \\
\hline $70 \%$ Ethanol & 30 Minuten & $20^{\circ} \mathrm{C}$ \\
\hline $90 \%$ Ethanol & 30 Minuten & $20^{\circ} \mathrm{C}$ \\
\hline $100 \%$ Ethanol & 15 Minuten & $20^{\circ} \mathrm{C}$ \\
\hline $100 \%$ Ethanol & 15 Minuten & $20^{\circ} \mathrm{C}$ \\
\hline $100 \%$ Ethanol & 15 Minuten & $20^{\circ} \mathrm{C}$ \\
\hline $100 \%$ Ethanol & 15 Minuten & $20^{\circ} \mathrm{C}$ \\
\hline Isopropanol & 15 Minuten & $20^{\circ} \mathrm{C}$ \\
\hline Propylenoxid & 15 Minuten & $20^{\circ} \mathrm{C}$ \\
\hline Propylenoxid & 15 Minuten & $20^{\circ} \mathrm{C}$ \\
\hline Propylenoxid : Epon $2: 1$ & 2 Stunden & $20^{\circ} \mathrm{C}$ \\
\hline Propylenoxid : Epon $1: 1$ & 2 Stunden & $20^{\circ} \mathrm{C}$ \\
\hline Propylenoxid : Epon $1: 2$ & 4 Stunden & $20^{\circ} \mathrm{C}$ \\
\hline Epon & 4 Stunden & $20^{\circ} \mathrm{C}$ \\
\hline
\end{tabular}

Die so kontrastierten und fixierten Nerven wurden dann in einem Kunstharzblock fixiert, welcher in einem Ofen bei $60{ }^{\circ} \mathrm{C}$ für $24 \mathrm{Std}$. aushärtete. Im Anschluss wurde jeder Kunstharzblock pyramidenstumpfförmig angefräst, um die Gewebeprobe an 
gewünschter Stelle wieder freizulegen. Von jedem N. tibialis wurden Semidünnschnitte $(0,5 \mu \mathrm{m})$ auf Höhe des medialen Knöchels angefertigt, welche mit Azur II Methylenblau (s. o.) gefärbt wurden.

\subsubsection{Axonzählung}

Mit einem Leica DM RXA-Mikroskop mit angeschlossener Kamera wurden die Nerven mit einer 40x Vergrößerung abfotografiert und die Einzelbilder mit der Adobe Photoshop Software zusammengefügt. Die Auszählung der myelinisierten Axone eines Nerven erfolgte manuell mittels des "CellCounter" Plugins der ImageJ Software. Physiologischerweise unmyelinisierte Axone $(<1 \mathrm{~mm})$ und Remak-Bündel-Axone wurden nicht erfasst.

Für die Nervenkompressionsanalyse wurden von den $\mathrm{Nn}$. ischiadici in gleicher Weise $2 \mathrm{~mm}$ hinter der Kompressionsstelle Semidünnschnitte angefertigt. Intakte (intakte Myelinscheide, sichtbares Axoplasma) und degenerierte (Degeneration von Myelinscheide und/oder axonaler Binnenstruktur) Axone des Nerven wurden ausgezählt und markiert (Abb. 8).

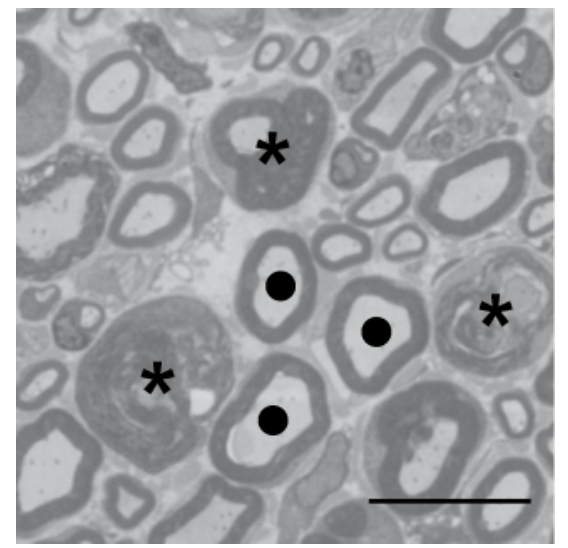

Abbildung 8: Repräsentatives Bild aus dem N. ischiadicus einer mit Placebo behandelten Ratte 48 Std. nach Nervenläsion. Punkte bezeichnen intakte, Sterne bezeichnen degenerierte Axone, Maßstab $10 \mu$ m (Meyer zu Horste et al. 2011).

\subsubsection{G-ratio und Axondurchmesser}

Der Myelinisierungsgrad eines Axons kann durch das sog. G-ratio ausgedrückt werden. Dies ist das Verhältnis zwischen Axondurchmesser und Durchmesser der gesamten Myelinscheide. In mikroskopischen Aufnahmen in 100-facher Vergrößerung wurde von 200 zufällig ausgewählten myelinisierten Axonen pro Tier der Umfang von 
Axon und Myelinscheide sowie deren Fläche mit der ImageJ Software gemessen. Der Axondurchmesser und der Durchmesser der Myelinscheide wurden aus den gemessenen Flächen berechnet. Das daraus berechnete G-Ratio jedes Axons wurde als Streudiagramm (scatter plot) für jeden Genotyp aufgetragen. Der durchschnittliche Axondurchmesser wurde für jedes einzelne Tier bestimmt und zwischen den unterschiedlichen Genotypen verglichen. Einzelne Axone wurden nach ihrem Durchmesser in 13 Gruppen eingeteilt (in $5 \mu \mathrm{m}$-Schritten von $\leq 0,5 \mu \mathrm{m}$ bis $>6 \mu \mathrm{m}$ ) und der Prozentsatz von Axonen in jeder Gruppe wurde zwischen den Genotypen verglichen.

\subsubsection{Molekularbiologie}

\subsubsection{DNA-Extraktion}

Zur Durchführung der Routine-Genotypisierung wurde zunächst die DNA der Tiere aus der vorliegenden Schwanzbiopsie (s. o.) isoliert. Dies erfolgte mit dem „DNeasy 96 kit“ von Qiagen nach der Anleitung des Herstellers. Zunächst wurden die Gewebestücke mit $180 \mu \mathrm{l}$ ATL-Puffer und $20 \mu \mathrm{l}$ Proteinase $\mathrm{K}$ bei $55^{\circ} \mathrm{C}$ über Nacht verdaut. Nach Zugabe von $400 \mu \mathrm{l}$ AL/E Puffer und kurzer Zentrifugation (1 min, 3000 rpm) wurde der Überstand auf die DNeasy-Säulchen pipettiert. Während der folgenden Zentrifugation (10 min, $6000 \mathrm{rpm}$ ) haftete sich die DNA an die Membran der Säulchen. Es folgten zwei Waschschritte durch $500 \mu \mathrm{l}$ AW1-Puffer und Zentrifugation (5 min, $6000 \mathrm{rpm}$ ) sowie $500 \mu \mathrm{l}$ AW2-Puffer und Zentrifugation ( $5 \mathrm{~min}, 6000 \mathrm{rpm}$ ). Zur Elution der DNA aus der Membran wurden $200 \mu$ vorgewärmter AE Puffer zugegeben und 5 min. bei $60^{\circ} \mathrm{C}$ inkubiert. Die abschließende Zentrifugation (2 min, $6000 \mathrm{rpm}$ ) löste die DNA aus der Membran und beförderte sie samt Pufferlösung in ein Eppendorfgefäß. Die so eluierte genomische DNA wurde bei $4{ }^{\circ} \mathrm{C}$ gelagert.

\subsubsection{PCR}

Die Genotypisierung der Tiere erfolgte durch PCR (Mullis et al. 1986) mit der aus den Schwanzbiopsien gewonnenen DNA. Die PCR nutzt das Temperaturoptimum der DNA-Polymerase von Thermus aquaticus $\left(72^{\circ} \mathrm{C}\right)$ und zwei flankierende Primer zur Vervielfältigung eines durch die Primer eingeschlossenen DNA-Fragmentes. Die 
jeweiligen Transgen-spezifischen Primer für PMP22 und Wlds (s. o.) wurden einem standardisierten Reaktionsansatz zugegeben. Dieser wurde dann im Thermocycler den verschiedenen Reaktionsschritten zur Amplifikation dieser spezifischen DNASequenzen unterzogen.

PCR-Ansatz zum Nachweis des PMP22-Transgens

$1 \mu \mathrm{DNA}$

$1 \mu \mathrm{dNTPs}$ (f.c. $250 \mu \mathrm{M}$ )

$1 \mu \mathrm{l}$ CPMP Forward-Primer (f.c. $300 \mathrm{nM}$ )

$1 \mu \mathrm{l}$ CPMP Reverse-Primer (f.c. $300 \mathrm{nM}$ )

$2 \mu \mathrm{l}$ RedTaq Reaction Buffer 10x

$1 \mu \mathrm{l}$ RedTaq DNA-Polymerase (f.c.1,6 U / $50 \mu \mathrm{l}$ )

$13 \mu \mathrm{lddH} 2 \mathrm{O}$

PCR-Ansatz zum Nachweis des Wids-Transgens

$1 \mu \mathrm{DNA}$

$1 \mu \mathrm{dNTPs}$ (f.c. $250 \mu \mathrm{M}$ )

$1 \mu \mathrm{l}$ Wlds Forward-Primer (f.c. $300 \mathrm{nM}$ )

$1 \mu \mathrm{l}$ Wlds Reverse-Primer (f.c. $300 \mathrm{nM}$ )

$2 \mu \mathrm{l}$ RedTaq Reaction Buffer 10x

$1 \mu \mathrm{l}$ RedTaq DNA-Polymerase (f.c.1,6 U / $50 \mu \mathrm{l}$ )

$13 \mu \mathrm{lddH} 2 \mathrm{O}$

Thermocycler-Programmschritte:

1. Anfangs-Denaturierung: $95^{\circ} \mathrm{C}, 3 \mathrm{~min}$.

2. Denaturierung: $\quad 95^{\circ} \mathrm{C}, 30$ Sek.

3. Primer-Annealing: $\quad 56^{\circ} \mathrm{C}, 30$ Sek.

4. Amplifikation: $\quad 72{ }^{\circ} \mathrm{C}, 60$ Sek.

Schritt 2 - 4 wurde für 36 Zyklen wiederholt

5. Abschlussamplifikation: $72^{\circ} \mathrm{C}, 4 \mathrm{~min}$.

6. Abschlusskühlung: $\quad 4^{\circ} \mathrm{C}$, bis zur Entnahme aus dem Gerät 


\subsubsection{Elektrophorese und Nachweis von PCR-Produkten}

Zum Nachweis der in der PCR amplifizierten DNA-Sequenzen wurden zunächst Agarose-Gele hergestellt. Hierzu wurden $350 \mathrm{ml}$ TAE-Puffer mit 5,25 g Agarose (1,5\%) in der Mikrowelle erhitzt und nach Zugabe von $35 \mu \mathrm{l}$ Ethidiumbromid in Gelkammerformen mit taschenbildenden Gelkämmen erkalten gelassen. Die gehärteten Gele wurden in ihren Kammern mit TAE-Puffer übergossen, und in die Taschen wurde ein standardisierter Marker sowie die in der PCR gewonnene DNA gegeben. Durch Anlegen einer Spannung begannen die DNA-Fragmente zu wandern und sich entsprechend ihrer Größe aufzuteilen. Nach einer Laufzeit von ca. 70 min. wurden die Gele unter UV-Licht abfotografiert und es stellten sich die durch das in die DNA interkalierte Ethidiumbromid nun sichtbar gewordenen Banden dar. Durch Vergleich mit dem Marker konnte die Bande gesuchter Größe zur Identifikation des jeweiligen Transgens identifiziert werden (Abb. 9).

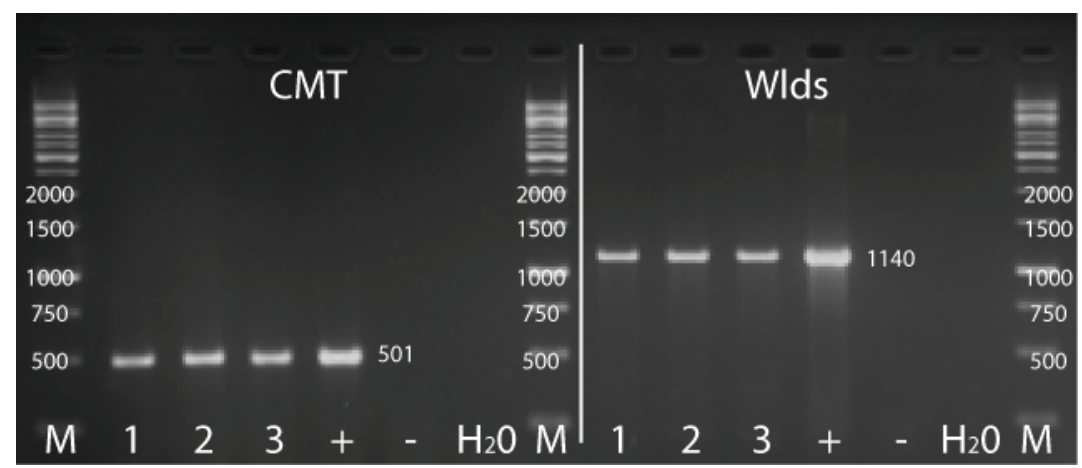

Abbildung 9: Repräsentative Genotypisierungs-PCRs für das CMT- und das WldsTransgen derselben CMDS-Tiere (Nummern 1 bis 3). Die PCRs weisen ein DNAFragment von 501 (CMT) bzw. 1140 (Wlds) bp Größe nach. Positiv (+), Negativ (-) und Wasserkontrolle (H2O) sowie Marker (M) mit Referenzbanden verschiedener Größe sind markiert (Meyer zu Horste et al. 2011).

\subsubsection{RNA-Extraktion}

Zur Durchführung von Expressionsanalysen wurden die Versuchstiere $(n=5$ pro Genotyp) aus der Verpaarungsstudie nach Abschluss der Untersuchungen durch CO2-Inhalation getötet und innen wurde lumbales Rückenmark entnommen, das unmittelbar in flüssigem Stickstoff schockgefroren wurde. Aus diesem Gewebe wurde mithilfe des „RNeasy lipid rich tissue kit“ (Quiagen) nach Angaben des Herstellers RNA extrahiert. Zunächst wurde das Gewebe in $1 \mathrm{ml}$ "QIAzol-Reagenz" eingelegt und im „Ultraturrax“-Gewebezerkleinerer homogenisiert. Danach wurden $200 \mu \mathrm{l}$ Chloroform 
hinzugegeben. Nach Zentrifugation bei $4^{\circ} \mathrm{C}$ wurde der Überstand in ein neues Gefäß gegeben und mit $600 \mu \mathrm{l}$ Ethanol vermischt. Danach wurden $700 \mu \mathrm{l}$ der Mischung auf die „RNeasy Mini spin columns“ gegeben und bei Raumtemperatur zentrifugiert. Dieser Schritt wurde einmal wiederholt und dann wurde in zwei Zentrifugationsschritten die Membran der columns mit zwei verschiedenen Waschpuffern des Extraktions-Kits gewaschen. Im Anschluss folgte die Elutionsphase mit RNase-freiem Wasser. Das RNA enthaltende Eluat wurde in Eppendorff-Gefäßen aufgefangen und aufbewahrt.

\subsubsection{RNA-Konzentrationsmessung}

Die gewonnene RNA wurde photometrisch quantifiziert und auf eine Konzentration von $1 \mu \mathrm{g} / \mu \mathrm{l}$ eingestellt. Dies erfolgte durch Bestimmung der Extinktion der RNA-Lösung bei $260 \mathrm{~nm}$ in einem Spektralphotometer. Über die entsprechend abgewandelte Formel nach Lambert und Beer ( $\mathrm{c}=\mathrm{E}_{260} \mathrm{x} \mathrm{k} / \mathrm{d}$ ) wurde die vorliegende Konzentration durch das Gerät bestimmt. Im Anschluss wurde durch Verdünnung die gewünschte Konzentration eingestellt.

\subsubsection{6 cDNA-Synthese}

Im Anschluss wurde aus der RNA unter Verwendung des „High Capacity cDNA Reverse Transcription Kit“" (Applied Biosystems) cDNA hergestellt. Hierzu wurde zunächst ein Reaktionsansatz hergestellt:

$2 \mu$ RT Puffer 10x

$0,8 \mu \mathrm{l}$ dNTPs

$2 \mu \mathrm{l}$ Zufallsprimer

$1 \mu \mathrm{l}$ Reverse Transcriptase

$1 \mu \mathrm{l}$ RNase-Inhibitor

3,2 $\mu \mathrm{l}$ Nuclease-freies Wasser

Von diesem wurden je $10 \mu \mathrm{l}$ mit $10 \mu \mathrm{l}$ RNA vermischt und im Thermocycler mit folgendem Programm inkubiert: 
1. $25^{\circ} \mathrm{C}$ für $25 \mathrm{~min}$.

2. $37^{\circ} \mathrm{C}$ für $120 \mathrm{~min}$.

3. $85^{\circ} \mathrm{C}$ für $85 \mathrm{~min}$.

4. $4{ }^{\circ} \mathrm{C}$ bis zur Entnahme aus dem Gerät.

\subsubsection{Real-Time PCR}

Die NMNAT1-Expression wurde mithilfe einer semi-quantitativen real-time PCRMethode mit dem SYBR Green-System und neu hierfür entwickelten Primern bestimmt. Bei dieser Methode lässt sich durch den in dsDNA interkalierenden Fluoreszenzfarbstoff SYBR Green das in der PCR entstandene Produkt quantifizieren. Hierzu wird die Zunahme der Fluoreszenz des Reaktionsansatzes gemessen.

Als interne Kontrolle (Housekeeping-Gen) wurde 18S gewählt, welches mit kommerziell erhältlichen Primern und dazu passender TaqMan-Probe nachgewiesen wurde.

Durchschnittswerte von zwei PCR-Durchläufen mit je drei Reaktionskammern pro Probe wurden ermittelt. Die Expression von NMNAT1 wurde mit der $\Delta \Delta \mathrm{Ct}$-Methode ermittelt, wobei die Wildtyp-Expression willkürlich als 1,0 definiert wurde. Hierzu wurde die PCR-Zyklenzahl notiert, bei der die Zunahme der Fluoreszenz im Reaktionsansatz das erste Mal die zehnfache Standardabweichung der Hintergrundfluoreszenz überschritt (= Ct-Wert). Danach wurde dieser Wert für das Housekeeping-Gen von dem für NMNAT1 abgezogen ( $\triangle \mathrm{Ct}$-Wert). Als nächster Schritt wurde der so ermittelte Wert für NMNAT1 in CMDS-Tieren von dem als 1,0 definierten Wert für NMNAT1 in Wildtyp-Tieren abgezogen, womit sich der $\Delta \Delta \mathrm{Ct}$-Wert ergab. Aus diesem konnte die Expression von NMNAT1 in CMDS-Tieren nach der Formel $2^{-\triangle \Delta C t}$ angegeben werden.

\subsubsection{Nikotinamid-Konzentration in Blut und N. ischiadicus}

Tiere der Behandlungsstudie wurden 24 Stunden nach der letzten Injektion durch $\mathrm{CO}_{2}$ Inhalation getötet und unmittelbar danach präpariert. Es wurden $2 \mathrm{ml}$ Blut aus dem rechten Ventrikel entnommen und zentrifugiert, um Serum zu erhalten. Dieses wurde abpipettiert, in flüssigem Stickstoff schockgefroren und bis zur endgültigen Analyse bei $-80^{\circ} \mathrm{C}$ aufbewahrt. Nach Perfusion der Tiere mit HBSS wurde der rechte N. ischiadicus präpariert und mit einem Ultraturrax-Gerät homogenisiert. Im Anschluss wurde er ebenfalls zentrifugiert, und der Überstand wurde abpipettiert. Diese Überstände und 
die Serumproben wurden auf Trockeneis an das Medizinische Labor Bremen geschickt und dort weiter untersucht. Hierzu wurden die Proteine ausgefällt und die verbleibenden Überstände verdünnt, per isokratischer HPLC von Matrixkomponenten getrennt und mit einem triple-quadrupol Massenspektrometer auf ihren NaM-Gehalt hin analysiert.

\subsubsection{Elektrophysiologie}

Die Nervenleitgeschwindigkeit (NCV) und das Muskelsummenaktionspotential (CMAP) wurden bei einem Alter der Tiere von 10 Wochen mit einem Jaeger-Toennies Neuroscreen Instrument ermittelt. Die Tiere erhielten eine Injektionsnarkose mit Ketamin und Xylazin wie oben beschrieben, während deren Dauer die Körpertemperatur mit einer Wärmeplatte konstant gehalten wurde. Zur klinischen Überprüfung der Narkosetiefe wurden die Atemfrequenz und die Reaktion der Tiere auf schmerzhafte Stimuli überwacht. Aus Gründen der besseren Reproduzierbarkeit wurden die Werte am Schwanz der Tiere bestimmt. Die Stimulation erfolgte mit ansteigenden Volt-Zahlen, bis eine supramaximale Stimulation erreicht war. Die Aufzeichnung erfolgte über subkutane Feinnadel-elektroden im Schwanzmuskel. CMAP Amplituden wurden peak-to-peak berechnet, also vom minimalen zum maximalen Ausschlag der Messkurve. Die NCV berechnete das Gerät automatisch aus den Unterschieden der Distanz und der motorischen Latenz zwischen proximaler und distaler Elektrode.

\subsubsection{Statistische Analyse}

Die Datenanalyse wurde mit Statistica 6.0 und GraphPad Prism 5.0 durchgeführt. Der Student's t-Test für unverbundene Proben wurde zur Bestimmung einer Signifikanz benutzt. Ein $p$-Wert unter 0,05 wurde als statistisch Signifikant gewertet. 


\section{Ergebnisse}

\subsection{Verpaarungsstudie zur Erzeugung doppelt-transgener Versuchstiere (WIds/CMT)}

Um einen möglichen axonprotektiven Effekt von WIds auf den CMT-Phänotyp zu erkennen, wurde zunächst ein Verpaarungsexperiment durchgeführt, indem die CMTRatten mit den Wids-Ratten gekreuzt wurden. Dies ergab heterozygote, doppelttransgene Tiere (für CMT und WIds). Diese Gruppe wurde mit dem arbiträr aus den jeweils ersten und letzten zwei Buchstaben von CMT und WIds bestehenden Akronym „CMDS“ bezeichnet. Die Tiere wurden über einen Zeitraum von insgesamt 13 Wochen untersucht. Es wurden Gruppen mit folgenden Genotypen gebildet: Wildtyp, Wids, CMT und CMDS (doppelt transgen für CMT und WIds).

\subsubsection{Griffstärke-Messung}

Alle Tiere wurden einem Griffstärke-Test der Vorderbeine unterzogen. Zunächst fanden wir einen signifikant geringeren Wert in der Griffstärke zu Beginn der Analyse (Alter der Tiere von 5 Wochen) bei den Wlds $(2,43 \pm 0,52 \mathrm{~N})$ - und CMDS $(2,59 \pm 0,26$ $\mathrm{N})$-Tieren im Vergleich zu Wt $(3,3 \pm 0,33 \mathrm{~N})$ - und CMT $(2,93 \pm 0,41 \mathrm{~N})$-Tieren (Abb. 10a). Zum Ende der Beobachtung hatten dann alle Gruppen eine ähnliche Griffstärke (Wt 6,3 \pm 0,39 N, Wlds 6,1 $\pm 0,29 \mathrm{~N}$, CMT 6,12 $\pm 0,58 \mathrm{~N}$, CMDS 6,2 $\pm 0,58 \mathrm{~N}$; Abb. 10b). Betrachtet man die dazwischen liegenden Analysepunkte, zeigte sich eine höhere relative Zunahme der Griffstärke der Wlds- und CMDS-Tiere gegenüber den Wildtyp- und CMT-Tieren ab einem Alter von 11 Wochen. Am Ende des Beobachtungszeitraumes war diese relative Zunahme der Griffstärke signifikant (WIds $3,67 \pm 0,51 \mathrm{~N}$ und CMDS 3,69 $\pm 0,54 \mathrm{~N}$ gegenüber Wt 3,0 $\pm 0,49 \mathrm{~N}$ und CMT 3,19 \pm $0,54 \mathrm{~N}$; Abb. 10c). 

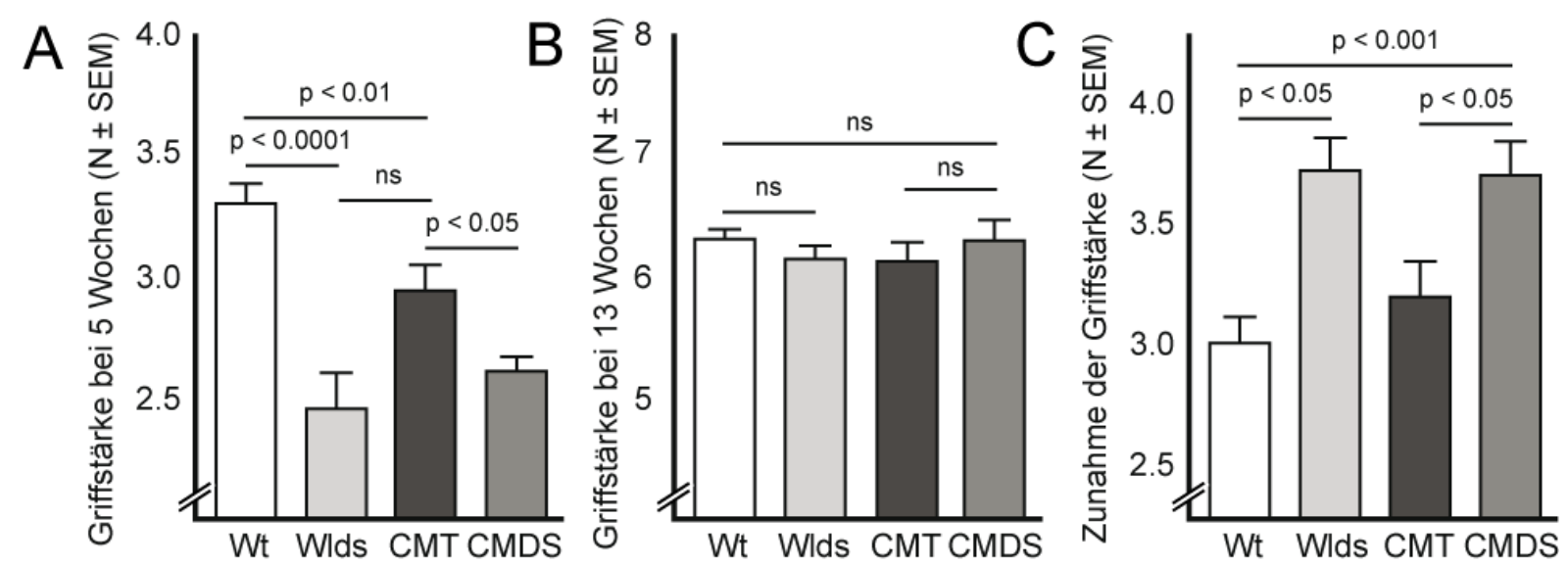

Abbildung 10: Griffstärke der Versuchstiere, Alter der Tiere 5 Wochen (A), 13 Wochen (B). Relative Zunahme der Griffstärke über den Beobachtungszeitraum (C). Messung in Newton (N), MW aus fünf Messungen pro Tier. Wt $(n=20)$, Wlds $(n=12)$, CMT $(n=15)$, CMDS $(n=17)$ (Meyer zu Horste et al. 2011)

\subsubsection{Elektrophysiologie}

Die elektrophysiologischen Untersuchungen der Nervenleitgeschwindigkeit wurden bei den Versuchstieren im Alter von 10 Wochen durchgeführt. Es zeigten sich verzögerte distale Latenzen und verbreiterte CMAP Amplituden bei den CMT-Tieren im Vergleich zu den Wildtyp-Kontrollen. Die Wids-Tiere erreichten in etwa gleiche Werte wie die Wildtyp-Tiere. Der Unterschied zwischen Wildtyp/WIds und CMDSTieren war weniger stark ausgeprägt (Abb. 11a).

Die quantitative Analyse zeigte, dass die Unterschiede der durchschnittlichen CMAPAmplituden zwischen CMT $(1,6 \pm 0,7 \mathrm{mV})$ - und Wildtyp $(5,7 \pm 2 \mathrm{mV}) /$ Wlds $(5,6 \pm 1,6$ $\mathrm{mV})$-Tieren sehr deutlich waren. Die CMDS-Tiere $(2,89 \pm 1 \mathrm{mV})$ lagen ebenfalls deutlich unter der Wildtyp/Wlds-Gruppe, zeigten jedoch insgesamt signifikant bessere Werte als die CMT-Gruppe (Abb. 11b). Dasselbe Muster der Werteverteilung zwischen den Gruppen fand sich auch bei der Nervenleitgeschwindigkeit (Wt $35 \pm 3,1 \mathrm{~m} / \mathrm{s}$, Wids $34,5 \pm 5,1 \mathrm{~m} / \mathrm{s}$, CMT $6 \pm 1,4 \mathrm{~m} / \mathrm{s}$, CMDS 10,6 2 2,6 m/s; Abb. 11c). 

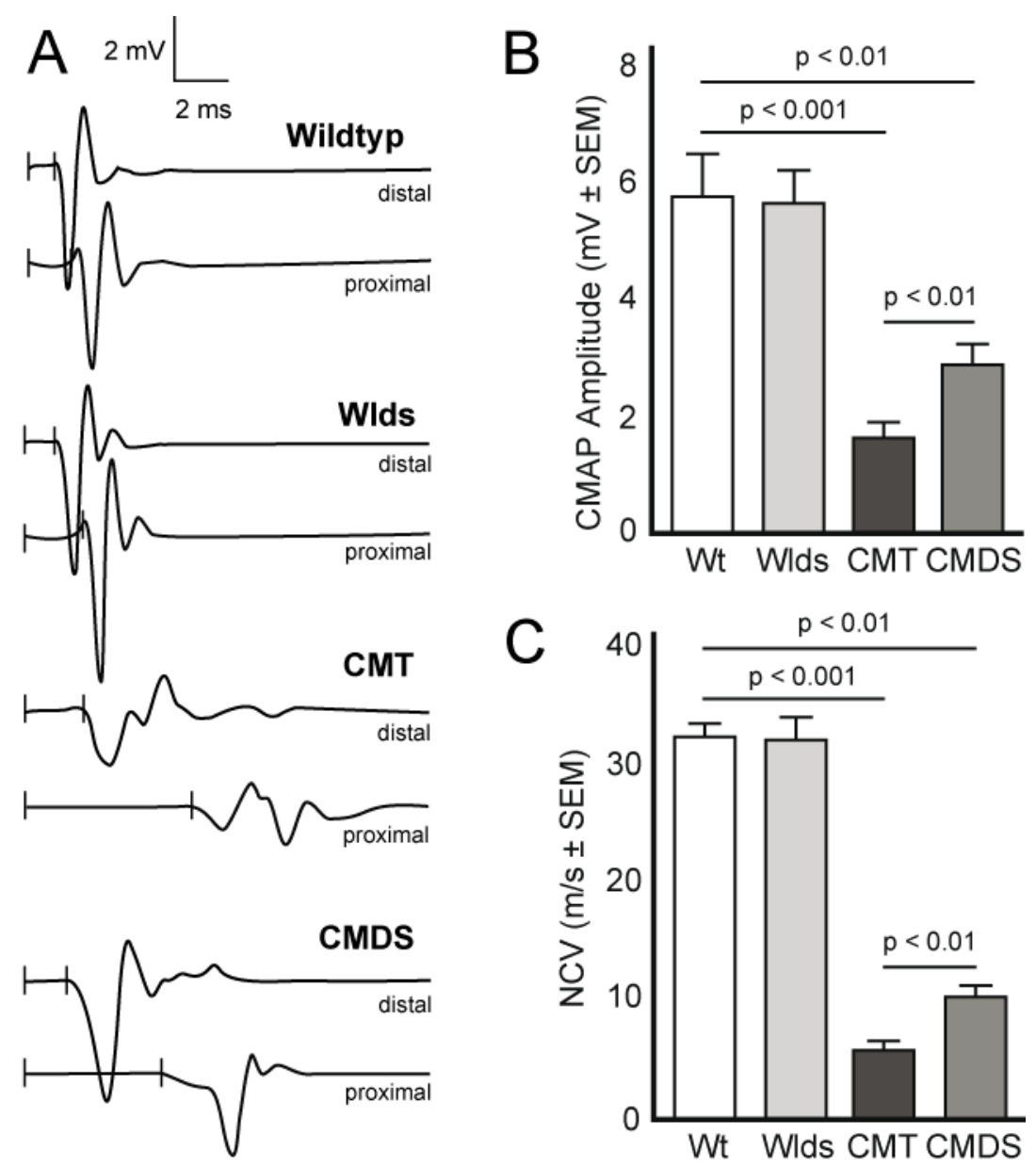

Abbildung 11: Repräsentative elektrophysiologische Potentiale aus dem Schwanznerv. Es zeigten sich verlängerte distale Latenzen und ein verbreitertes CMAP der CMT-Tiere im Vergleich zu Wildtyp. Die CMDS-Gruppe nahm eine mittlere Position ein (A). Werte für CMAP (B) und NCV (C) zeigten ein ähnliches Bild, wobei die elektrophysiologischen Anzeichen für Demyelinisierung in den CMDS-Tieren weniger stark ausgeprägt waren als in CMT. Wt $(n=9)$, Wlds $(n=8)$, CMT $(n=9)$, CMDS $(n=14)$. (s. a. Material und Methoden) (Meyer zu Horste et al. 2011).

\subsubsection{Histologie}

Zur weiteren Analyse führten wir nach Ende des Versuchszeitraums eine histologische Analyse mit Auszählung der myelinisierten Axone der Nn. tibiales der Versuchstiere durch. Wie erwartet fanden wir eine signifikant geringere Anzahl intakter Axone in den Nerven der CMT-Tiere (2504 \pm 177) im Vergleich zu den Wildtyp-Tieren (2686 \pm 109$)$. Die Gruppe der Wids-Kontrollen $(2681 \pm 146)$ lag ebenfalls wie erwartet auf WildtypNiveau. Die neue Erkenntnis dieses Versuchs war, dass die Anzahl myelinisierter Axone in Nerven der CMDS-Tiere (2700 \pm 138 ), passend zu den Ergebnissen aus den elektrophysiologischen Untersuchungen, signifikant höher lag als bei den CMT-Tieren und sogar das Niveau der Wildtyp-Kontrolltiere erreichte (Abb. 12). 


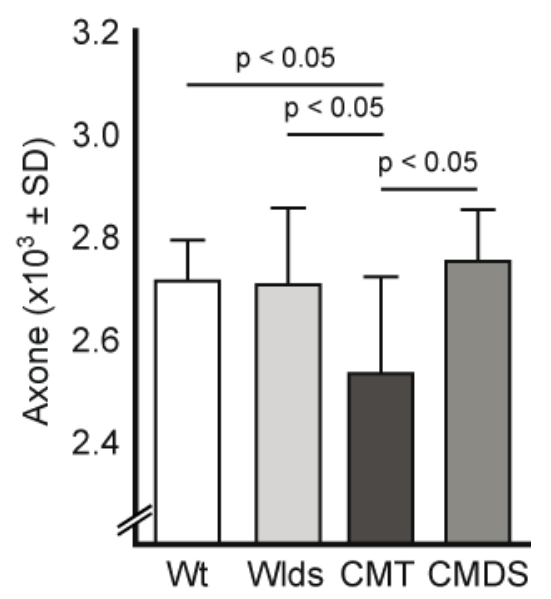

Abbildung 12: Anzahl myelinisierter Axone in den Nn. tibiales der Versuchstiere. Alter 13 Wochen. Wt $(n=14)$, WIds $(n=12)$, CMT $(n=15)$, CMDS $(n=12)$, manuelle Zählung an Semidünnschnitt-Präparaten (Meyer zu Horste et al. 2011)

\subsubsection{G-Ratio-Messungen}

Mit den vorhandenen Präparaten wurden dann Messungen von Axondurchmesser und Myelindicke durchgeführt. Es zeigte sich zunächst, dass in CMT-Tieren $(2,7 \pm 0,13$ $\mu \mathrm{m})$ signifikant kleinere Axone vorkommen als in Wildtyp (3,4 $\pm 0,2 \mu \mathrm{m})$ - und WidsTieren $(3,3 \pm 0,1 \mu \mathrm{m})$. In den Nerven der CMDS-Tiere $(2,9 \pm 0,23 \mu \mathrm{m})$ fanden sich aber durchschnittlich signifikant größere Axone als in denen der CMT-Tiere. Diese Tiere nehmen somit eine Mittelstellung zwischen CMT und WT/WIds ein (Abb. 13b). Die prozentuale Verteilung der Axondurchmesser von CMT- und CMDS-Tieren gegeneinander aufgetragen zeigt eine „Rechtsverschiebung“ der Kurve zugunsten von dickeren Axonen in CMDS-Tieren (Abb. 13c).

Die Messung der Myelindicke bezogen auf die Axondicke (g-ratio) zeigte darüber hinaus, dass dieses Verhältnis in Wildtyp- und Wids-Tieren konstant und unabhängig von der Axondicke ist, wohingegen es in CMDS- und CMT-Tieren eine positive Korrelation der beiden Parameter gab. Dies zeigt eine relative Hypermyelinisierung kleiner und eine Hypomyelinisierung großer Axone in diesen beiden Gruppen an. Auch hier fand sich ein Trend zu insgesamt größeren Axonen in der CMDS-Gruppe im Vergleich mit der CMT-Gruppe (Abb. 13a). 

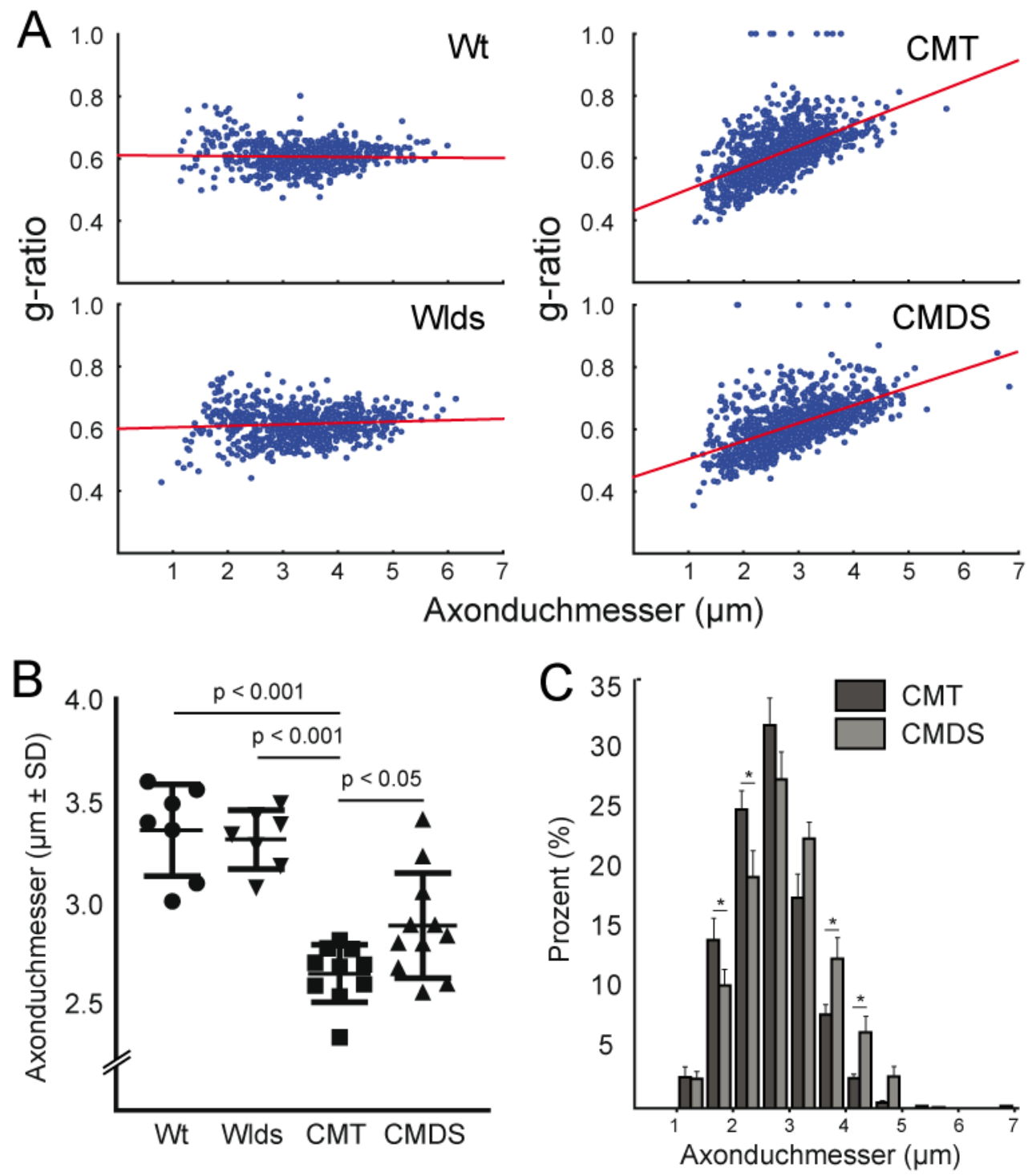

Abbildung 13: G-ratios bleiben konstant in Wt und Wlds-Tieren, bilden aber eine positive Korrelation mit den jeweiligen Axondurchmessern in CMT und CMDS. Ein gratio von 1 bezeichnet ein vollständig demyelinisiertes Axon. ( $n=6-10$ pro Genotyp) (A). Der durchschnittliche Axondurchmesser war in CMT-Tieren signifikant geringer als in allen anderen Gruppen, in CMDS-Tieren jedoch signifikant höher als in CMT (B). In CMDS-Tieren fanden sich insgesamt mehr Axone mit größerem Durchmesser verglichen zu CMT (C). Manuelle Auszählung an Semidünnschnitten mit der ImageJ Software (Meyer zu Horste et al. 2011)

\subsection{Nervenkompression nach NaM Behandlung}

\subsubsection{NMNAT1-Expression}

Gemäß unserer Arbeitshypothese spielt der NMNAT1-Anteil des WIds-Transgens eine wichtige Rolle für dessen axonale Protektion. Bei den Versuchstieren wurde daher die Menge an NMNAT1 mRNA im Rückenmark bestimmt. Es fand sich eine nicht- 
signifikante Erhöhung in Wlds (1,39 $\pm 0,3)$ - und CMDS-Tieren $(1,38 \pm 0,28)$ gegenüber Wt $(1,05 \pm 0,18)$ - und CMT $(0,89 \pm 0,3)$-Tieren (Abb. 14). In der Literatur finden sich Hinweise dafür, dass verschiedene Substrate des Enzyms in vitro und in vivo axonprotektiv wirken (s. o.). Wir untersuchten daher, ob Nikotinamid als bioverfügbare Substratvorstufe von NMNAT1 die axonale Degeneration nach einer Nervenläsion reduziert.

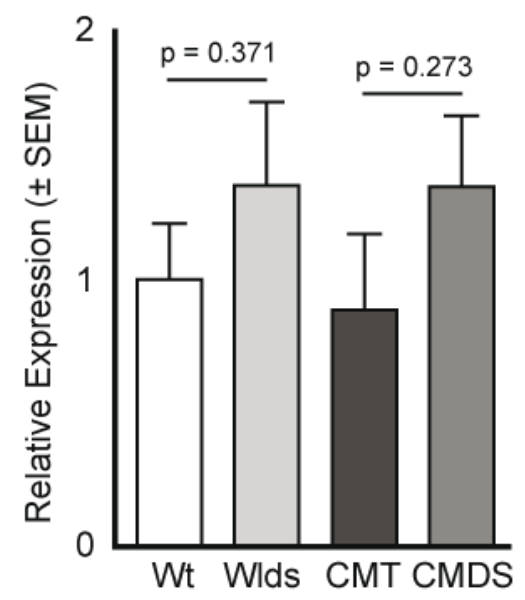

Abbildung 14: NMNAT1-Expression im Rückenmark ( $\mathrm{n}=5$ pro Genotyp) (Meyer zu Horste et al. 2011)

\subsubsection{Histologie}

Zur Beantwortung dieser Frage wurde eine experimentelle Nervenkompression durchgeführt, die zu axonaler Degeneration führt. Hierfür wurden Wildtyp-Ratten mit intraperitonealen Injektionen von Nikotinamid oder Placebo behandelt, eine Gruppe Wlds-Tiere diente als Positivkontrolle. Nach Druckläsion des Nerven wurde die axonale Degeneration $2 \mathrm{~mm}$ distal der Kompressionsstelle 24, 48 und 72 Std. nach der Nervenschädigung untersucht. Es fanden sich in den $\mathrm{Nn}$. ischiadici der Versuchstiere aus der NaM-Behandlungsgruppe distal der Kompressionsstelle weniger degenerierte Axone als in der Placebo-Gruppe. Dieses Phänomen war $24 \mathrm{Std}$. nach Nervenschädigung am stärksten ausgeprägt ( $\mathrm{NaM} 31 \pm 5 \%, \mathrm{NaCl} 78 \pm 11 \%$ ) und nahm mit fortschreitender Zeit ab (nach $48 \mathrm{Std}$. NaM $60 \pm 6 \%, \mathrm{NaCl} 82 \pm 3 \%$ ), so dass nach 72 Std. ( $\mathrm{NaM} 61 \pm 12 \%, \mathrm{NaCl} 85 \pm 3 \%$ ) nur noch ein nicht-signifikanter Unterschied zu sehen war. Die WIds-Gruppe zeigte nur eine geringe Degeneration der Axone zu allen beobachteten Zeitpunkten (Abb. 15). Somit verzögerte die Behandlung 
mit Nikotinamid die posttraumatische Degeneration von Axonen, ohne sie jedoch letztendlich verhindern zu können.

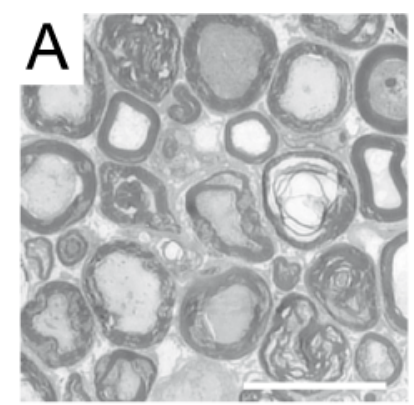

Placebo - 24 Std

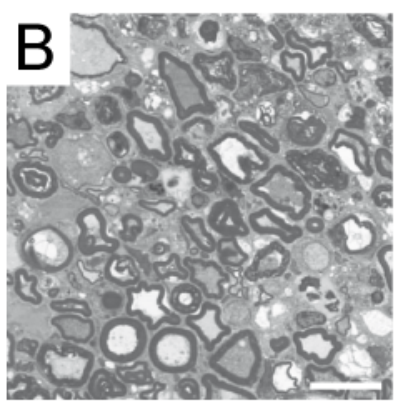

Placebo - 48 Std

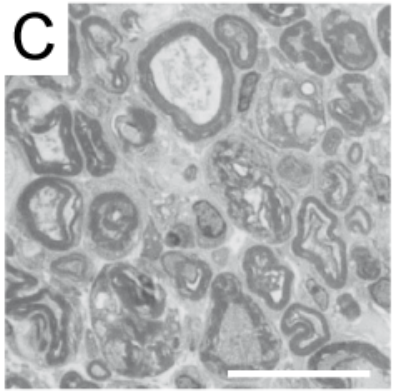

Placebo - 72 Std

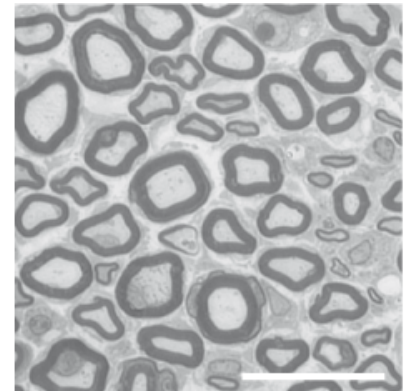

Nicotinamid - 24 Std

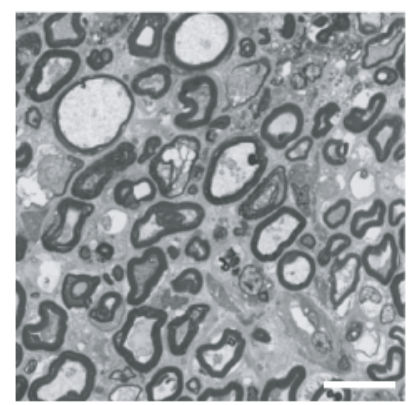

Nicotinamid - 48 Std

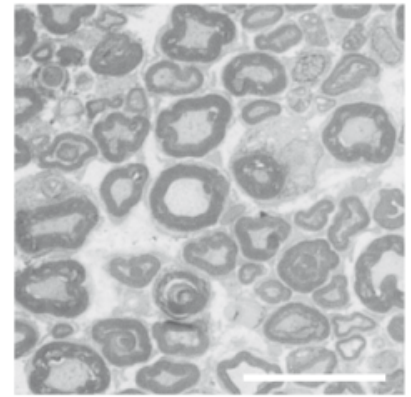

Nicotinamid - 72 Std

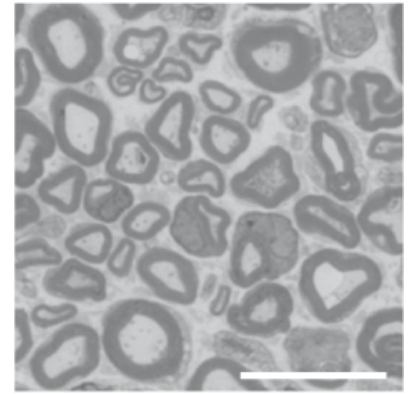

Wlds - 24 Std

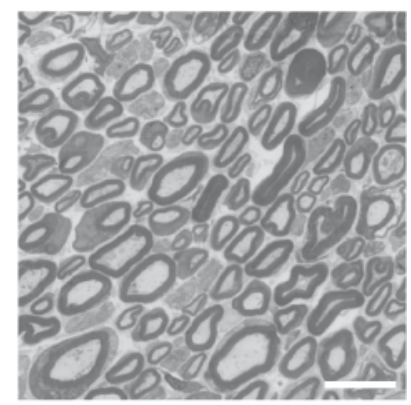

Wlds - 48 Std

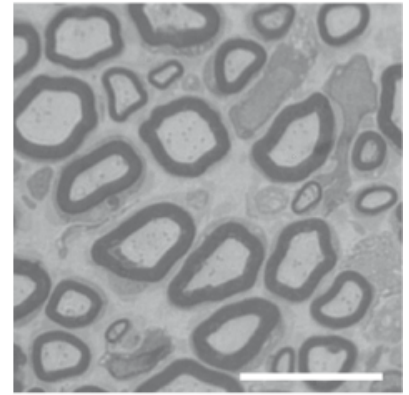

Wlds - 72 Std

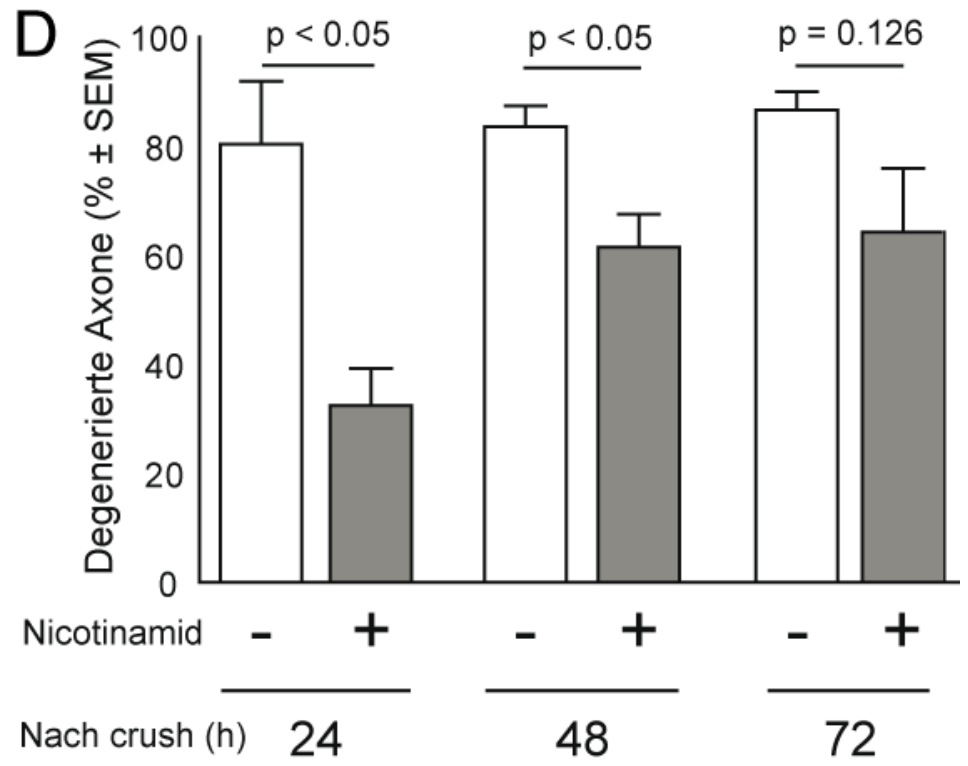


Abbildung 15: Histologische Analyse 24 (A), 48 (B) und 72 (C) Std. nach Läsion des $N$. ischiadicus ( $n=5$ pro Gruppe und Zeitpunkt). Gezeigt sind repräsentative Bilder der Placebo-Gruppe (linke Spalte) im Vergleich zur Behandlungsgruppe (mittlere Spalte) und unbehandelten, jedoch ebenfalls läsionierten Nerven von Wlds-Kontrollen (rechte Spalte). In der Auswertung zeigte sich eine signifikant geringere Degeneration 24 und 48 Std. nach Läsion in den mit Nikotinamid behandelten Tieren. Nach 72 Std. war dieser Unterschied nicht mehr nachweisbar (D). Manuelle Auszählung an Semidünnschnitten mit der ImageJ Software. Maßstab $20 \mu$ m (Meyer zu Horste et al. 2011).

\subsubsection{Nikotinamid-Konzentration in Serum und Nervengewebe}

Nach Abschluss der fünftägigen Behandlung der Tiere mit NaM ließen wir Blutserum und Homogenisat des $\mathrm{N}$. ischiadicus in einem externen Labor auf ihren NaM-Gehalt

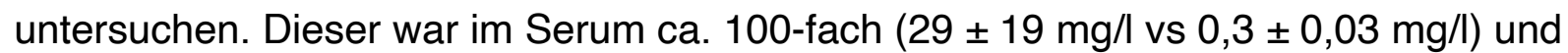
im Nervenhomogenisat ca. 2-fach $(0,552 \pm 0,235 \mathrm{mg} / \mathrm{l}$ vs 0,215 \pm 0,01 mg/l) erhöht. Wir gingen daher davon aus, dass NaM in dieser Studie sein Zielgewebe erreicht hatte (Abb. 16).
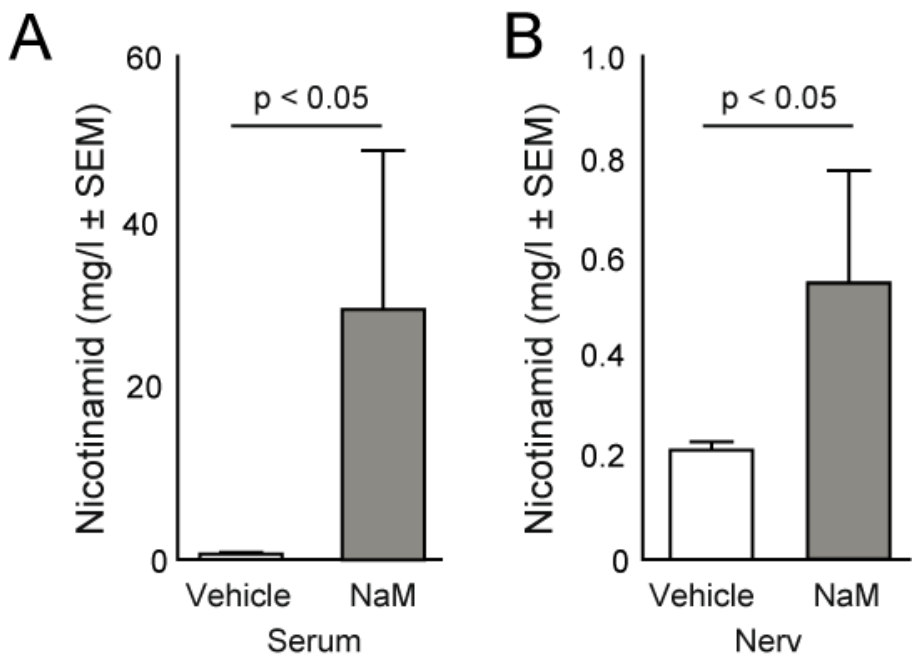

Abbildung 16: Konzentration von Nikotinamid in Serum (A) und Nervenhomogenisat (B) nach fünf Behandlungstagen durch intraperitoneale Injektion (Meyer zu Horste et al. 2011)

\subsection{Nikotinamid-Behandlung von Wildtyp- und CMT-Ratten}

Auf Grund dieser Entdeckungen sollten nun die Erkenntnisse aus den bisherigen Untersuchungen auf die CMT-Erkrankung übertragen werden. Kohorten von Wildtypund CMT-Ratten wurden daher über acht Wochen mit intraperitonealen Injektionen 
von NaM und Placebo ( $\mathrm{NaCl}$ ) behandelt. Dies geschah in der Annahme, dass die Gabe von NaM auch in der CMT-Erkrankung in vivo die Axondegeneration und somit das Fortschreiten des Muskelschwäche-Phänotyps verzögern kann.

\subsubsection{NaM-Konzentration in Serum und Nervengewebe}

Nach Abschluss der achtwöchigen Behandlung wurden Blutserum und Homogenisat des N. ischiadicus in einem externen Labor auf den NaM-Gehalt untersucht. Dieser war im Serum ca. 1000-fach (268 $\pm 75 \mathrm{mg} / \mathrm{l}$ vs $0,29 \pm 0,065 \mathrm{mg} / \mathrm{l})$ und im Nervenhomogenisat ca. 10 -fach $(2,97 \mathrm{mg} / \mathrm{l}$ vs $0,27 \mathrm{mg} / \mathrm{l})$ erhöht. Es ist daher davon auszugehen, dass NaM auch in diesem Teil der Studie sein Zielgewebe erreicht hatte (Abb. 17).
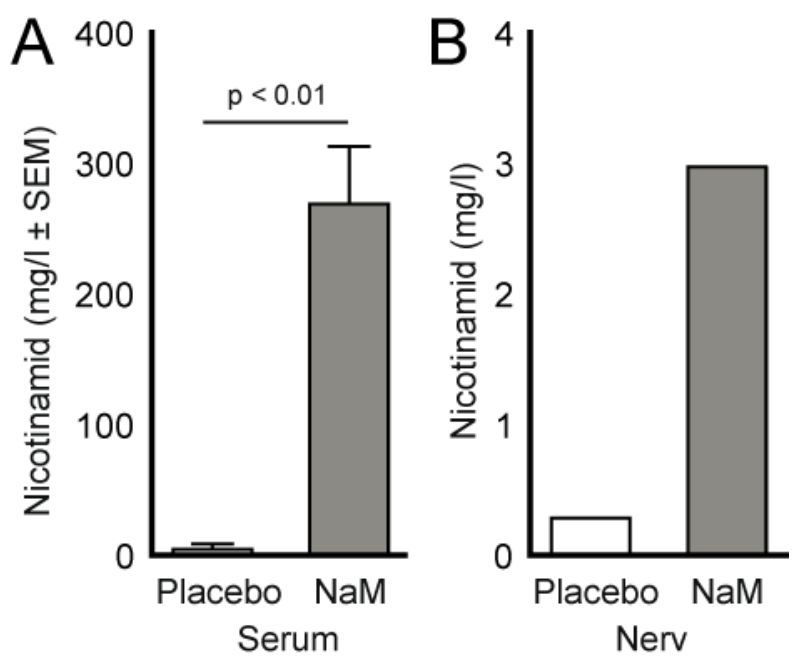

Abbildung 17: Konzentration von Nikotinamid in Serum ( $\mathrm{n}=3$ pro Gruppe) (A) und Nervenhomogenisat ( $n=1$ jeweils) (B) nach acht Wochen Behandlung durch intraperitoneale Injektion, gemessen mit HPLC 24 Std. nach der letzten Injektion (Meyer zu Horste et al. 2011)

\subsubsection{Griffstärke-Messung}

Zur Evaluation des Phänotyps wurden die bereits beschriebenen Griffstärkemessungen über 8 Wochen durchgeführt. Während des Experiments konnte ein signifikanter Unterschied zwischen den Wildtyp- und CMT-Gruppen (NaCl-Wt 8,9 $\pm 0,8$ $\mathrm{N}$ vs. NaCl-CMT 8,15 $\pm 0,8 \mathrm{~N}$ ) beobachtet werden. Zwischen der Behandlungs- und Placebogruppe ließ sich jedoch für die Wildtyp-Tiere kein signifikanter Unterschied 
feststellen ( $\mathrm{NaCl} 8,9 \pm 0,8 \mathrm{~N}$ vs. NaM 9,1 \pm 0,05 N). Die CMT-Gruppe (NaCl 8,15 0,8 $\mathrm{N}$ vs. NaM 8,47 $\pm 1 \mathrm{~N}$ ) zeigte einen nicht-signifikanten Trend (Abb. 18a).

\subsubsection{Umfangmessung der Hinterläufe}

Als repräsentatives Maß für die Muskelmasse wurde der Umfang der Hinterläufe der Tiere bestimmt. In den zwei Wildtyp-Gruppen konnten keine Unterschiede festgestellt werden ( $\mathrm{NaCl} 63,3 \pm 2,75 \mathrm{~mm}$, NaM 61,7 \pm 3,79 mm). In den CMT-Gruppen war der Umfang in der mit NaM behandelten Gruppe jedoch signifikant geringer ( $\mathrm{NaCl} 64,2 \pm$ 2,8 mm, NaM $60 \pm 3,37 \mathrm{~mm}$ ) (Abb. 18b).

\subsubsection{Histologie}

In der histologischen Analyse der myelinisierten Axone der $\mathrm{Nn}$. tibiales der Versuchstiere fanden sich keine Unterschiede in der Axonanzahl zwischen der Placebo- und der Behandlungsgruppe, weder innerhalb der CMT ( $\mathrm{NaCl} 2523 \pm 161$, NaM $2519 \pm$ 165)- noch der Wildtyp-Tiere ( NaCl $2748 \pm 125$, NaM $2785 \pm 268)$. Der bereits bekannte Unterschied zwischen CMT- und Wt-Tieren konnte reproduziert werden (Abb. 18c).
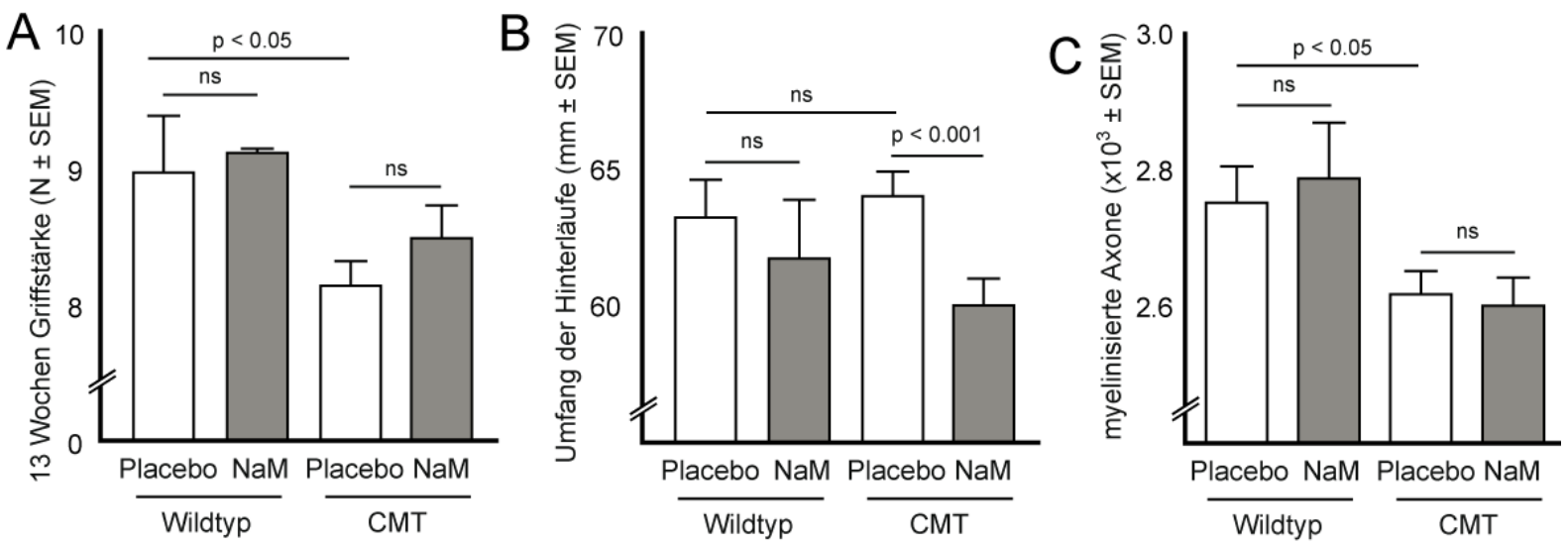

Abbildung 18: Ergebnisse der Nikotinamid-Behandlungsstudie. Nach acht Wochen Behandlung fand sich ein Trend, jedoch kein signifikanter Unterschied in der Griffstärke der Tiere in den CMT-Gruppen (A). Der Umfang des rechten Hinterlaufes bei 13 Wochen war in der mit NaM behandelten CMT-Gruppe signifikant geringer (B). Die Anzahl myelinisierter Axone im $\mathrm{N}$. tibialis ändert sich durch eine Behandlung mit NaM nicht (C). CMT ( $n=36)$ Wt $(n=7)$ (Meyer zu Horste et al. 2011).

Axondurchmesser und g-ratio wurden daraufhin nicht mehr untersucht. Es war also in dieser Teilstudie kein positiver Einfluss von Nikotinamid auf den Phänotyp der CMTRatte nachweisbar. 


\section{Diskussion}

In dieser Arbeit wurde die Biologie der axonalen Degeneration in mehreren Versuchen erforscht. Im Kern wurde der Einfluss des WIds-Transgens, das axonprotektive Eigenschaften besitzt, auf die CMT1A-Erkrankung analysiert, die sich durch sekundären Axonverlust als Folge einer primären Schwann-Zell-Pathologie auszeichnet. Eine Theorie über den Mechanismus der Wlds-Protektion wurde dem Versuch zu Grunde gelegt, den Wlds-Effekt therapeutisch nutzbar zu machen.

\subsection{Erzeugung und Charakterisierung von doppelt-transgenen Versuchstieren}

\subsubsection{Phänotypanalyse}

Die menschliche CMT1A-Erkrankung zeichnet sich $u$. a. durch eine periphere Muskelschwäche, abnorme Elektrophysiologie und histologisch nachweisbare Demyelinisierung von Axonen aus (Pareyson und Marchesi 2009). Diese Merkmale sind ebenfalls in einer das PMP22-Transgen tragenden Rattenlinie (Sereda et al. 1996) zu finden. Sie ist daher ein etabliertes Tiermodell für diese Erkrankung (Sereda und Nave 2006). Das Wids-Gen wurde zunächst zufällig als Spontanmutation in Mäusen entdeckt (Lunn et al. 1989) und charakterisiert (Mack et al. 2001). Später wurde zur besseren Erforschung der WIds-Eigenschaften auch eine transgene Rattenlinie erzeugt, in der die neuroprotektiven Eigenschaften von Wlds erhalten sind (Adalbert et al. 2005).

Für dieses Forschungsvorhaben wurden zunächst durch Verpaarungsexperimente doppelt-transgene Ratten erzeugt, die das PMP22- und WIds-Transgen tragen. Die Tiere wurden Phänotypanalysen unterzogen, die sich auf die Muskelkraft der Tiere, gemessen als Griffstärke, konzentrierten (s. o.). Dieser Parameter zeichnet sich durch seine Objektivierbarkeit und hohe klinische Relevanz aus.

$\mathrm{Zu}$ Beginn der Untersuchung konnten ein signifikant geringeres Körpergewicht und geringere Griffstärke-Werte bei fünf Wochen alten Tieren in der Wids-Gruppe im Vergleich zu Wildtyp-Tieren der CMT1A-Linie beobachtet werden. Der Unterschied ist wahrscheinlich mit Zuchtlinien-Differenzen der verpaarten Rattenlinien zu erklären. 
Dies kann u.a. zu Unterschieden im zeitlichen Ablauf des (Muskel)Massenwachstums der Tiere führen, ggf. vermittelt durch unterschiedliche Ausprägung von Merkmalen von Inzucht-Stämmen wie Homozygosität oder Spontanmutationen in den beiden Linien. Beide wurden zwar auf einem Sprague-Dawley-Hintergrund erzeugt, vor der Verpaarung aber für über 20 Generationen in verschiedenen Kolonien gehalten. Daher wurde die Zunahme der Griffstärke während der Beobachtungszeit berechnet. Diese altersabhängige Zunahme der Griffstärke - als $M a ß$ für eine geringere Ausprägung der CMT1A-Neuropathie - war bei den CMDS-Tieren am stärksten ausgeprägt. Dies kann vollständig durch die höhere Axonanzahl und die höheren CMAP-Amplituden bei diesen Tieren im Vergleich zu den CMT1A-Tieren erklärt werden (s. u.).

\subsubsection{Elektrophysiologie}

Die CMT1A-Erkrankung führt zu verschiedenen charakteristischen Auffälligkeiten in der elektrophysiologischen Untersuchung. So kommt es zu einer Verlangsamung der NCV und Abnahme der CMAP-Amplitude sowie einer Dispersion derselben. Diese Auffälligkeiten treten beim Menschen (Lupski und Chance 2005; Pareyson und Marchesi 2009) und beim PMP22-transgenen Modelltier (Meyer zu Horste et al. 2007; Sereda et al. 1996) in sehr ähnlicher Weise auf. In den doppelt transgenen Ratten der Studie fand sich eine geringere Ausprägung dieser elektrophysiologischen Auffälligkeiten, welche man normalerweise in PM22-transgenen Tieren findet. Sowohl CMAP als auch NCV zeigten sich in den CMDS-Tieren deutlich und signifikant verbessert im Vergleich zu den CMT-Tieren. Diese Parameter sind ein indirekter Hinweis auf die Anzahl und den Zustand der Axone im getesteten peripheren Nerv. Es lässt sich daher aus den elektrophysiologischen Untersuchungen schließen, dass der axonale Verlust in den CMDS-Tieren weniger stark ausgeprägt ist. Die funktionelle Messung korreliert daher mit den Ergebnissen auf phänotypischer (s. o.) und struktureller (s. u.) Ebene.

\subsubsection{Histologie}

Die histologische Analyse der Axone im N. tibialis der Versuchstiere lieferte zwei Ergebnisse: Erstens war der morbiditätsrelevante Axonverlust in den CMDS-Tieren geringer und zweitens war der Durchmesser der Axone in den CMDS-Tieren 
durchschnittlich erhöht - jeweils im Vergleich mit den CMT-Tieren. Der Axonverlust in den CMT-Tieren betrifft bekanntermaßen vor allem groß- und mittelkalibrige Axone (Meyer zu Horste et al. 2007). Die Ergebnisse deuten daher darauf hin, dass das WIdsTransgen vor allem Axone mit großem Durchmesser vor der Degeneration bewahrt. Da dies fast immer motorische Fasern sind, beruht die höhere Griffstärke der CMDSTiere wahrscheinlich darauf, dass das Wids-Gen im experimentellen Setting präferentiell die großen Motoraxone vor der Degeneration bewahrt. Größere Axone brauchen mehr Nährstoffe und sind gleichzeitig schwieriger durch Diffusion zu ernähren, was auf einen verbesserten lokalen Energiestoffwechsel im WldsMechanismus hinweisen könnte. So ist es möglich, dass Wids mit seinen NMNATEigenschaften durch Änderungen im intraaxonalen Energiestoffwechsel das lokale Gleichgewicht der Bestandteile des NAD-Stoffwechsels günstig, d. h. Axon-protektiv, beeinflusst. Es wird z. B. die Akkumulation von (vermutlich toxischem) NMN (Di Stefano et al. 2015) und der Abbau von NAD verhindert (Gerdts et al. 2015).

Eine weitere Möglichkeit besteht darin, dass durch die Schwann-Zell-Pathologie nicht nur ein Myelin-Strukturdefekt auftritt, sondern auch die unterstützende Funktion der Schwann-Zellen für die Axone wegfällt, worunter eine metabolische Interaktion zwischen beiden Zelltypen fällt (Nave 2010; Nave und Werner 2014). Eventuell werden die Axone durch das Wlds-Gen in die Lage versetzt, die verlorene unterstützende Funktion der Schwann-Zellen besser ersetzen oder deren Fehlen besser kompensieren zu können. Eine spezifische Protektion der motorischen Endplatte, wie vorbeschrieben (Ribchester et al. 1995), könnte ebenfalls eine Rolle spielen.

Es ließ sich in den CMDS-Tieren keine veränderte Myelinisierung - ausgedrückt durch g-ratios - im Vergleich zu den CMT-Tieren feststellen (Abb. 13). Große Axone haben eine höhere NCV als kleine. Es ist daher davon auszugehen, dass die Erhaltung von mehr großkalibrigen Axonen und nicht eine veränderte Myelinisierung die Verbesserung der elektrophysiologischen Werte der CMDS-Tiere erklärt.

\subsubsection{Schlussfolgerung}

$\mathrm{Da}$ in dieser Studie gezeigt werden konnte, dass Wlds in einem Tiermodell für die CMT1A-Erkrankung neuroprotektiv wirkt und dies bereits früher für die seltene CMT1B-Unterform beschrieben wurde (Samsam et al. 2003), ist davon auszugehen, 
dass der Mechanismus von Wids an der gemeinsamen Endstrecke des Neuronenuntergangs ansetzt. Die Ergebnisse deuten darauf hin, dass dies unabhängig von der zugrunde liegenden Schwann-Zell-Pathologie gilt. Hinweise dafür, dass Wlds auch vor direkter axonaler Schädigung in Motoneuron-Erkrankungen schützt (Ferri et al. 2003) unterstützen dieses Konzept.

Damit ließ sich zeigen, dass das Wlds-Transgen auch im Kontext der genetischen CMT1A-Erkrankung in vivo einen axonprotektiven Effekt hat und es zu einer zumindest partiellen Rettung des neuropathischen Phänotyps durch Erhaltung v. a. großkalibriger Axone kommt.

\subsection{Behandlung mit Nikotinamid und Nervenkompression}

\subsubsection{Bekannte Effekte von Nikotinamid}

Um den so nachgewiesenen neuroprotektiven Effekt von Wlds therapeutisch nutzbar zu machen, wurde eine Testreihe mit Nikotinamid, dem bioverfügbaren und membrangängigen Substratvorläufer des NMNAT1-Enzyms durchgeführt. Zunächst wurde ein Paradigma für akute Nervenschädigung gewählt, und zwar um eine rasche Antwort auf die Frage zu bekommen, ob der Effekt von Wlds wirklich die gemeinsame Endstrecke der axonalen Degeneration betrifft und ob dieser Effekt durch Nikotinamid nachgeahmt werden kann. Der Grund für dieses Vorgehen ergab sich daraus, dass zum einen die enzymatische Aktivität von NMNAT1 für den protektiven Phänotyp notwendig ist (Avery et al. 2009; Sasaki et al. 2009b). Zum anderen konnte in verschiedenen Versuchsanordnungen eine zyto- und neuroprotektive Wirkung für Nikotinamid selbst nachgewiesen werden. So wirkt es in vitro nach Zugabe zu verschiedenen Modellen axonaler Degeneration (Wang et al. 2005) protektiv. In vivo ließ sich eine protektive Wirkung bei verschiedenen Tiermodellen für ischämischen Hirninfarkt (Cai et al. 2006; Feng et al. 2006; Maynard et al. 2001; Mokudai et al. 2000; Sakakibara et al. 2002), traumatischen Hirnschaden (Hoane et al. 2008; Holland et al. 2008) und in experimenteller Autoimmun-Enzephalomyelitis (Kaneko et al. 2006) nachweisen. Neben diesen Studien, die sich auf das Nervensystem beziehen, wurde auch ein membranstabilisierender, antiinflammatorischer und mutmaßlich antithrombogener Effekt in vitro in Endothelzellen beschrieben (Chong et al. 2002). 
Eine Wirkung von Nikotinamid als Zyto- und Neurorotektivum mit breitem Spektrum ist daher gut belegt (Maiese und Chong 2003).

\subsubsection{Nikotinamid-Konzentration}

Es konnte zunächst bestätigt werden, dass intraperitoneal verabreichtes Nikotinamid zu einem deutlichen Anstieg der Konzentration in Serum und Nervengewebe führt und damit seinen Zielort erreicht. Dies war bereits nach fünf Tagen der Fall (Abb. 16) und sogar noch ausgeprägter nach acht Wochen Behandlung (s. u.). Die ZNS-Gängigkeit von Nam ist etabliert (Spector 1979), diese Daten passen somit zu den bekannten Werten der Pharmakokinetik von Nikotinamid bei Menschen und Ratten in der Literatur (Dragovic et al. 1995; Kimura et al. 2006; McCreanor und Bender 1986). NikotinamidKonzentrationsbestimmungen in peripherem Nervengewebe bei Ratten lagen jedoch bisher in der Literatur nicht vor, somit stellt diese Analyse die erste Messung dieser Art dar.

\subsubsection{NMNAT1-Expression}

Es wurde nun die Expression von NMNAT1 im Rückenmark der Versuchstiere überprüft. Dadurch konnte sichergestellt werden, dass nicht nur NaM als Substratvorstufe, sondern auch das notwendige Enzym im Zielgewebe vorhanden ist. Hierbei ließ sich ein nicht-signifikanter Trend zu höherer Expression von NMNAT1 RNA in Wlds-transgenen Tieren beobachten. Dass Wlds zusätzlich zur endogenen NMNAT1 exprimiert wird, ist bekannt (Conforti et al. 2007; Conforti et al. 2000). Eine quantitative Messung lag jedoch bisher nicht vor, sondern nur semi-quantitative Western-Blot-Analysen. Es ist anzunehmen, dass diese Daten das Vorliegen zusätzlicher NMNAT1-Kopien im Gewebe von WIds-Tieren anzeigen, da NMNAT ein integraler Bestandteil von Wlds ist. Es konnte also bestätigt werden, dass das therapeutische Agens ins Gewebe vordringt und das für den protektiven Phänotyp notwendige Enzym im Zielgewebe exprimiert wird.

\subsubsection{Histologie}

Nach Gabe von Nikotinamid und Läsion des Nerven, wie oben beschrieben, wurde eine histologische Quantifizierung der Axone im N. ischiadicus durchgeführt. Es ließ sich nachweisen, dass Nikotinamid die axonale Degeneration nach experimenteller 
Nervenkompression in vivo verlangsamt. So zeigte sich eine signifikant bessere strukturelle Erhaltung von mehr Axonen im Nerv in der Behandlungsgruppe bis etwas weniger als 72 Std. nach crush. Zu diesem Zeitpunkt war der Effekt nicht mehr signifikant. Die Degeneration konnte so zwar verzögert, nicht jedoch ganz aufgehalten werden. Die protektive Wirkung von NaM war geringer und von kürzerer Dauer als die von Wlds und die Degeneration war überraschenderweise schneller und kompletter abgelaufen als in anderen Studien mit YFP-exprimierenden Axonen (Beirowski et al. 2005; Beirowski et al. 2004). Dies könnte an Unterschieden im experimentellen Prozedere gelegen haben, da diese Untersuchung die axonale Degeneration $2 \mathrm{~mm}$ distal der crush-Stelle untersuchte und die anderen Studien mit einem ca. 2,5 cm langen Nervensegment arbeiteten und Analysen deutlich weiter entfernt von der Läsionsstelle durchführten. Unterschiede im zeitlichen Ablauf der WD zwischen dünnen und dicken Axonen sind beschrieben (Lubinska 1977), wurden aber ggf. durch das experimentelle Setting nicht berücksichtigt. Eine weitere Möglichkeit sind Gewebsunterschiede zwischen Maus und Ratte u/o spezifische Effekte der untersuchten Transgene (WIds, YFP).

Als Erklärung dafür, dass die Gabe von NaM den Effekt des Wlds-Transgens nicht vollständig nachahmte, kann angenommen werden, dass ein Mehrangebot von Substratvorstufe nicht zwangsläufig zu einer vermehrten enzymatischen Aktivität von NMNAT1 führt, die bei Vorliegen des Wids-Transgens ca. 4-fach gesteigert ist (Conforti et al. 2007; Mack et al. 2001). Die für eine neuroprotektive Wirkung ebenfalls wichtige Lokalisation von NMNAT1 außerhalb des Nukleus im „richtigen“ subzellulären Kompartiment (Axon) wird wahrscheinlich durch die Verabreichung von Nikotinamid nicht geändert. Ergebnisse mehrerer Studien zur Wirkung extranukleärer (zytoplasmatischer und axonaler) transgener NMNAT1-Formen verdeutlichen die Wichtigkeit der axonalen Lokalisation des Proteins für die protektive Wirkung (Babetto et al. 2010; Beirowski et al. 2009; Sasaki et al. 2009a). Die enzymatische Aktivität von NMNAT ist notwendig für diesen protektiven Phänotyp, jedoch ggf. unabhängig von den bekannten Substraten und Produkten des Enzyms. Es gibt daher evtl. bisher unbekannte NMNAT1-Metabolite, die den protektiven Phänotyp erklären könnten (Sasaki et al. 2016; Sasaki et al. 2009b). Zwei weitere Möglichkeiten bestehen darin, dass mehr Nikotinamid im Organismus bei systemischer Gabe auch toxische Effekte hat, die die protektive Wirkung negativ modulieren (s. u.) oder dass die protektive 
Wirkung von Nikotinamid ganz unabhängig vom „Wlds-Effekt“ ist und nicht durch die NMNAT-Enzyme vermittelt wird.

\subsubsection{Schlussfolgerung}

Es gelang somit erstmalig der Nachweis, dass Nikotinamid bei akuter axonaler Schädigung in vivo im PNS neuroprotektiv wirkt. Dieses Ergebnis weist Nikotinamid für weitere Testungen als Therapeutikum bei akuten Nervenschäden aus. Es könnte dort als unterstützende Behandlung in Frage kommen.

\subsection{Langzeit-Behandlung von CMT1A-Tieren mit Nikotinamid}

Auf Grund der vorangehenden Beobachtungen, dass Wids die Ausprägung des CMTPhänotyps abschwächt und Nikotinamid-Gabe diesen Wlds-Effekt zum Teil nachahmen kann, wurden die Auswirkungen einer Nikotinamid-Langzeitbehandlung auf die CMT-Erkrankung in Ratten untersucht. Das Ziel war, eine neue Therapieoption für diese chronische Neuropathie zu finden.

\subsubsection{Nikotinamid-Konzentration}

Wie im Nervenkompressionsexperiment wurde die Konzentration von Nikotinamid nach Abschluss der Behandlung im Serum und Zielgewebe (Nerv) bestimmt und in der Behandlungsgruppe eine deutlich erhöhte Konzentration gefunden - nochmals deutlich erhöht im Vergleich zur Kurzzeit-Behandlung für die Nervenkompression. Die Sicherheit einer Gabe von Nikotinamid in hohen Dosen und über lange Zeiträume wurde in mehreren Studien in unterschiedlichen Settings an Menschen und Tieren untersucht. Zusammenfassend spricht die Datenlage für eine gute Verträglichkeit und eine geringe Toxizität bei großer therapeutischer Breite (Knip et al. 2000).

In mehreren Studien zur Wirkung von Nikotinamid bei ischämischem Schlaganfall wurde eine optimale protektive Wirkung von Nikotinamid bei einer Dosis von 500 mg/kg KG festgestellt (Feng et al. 2006; Maynard et al. 2001; Mokudai et al. 2000). Auch bei experimenteller Autoimmun-Enzephalomyelitits brachte diese Dosis bessere Ergebnisse als $125 \mathrm{mg} / \mathrm{kg}$ (Kaneko et al. 2006). In letztgenannter Studie wurde eine Behandlung der Tiere über eine Dauer von 5 Wochen durchgeführt, ohne dass signifikante Nebenwirkungen erwähnt werden. Aus diesen Gründen fiel auch hier die 
Entscheidung für eine Behandlung mit dieser Dosis in beiden Teilexperimenten. Demgegenüber zeigen einige Studien jedoch Hinweise auf eine mögliche toxische Wirkung einer Hochdosistherapie mit NaM (s. u.).

\subsubsection{Phänotypanalyse und Histologie}

Nach Durchführung der Langzeit-Behandlungsstudie fand sich in erwachsenen CMTRatten zwei Monate nach täglicher, intraperitonealer Nikotinamid-Injektion kein Unterschied zur Kontrollgruppe bezüglich Phänotyp oder Axonverlust.

Mehrere Erklärungen kommen hierfür in Frage: Möglicherweise war der Grad der Neuroprotektion, der durch Nikotinamid erreichbar war, zu gering oder dauerte nicht lang genug an, um einen chronischen axonalen Schaden zu verhindern. Die Behandlungszeit und-dauer wurde an das Alter der Ratten so angepasst, dass es die Situation bei Menschen mit Auftreten von ersten Symptomen der CMT1A in der Adoleszenz so gut wie möglich nachahmt. Es ist daher nicht auszuschließen, dass ein früherer Beginn oder eine längere Dauer der Therapie einen positiven Effekt gehabt hätten. Aufgrund der oben diskutierten Details des NAD-Stoffwechsels war ein Mehrangebot von Nikotinamid evtl. nicht ausreichend, um andere Mechanismen der Wirkung von Wids, wie Steigerung der Enzymaktivität und/oder intrazellulären Ortswechsel des Enzyms, zu beeinflussen.

Biochemisch wird NaM vom NAMPT-Enzym umgewandelt und nicht direkt von NMNAT1 (Abb. 3). Da die Aktivität von NAMPT der limitierende Faktor in der Reaktionskette von NaM zu NAD ist, wurde evtl. nicht genug Substrat für NMNAT zur Verfügung gestellt und daher hat sich NaM im Gewebe übermäßig angereichert. Auch die Akkumulation größerer Mengen NMN, dem Produkt von NAMPT, ist möglich. Neuere Daten deuten darauf hin, dass eine solche Akkumulation selbst neurotoxische Wirkung entfalten kann und die weitere Verstoffwechselung von NMN im Falle des Vorliegens des Wids-Transgens den protektiven Effekt erklärt (Di Stefano et al. 2015; Loreto et al. 2015). In Wildtyp-Tieren (für Wlds), wie in diesem Fall, fehlt diese zusätzliche NMNAT-Aktivität und eine pro-degeneratorische Wirkung von akkumuliertem NMN könnte die Folge sein. Die Daten zu NMN sind jedoch nicht einheitlich. So zeigte eine andere aktuelle Studie, dass eine Langzeitgabe des Moleküls per os in Mäusen eine deutliche, protektive Wirkung in Bezug auf altersrelevante Pathologien hat, wobei hier jedoch das Nervensystem nicht direkt untersucht wurde (Mills et al. 2016). 
Ein weiterer Hinweis auf eine toxische oder allgemein wachstumshemmende Wirkung bei Langzeitbehandlung könnte der Verlust von Muskelmasse (gemessen als Umfang der Hinterläufe) der mit Nikotinamid behandelten Tiere sein. Ein vermindertes Wachstum von Ratten bei oraler NaM-Gabe ist vorbeschrieben (Handler und Dann 1942). Auch in anderen Studien wurde eine wenn auch vorübergehende Wachstumsverlangsamung bei Gabe während der Wachstumsphase gefunden (Feng et al. 2006). Des Weiteren haben manche Untersuchungen abnorme Leberwerte und eine Entwicklung von Fettlebern gezeigt (Knip et al. 2000). Dies deutet eine gewisse Toxizität und eine allgemein ungünstige Beeinflussung des Energiestoffwechsels bei hohen Dosen von NaM an.

\subsubsection{Schlussfolgerung}

Durch eine Behandlung mit Nikotinamid kann daher der neuroprotektive Effekt des Wlds-Gens auf die CMT1A-Erkrankung nicht nachgeahmt werden. 


\section{Zusammenfassung}

Es ließ sich in dieser Arbeit zeigen, dass die Expression des WIds-Gen im CMTModelltier den klinischen Phänotyp der Erkrankung durch Erhaltung von mehr Axonen im peripheren Nerv abschwächt. Eine ähnliche bessere Resistenz von Wlds-Axonen gegen akuten axonalen Schaden konnte ebenfalls nachgewiesen werden. Dieser bestand, weniger stark ausgeprägt, auch nach Zugabe von NaM, der bioverfügbaren Substratvorstufe des NMNAT1-Enzyms. Eine Nutzbarmachung dieses Effekts bei chronisch-sekundärem axonalen Schaden durch externe Zufuhr von NaM im Modelltier der chronischen CMT-Neuropathie gelang jedoch nicht. 


\section{Abbildungsverzeichnis}

Abbildung 1: Elektonenmikroskopische Bilder von Myelin im PNS 3

Abbildung 2: Proteindomänen-Struktur von Wlds 8

Abbildung 3: Die NAD-Synthese beim Menschen 10

Abbildung 4: Die zwei peripheren Myelinproteine PMP22 und MPZ/P0 und ihre Lokalisation 13

Abbildung 5: Ohrloch-Code zur eindeutigen Identifikation der Versuchstiere 22

Abbildung 6: Studienverlauf der Behandlungsstudie 24

Abbildung 7: Kraftmessvorrichtung und deren Anwendung 25

Abbildung 8: Repräsentatives Bild aus dem N. ischiadicus einer mit Placebo behandelten Ratte

Abbildung 9: Repräsentative Genotypisierungs-PCRs für das CMT- und das WIds-

Transgen 30

Abbildung 10: Griffstärke der Versuchstiere 35

Abbildung 11: Repräsentative elektrophysiologische Potentiale aus dem

Schwanznerv 36

Abbildung 12: Anzahl myelinisierter Axone in den Nn. tibiales der Versuchstiere 37

Abbildung 13: G-ratios bleiben konstant in Wt und Wlds-Tieren, bilden aber eine positive Korrelation mit den jeweiligen Axondurchmessern in CMT und CMDS 38

Abbildung 14: NMNAT1-Expression im Rückenmark ( $n=5$ pro Genotyp) 39

Abbildung 15: Histologische Analyse 24 (A), 48 (B) und 72 (C) Std. nach Läsion des

$\mathrm{N}$. ischiadicus

Abbildung 16: Konzentration von Nikotinamid in Serum (A) und Nervenhomogenisat

(B) nach fünf Behandlungstagen durch intraperitoneale Injektion 41

Abbildung 17: Konzentration von Nikotinamid in Serum 42

Abbildung 18: Ergebnisse der Nikotinamid-Behandlungsstudie 43 


\section{Literaturverzeichnis}

Adalbert R, Gillingwater TH, Haley JE, Bridge K, Beirowski B, Berek L, Wagner D, Grumme D, Thomson D, Celik A, et al. (2005): A rat model of slow Wallerian degeneration (WIdS) with improved preservation of neuromuscular synapses Eur J Neurosci 21, 271-277

Aggarwal S, Yurlova L, Simons M (2011): Central nervous system myelin: structure, synthesis and assembly Trends Cell Biol 21, 585-593

Ali YO, Allen HM, Yu L, Li-Kroeger D, Bakhshizadehmahmoudi D, Hatcher A, McCabe C, Xu J, Bjorklund N, Taglialatela G, et al. (2016): NMNAT2:HSP90 Complex Mediates Proteostasis in Proteinopathies PLoS Biol 14, e1002472

Araki T, Sasaki Y, Milbrandt J (2004): Increased nuclear NAD biosynthesis and SIRT1 activation prevent axonal degeneration Science $\underline{305}, 1010-1013$

Avery MA, Sheehan AE, Kerr KS, Wang J, Freeman MR (2009): WId S requires Nmnat1 enzymatic activity and N16-VCP interactions to suppress Wallerian degeneration $\mathrm{J}$ Cell Biol $\underline{184}, 501-513$

Babetto E, Beirowski B, Janeckova L, Brown R, Gilley J, Thomson D, Ribchester RR, Coleman MP (2010): Targeting NMNAT1 to axons and synapses transforms its neuroprotective potency in vivo J Neurosci 30, 13291-13304

Beirowski B, Berek L, Adalbert R, Wagner D, Grumme DS, Addicks K, Ribchester RR, Coleman MP (2004): Quantitative and qualitative analysis of Wallerian degeneration using restricted axonal labelling in YFP-H mice J Neurosci Methods 134, 23-35

Beirowski B, Adalbert R, Wagner D, Grumme DS, Addicks K, Ribchester RR, Coleman MP (2005): The progressive nature of Wallerian degeneration in wild-type and slow Wallerian degeneration (WIdS) nerves BMC Neurosci $\underline{6}, 6$

Beirowski B, Babetto E, Gilley J, Mazzola F, Conforti L, Janeckova L, Magni G, Ribchester RR, Coleman MP (2009): Non-nuclear WId(S) determines its neuroprotective efficacy for axons and synapses in vivo J Neurosci $\underline{29}, 653-668$

Cai AL, Zipfel GJ, Sheline CT (2006): Zinc neurotoxicity is dependent on intracellular NAD levels and the sirtuin pathway Eur J Neurosci 24, 2169-2176

Charcot JM, Marie P (1886): Sur une forme particulière d'atrophie musculaire progressive, souvent familiale débutant par les pieds et les jambes et atteignant plus tards les mains. Rev Méd (Paris) ㅁ, 97-138 
Chong ZZ, Lin SH, Maiese K (2002): Nicotinamide modulates mitochondrial membrane potential and cysteine protease activity during cerebral vascular endothelial cell injury $\mathrm{J}$ Vasc Res 39, 131-147

Coleman MP (2005): Axon degeneration mechanisms: commonality amid diversity Nat Rev Neurosci $\underline{6}, 889-898$

Coleman MP, Freeman MR (2010): Wallerian degeneration, wld(s), and nmnat Annu Rev Neurosci 33, 245-267

Conforti L, Tarlton A, Mack TG, Mi W, Buckmaster EA, Wagner D, Perry VH, Coleman MP (2000): A Ufd2/D4Cole1e chimeric protein and overexpression of Rbp7 in the slow Wallerian degeneration (WldS) mouse Proc Natl Acad Sci U S A 97, 11377-11382

Conforti L, Fang G, Beirowski B, Wang MS, Sorci L, Asress S, Adalbert R, Silva A, Bridge K, Huang XP, et al. (2007): NAD(+) and axon degeneration revisited: Nmnat1 cannot substitute for WId(S) to delay Wallerian degeneration Cell Death Differ 14, 116-127

Conforti L, Wilbrey A, Morreale G, Janeckova L, Beirowski B, Adalbert R, Mazzola F, Di Stefano M, Hartley R, Babetto E, et al. (2009): Wld S protein requires Nmnat activity and a short $\mathrm{N}$-terminal sequence to protect axons in mice $\mathrm{J}$ Cell Biol 184, 491-500

Conforti L, Gilley J, Coleman MP (2014): Wallerian degeneration: an emerging axon death pathway linking injury and disease Nat Rev Neurosci 15, 394-409

Di Stefano M, Conforti L (2013): Diversification of NAD biological role: the importance of location FEBS J 280, 4711-4728

Di Stefano M, Nascimento-Ferreira I, Orsomando G, Mori V, Gilley J, Brown R, Janeckova L, Vargas ME, Worrell LA, Loreto A, et al. (2015): A rise in NAD precursor nicotinamide mononucleotide (NMN) after injury promotes axon degeneration Cell Death Differ $\underline{22}, 731$ 742

Dragovic J, Kim SH, Brown SL, Kim JH (1995): Nicotinamide pharmacokinetics in patients Radiother Oncol 36, 225-228

Essuman K, Summers DW, Sasaki Y, Mao X, DiAntonio A, Milbrandt J (2017): The SARM1 Toll/Interleukin-1 Receptor Domain Possesses Intrinsic NAD(+) Cleavage Activity that Promotes Pathological Axonal Degeneration Neuron 93, 1334-1343 e1335

Eulenburg M (1856): Über progressive Muskelatrophie Dtsch Klin $\underline{8}$, 129-131

Feng Y, Paul IA, LeBlanc MH (2006): Nicotinamide reduces hypoxic ischemic brain injury in the newborn rat Brain Res Bull $\underline{69}, 117-122$ 
Ferri A, Sanes JR, Coleman MP, Cunningham JM, Kato AC (2003): Inhibiting axon degeneration and synapse loss attenuates apoptosis and disease progression in a mouse model of motoneuron disease Curr Biol 13, 669-673

Fischer LR, Culver DG, Davis AA, Tennant P, Wang M, Coleman M, Asress S, Adalbert R, Alexander GM, Glass JD (2005): The WldS gene modestly prolongs survival in the SOD1G93A fALS mouse Neurobiol Dis $\underline{19}, 293-300$

Freeman MR (2014): Signaling mechanisms regulating Wallerian degeneration Curr Opin Neurobiol 27, 224-231

Gerdts J, Summers DW, Sasaki Y, DiAntonio A, Milbrandt J (2013): Sarm1-mediated axon degeneration requires both SAM and TIR interactions J Neurosci $\underline{33}, 13569-13580$

Gerdts J, Brace EJ, Sasaki Y, DiAntonio A, Milbrandt J (2015): SARM1 activation triggers axon degeneration locally via NAD(+) destruction Science 348, 453-457

Gerdts J, Summers DW, Milbrandt J, DiAntonio A (2016): Axon Self-Destruction: New Links among SARM1, MAPKs, and NAD+ Metabolism Neuron 89, 449-460

Gilley J, Coleman MP (2010): Endogenous Nmnat2 is an essential survival factor for maintenance of healthy axons PLoS Biol $\underline{8}$, e1000300

Gutmann L, Shy M (2015): Update on Charcot-Marie-Tooth disease Curr Opin Neurol $\underline{28}$, $462-467$

Handler P, Dann WJ (1942): The inhibition of rat growth by nicotinamide J Biol Chem $\underline{146}$, 357-368

Hoane MR, Pierce JL, Holland MA, Anderson GD (2008): Nicotinamide treatment induces behavioral recovery when administered up to 4 hours following cortical contusion injury in the rat Neuroscience 154, 861-868

Holland MA, Tan AA, Smith DC, Hoane MR (2008): Nicotinamide treatment provides acute neuroprotection and GFAP regulation following fluid percussion injury $\mathrm{J}$ Neurotrauma 25 , 140-152

Kaneko S, Wang J, Kaneko M, Yiu G, Hurrell JM, Chitnis T, Khoury SJ, He Z (2006):

Protecting axonal degeneration by increasing nicotinamide adenine dinucleotide levels in experimental autoimmune encephalomyelitis models $\mathrm{J}$ Neurosci 26, 9794-9804

Karlsson U, Schultz RL (1965): Fixation Of The Central Nervous System From Electron Microscopy By Aldehyde Perfusion. I. Preservation With Aldehyde Perfusates Versus Direct 
Perfusion With Osmium Tetroxide With Special Reference To Membranes And The Extracellular Space J Ultrastruct Res 12, 160-186

Khajavi M, Inoue K, Wiszniewski W, Ohyama T, Snipes GJ, Lupski JR (2005): Curcumin treatment abrogates endoplasmic reticulum retention and aggregation-induced apoptosis associated with neuropathy-causing myelin protein zero-truncating mutants Am J Hum Genet $\underline{77}, 841-850$

Kimura N, Fukuwatari T, Sasaki R, Shibata K (2006): Comparison of metabolic fates of nicotinamide, NAD+ and NADH administered orally and intraperitoneally; characterization of oral NADH J Nutr Sci Vitaminol (Tokyo) $\underline{52}$, 142-148

Knip M, Douek IF, Moore WP, Gillmor HA, McLean AE, Bingley PJ, Gale EA, European Nicotinamide Diabetes Intervention Trial G (2000): Safety of high-dose nicotinamide: a review Diabetologia 43 , 1337-1345

Kugler P: Nervensystem. Grundzüge der Organisation. In: Benninghoff A, Drenckhahn D (Hrsg.): Anatomie. Band 2; Elsevier Urban\&Fischer, München 2004, 232-247

Kugler P, Drenckhahn D: Nervengewebe. In: Benninghoff A, Drenckhahn D (Hrsg.): Anatomie. Band 1; Urban\&Fischer, München 2003, 170-207

Loreto A, Di Stefano M, Gering M, Conforti L (2015): Wallerian Degeneration Is Executed by an NMN-SARM1-Dependent Late $\mathrm{Ca}(2+)$ Influx but Only Modestly Influenced by Mitochondria Cell Rep 13, 2539-2552

Lubinska $L$ (1977): Early course of Wallerian degeneration in myelinated fibres of the rat phrenic nerve Brain Res 130, 47-63

Luft JH (1961): Improvements in epoxy resin embedding methods. J Biophys Biochem Cytol $\underline{9}, 409-414$

Lunn ER, Perry VH, Brown MC, Rosen H, Gordon S (1989): Absence of Wallerian Degeneration does not Hinder Regeneration in Peripheral Nerve Eur J Neurosci 1, 27-33

Lupski JR, Chance PF: Hereditary Motor and Sensory Neuropathies Involving Altered Dosage or Mutation of PMP22: The CMT1A Duplication and HNPP deletion. In: Dyck PJ, Thomas PK (Hrsg.): Peripheral Neuropathy. Band 2; Elsevier Saunders, Philadelphia 2005, 1659-1680, (https://doi.org/10.1016/B978-0-7216-9491-7.50073-9)

Mack TG, Reiner M, Beirowski B, Mi W, Emanuelli M, Wagner D, Thomson D, Gillingwater T, Court F, Conforti L, et al. (2001): Wallerian degeneration of injured axons and synapses is delayed by a Ube4b/Nmnat chimeric gene Nat Neurosci 4, 1199-1206 
Maiese K, Chong ZZ (2003): Nicotinamide: necessary nutrient emerges as a novel cytoprotectant for the brain Trends Pharmacol Sci 24, 228-232

Maynard KI, Ayoub IA, Shen CC (2001): Delayed multidose treatment with nicotinamide extends the degree and duration of neuroprotection by reducing infarction and improving behavioral scores up to two weeks following transient focal cerebral ischemia in Wistar rats Ann N Y Acad Sci 939, 416-424

McCreanor GM, Bender DA (1986): The metabolism of high intakes of tryptophan, nicotinamide and nicotinic acid in the rat $\mathrm{Br} \mathrm{J}$ Nutr $\underline{56}, 577-586$

Meyer OA, Tilson HA, Byrd WC, Riley MT (1979): A method for the routine assessment of fore- and hindlimb grip strength of rats and mice Neurobehav Toxicol 1 , 233-236

Meyer zu Horste G, Miesbach TA, Muller JI, Fledrich R, Stassart RM, Kieseier BC, Coleman MP, Sereda MW (2011): The Wlds transgene reduces axon loss in a Charcot-Marie-Tooth disease $1 \mathrm{~A}$ rat model and nicotinamide delays post-traumatic axonal degeneration Neurobiol Dis $\underline{42}, 1-8$

Meyer zu Horste G, Prukop T, Liebetanz D, Mobius W, Nave KA, Sereda MW (2007): Antiprogesterone therapy uncouples axonal loss from demyelination in a transgenic rat model of CMT1A neuropathy Ann Neurol 61, 61-72

Mi W, Beirowski B, Gillingwater TH, Adalbert R, Wagner D, Grumme D, Osaka H, Conforti L, Arnhold S, Addicks K, et al. (2005): The slow Wallerian degeneration gene, WldS, inhibits axonal spheroid pathology in gracile axonal dystrophy mice Brain $\underline{128}, 405-416$

Micallef J, Attarian S, Dubourg O, Gonnaud PM, Hogrel JY, Stojkovic T, Bernard R, Jouve E, Pitel S, Vacherot F, et al. (2009): Effect of ascorbic acid in patients with Charcot-Marie-Tooth disease type 1A: a multicentre, randomised, double-blind, placebo-controlled trial Lancet Neurol $\underline{8}, 1103-1110$

Mills KF, Yoshida S, Stein LR, Grozio A, Kubota S, Sasaki Y, Redpath P, Migaud ME, Apte RS, Uchida K, et al. (2016): Long-Term Administration of Nicotinamide Mononucleotide Mitigates Age-Associated Physiological Decline in Mice Cell Metab 24, 795-806

Mokudai T, Ayoub IA, Sakakibara Y, Lee EJ, Ogilvy CS, Maynard KI (2000): Delayed treatment with nicotinamide (Vitamin B(3)) improves neurological outcome and reduces infarct volume after transient focal cerebral ischemia in Wistar rats Stroke 31, 1679-1685

Mullis K, Faloona F, Scharf S, Saiki R, Horn G, Erlich H (1986): Specific enzymatic amplification of DNA in vitro: the polymerase chain reaction Cold Spring Harb Symp Quant Biol $\underline{51}, 263-273$ 
Nave KA, Trapp BD (2008): Axon-glial signaling and the glial support of axon function Annu Rev Neurosci 31, 535-561

Nave KA, Werner HB (2014): Myelination of the nervous system: mechanisms and functions Annu Rev Cell Dev Biol $\underline{30}$, 503-533

Neukomm LJ, Freeman MR (2014): Diverse cellular and molecular modes of axon degeneration Trends Cell Biol 24, 515-523

Osterloh JM, Yang J, Rooney TM, Fox AN, Adalbert R, Powell EH, Sheehan AE, Avery MA, Hackett R, Logan MA, et al. (2012): dSarm/Sarm1 is required for activation of an injuryinduced axon death pathway Science $\underline{337}, 481-484$

Pareyson D, Marchesi C (2009): Natural history and treatment of peripheral inherited neuropathies Adv Exp Med Biol 652, 207-224

Pareyson D, Reilly MM, Schenone A, Fabrizi GM, Cavallaro T, Santoro L, Vita G, Quattrone A, Padua L, Gemignani F, et al. (2011): Ascorbic acid in Charcot-Marie-Tooth disease type $1 \mathrm{~A}$ (CMT-TRIAAL and CMT-TRAUK): a double-blind randomised trial Lancet Neurol 10, 320328

Passage E, Norreel JC, Noack-Fraissignes P, Sanguedolce V, Pizant J, Thirion X, RobagliaSchlupp A, Pellissier JF, Fontes M (2004): Ascorbic acid treatment corrects the phenotype of a mouse model of Charcot-Marie-Tooth disease Nat Med 10, 396-401

Ribchester RR, Tsao JW, Barry JA, Asgari-Jirhandeh N, Perry VH, Brown MC (1995):

Persistence of neuromuscular junctions after axotomy in mice with slow Wallerian degeneration (C57BL/WIdS) Eur J Neurosci 7, 1641-1650

Richardson KC, Jarett L, Finke EH (1960): Embedding in epoxy resins for ultrathin sectioning in electron microscopy Stain Technol $\underline{35}, 313-323$

Sadanaga-Akiyoshi F, Yao H, Tanuma S, Nakahara T, Hong JS, Ibayashi S, Uchimura H, Fujishima M (2003): Nicotinamide attenuates focal ischemic brain injury in rats: with special reference to changes in nicotinamide and NAD+ levels in ischemic core and penumbra Neurochem Res $\underline{28}, 1227-1234$

Sahenk Z, Nagaraja HN, McCracken BS, King WM, Freimer ML, Cedarbaum JM, Mendell JR (2005): NT-3 promotes nerve regeneration and sensory improvement in CMT1A mouse models and in patients Neurology $65,681-689$

Sakakibara Y, Mitha AP, Ayoub IA, Ogilvy CS, Maynard KI (2002): Delayed treatment with nicotinamide (vitamin B3) reduces the infarct volume following focal cerebral ischemia in 
spontaneously hypertensive rats, diabetic and non-diabetic Fischer 344 rats Brain Res $\underline{931}$, 68-73

Samsam M, Mi W, Wessig C, Zielasek J, Toyka KV, Coleman MP, Martini R (2003): The Wids mutation delays robust loss of motor and sensory axons in a genetic model for myelinrelated axonopathy J Neurosci $\underline{23}, 2833-2839$

Sasaki Y, Araki T, Milbrandt J (2006): Stimulation of nicotinamide adenine dinucleotide biosynthetic pathways delays axonal degeneration after axotomy $\mathrm{J}$ Neurosci $\underline{26}$, 8484-8491

Sasaki Y, Vohra BP, Baloh RH, Milbrandt J (2009a): Transgenic mice expressing the Nmnat1 protein manifest robust delay in axonal degeneration in vivo J Neurosci $\underline{29}$, 65266534

Sasaki Y, Vohra BP, Lund FE, Milbrandt J (2009b): Nicotinamide mononucleotide adenylyl transferase-mediated axonal protection requires enzymatic activity but not increased levels of neuronal nicotinamide adenine dinucleotide J Neurosci 29, 5525-5535

Sasaki Y, Milbrandt $\mathrm{J}$ (2010): Axonal degeneration is blocked by nicotinamide mononucleotide adenylyltransferase (Nmnat) protein transduction into transected axons $\mathrm{J}$ Biol Chem 285, 41211-41215

Sasaki Y, Nakagawa T, Mao X, DiAntonio A, Milbrandt J (2016): NMNAT1 inhibits axon degeneration via blockade of SARM1-mediated $N A D(+)$ depletion Elife $\underline{5}$

Scherer SS, Wrabetz L (2008): Molecular mechanisms of inherited demyelinating neuropathies Glia $\underline{56}, 1578-1589$

Scheschonka A, Heinrich B, Becker C-M: Nervensystem. In: Löffler G, Petrides PE, Heinrich PC (Hrsg.): Biochemie und Pathobiochemie. Springer, Heidelberg 2007, 1024-1051

Sereda MW, Griffiths I, Puhlhofer A, Stewart H, Rossner MJ, Zimmerman F, Magyar JP, Schneider A, Hund E, Meinck HM, et al. (1996): A transgenic rat model of Charcot-MarieTooth disease Neuron $\underline{16}, 1049-1060$

Sereda MW, Meyer zu Horste G, Suter U, Uzma N, Nave KA (2003): Therapeutic administration of progesterone antagonist in a model of Charcot-Marie-Tooth disease (CMT1A) Nat Med $\underline{9}, 1533-1537$

Sereda MW, Nave KA (2006): Animal models of Charcot-Marie-Tooth disease type 1A (CMT1A) Neuromolecular Med $\underline{8}, 205-215$

Sherman DL, Brophy PJ (2005): Mechanisms of axon ensheathment and myelin growth Nat Rev Neurosci $\underline{6}, 683-690$ 
Silbernagl S, Despopoulos A: Aktionspotential. In: Silbernagl S, Despopoulos A:

Taschenatlas Physiologie; Thieme, Stuttgart 2007, 46-49

Spector R (1979): Niacin and niacinamide transport in the central nervous system. In vivo studies J Neurochem $\underline{33}$, 895-904

Suter U, Scherer SS (2003): Disease mechanisms in inherited neuropathies Nat Rev Neurosci 4 , 714-726

Suzuki K (2010): Myelin: A Specialized Membrane for Cell Communication Nat Ed $\underline{3}$

Tooth $\mathrm{HH}$ : The peroneal type of progressive muscular atrophy. Med. Diss. Cambridge 1886

Verhamme C, de Haan RJ, Vermeulen M, Baas F, de Visser M, van Schaik IN (2009): Oral high dose ascorbic acid treatment for one year in young CMT1A patients: a randomised, double-blind, placebo-controlled phase II trial BMC Med $\underline{7}, 70$

Waller A (1850): Experiments on the section of glossopharyngeal and hypoglossal nerves of the frog and observations of the alternatives produced thereby in the structure of their primitive fibers. Philos Trans R Soc Lond Biol 140

Wang J, Zhai Q, Chen Y, Lin E, Gu W, McBurney MW, He Z (2005): A local mechanism mediates NAD-dependent protection of axon degeneration J Cell Biol 170, 349-355

Wang JT, Medress ZA, Barres BA (2012): Axon degeneration: molecular mechanisms of a self-destruction pathway J Cell Biol 196, 7-18

Wang JT, Medress ZA, Vargas ME, Barres BA (2015): Local axonal protection by WIdS as revealed by conditional regulation of protein stability Proc Natl Acad Sci U S A 112, 1009310100

Wang MS, Davis AA, Culver DG, Glass JD (2002): WIdS mice are resistant to paclitaxel (taxol) neuropathy Ann Neurol $\underline{52}, 442-447$

Yang J, Wu Z, Renier N, Simon DJ, Uryu K, Park DS, Greer PA, Tournier C, Davis RJ, Tessier-Lavigne $M$ (2015): Pathological axonal death through a MAPK cascade that triggers a local energy deficit Cell $\underline{160}, 161-176$

Zhai RG, Cao Y, Hiesinger PR, Zhou Y, Mehta SQ, Schulze KL, Verstreken P, Bellen HJ (2006): Drosophila NMNAT maintains neural integrity independent of its NAD synthesis activity PLoS Biol $\underline{4}$, e416

Zhai RG, Zhang F, Hiesinger PR, Cao Y, Haueter CM, Bellen HJ (2008): NAD synthase NMNAT acts as a chaperone to protect against neurodegeneration Nature 452, 887-891 


\section{Danksagung}

Ich danke Prof. Dr. Klaus-Armin Nave für seine Unterstützung und für die Bereitstellung von Ressourcen für die Durchführung der Arbeit.

Ich danke Prof. Dr. Michael W. Sereda für die Betreuung, Begleitung und Vertretung der Arbeit.

Ich danke PD Dr. Gerd Meyer zu Hörste für seine Anregung zum Dissertationsthema und die motivierende Unterstützung, wissenschaftliche Begleitung sowie kritische Korrektur der Arbeit.

Den Kollegen der PNS-Gruppe, insbesondere Dr. Thomas Prukop, Dr. Ruth Stassart, Dr. Bastian Brinkmann und Dr. Robert Fledrich, danke ich für die freundliche Aufnahme, die Einarbeitung in die Methoden und ihre Unterstützung bei der Durchführung der Arbeit.

Ich danke Dr. Susanne Quintes für die kritische Korrektur der Arbeit.

Ich danke den Kollegen der Abteilung Neurogenetik für die angenehme Arbeitsatmosphäre, für ihre praktische Unterstützung sowie die fachlichen Diskussionen und Anregungen. 